CALIFORNIA STATE UNIVERSITY, NORTHRIDGE

\title{
LOW EARTH ORBIT BUSINESS CENTER
}

A Project submitted in partial satisfaction of the requirements for the degree of Master of Science in

Engineering

by

Dallas Gene Bienhoff

May 1985 
The Project of Dallas Gene Bienhoff is approved:

Dr. B. J. Bluth

Dr. Bonita J. Campbell

Professor Tímothy Wm. Fox - Chair

California State University, Northridge 


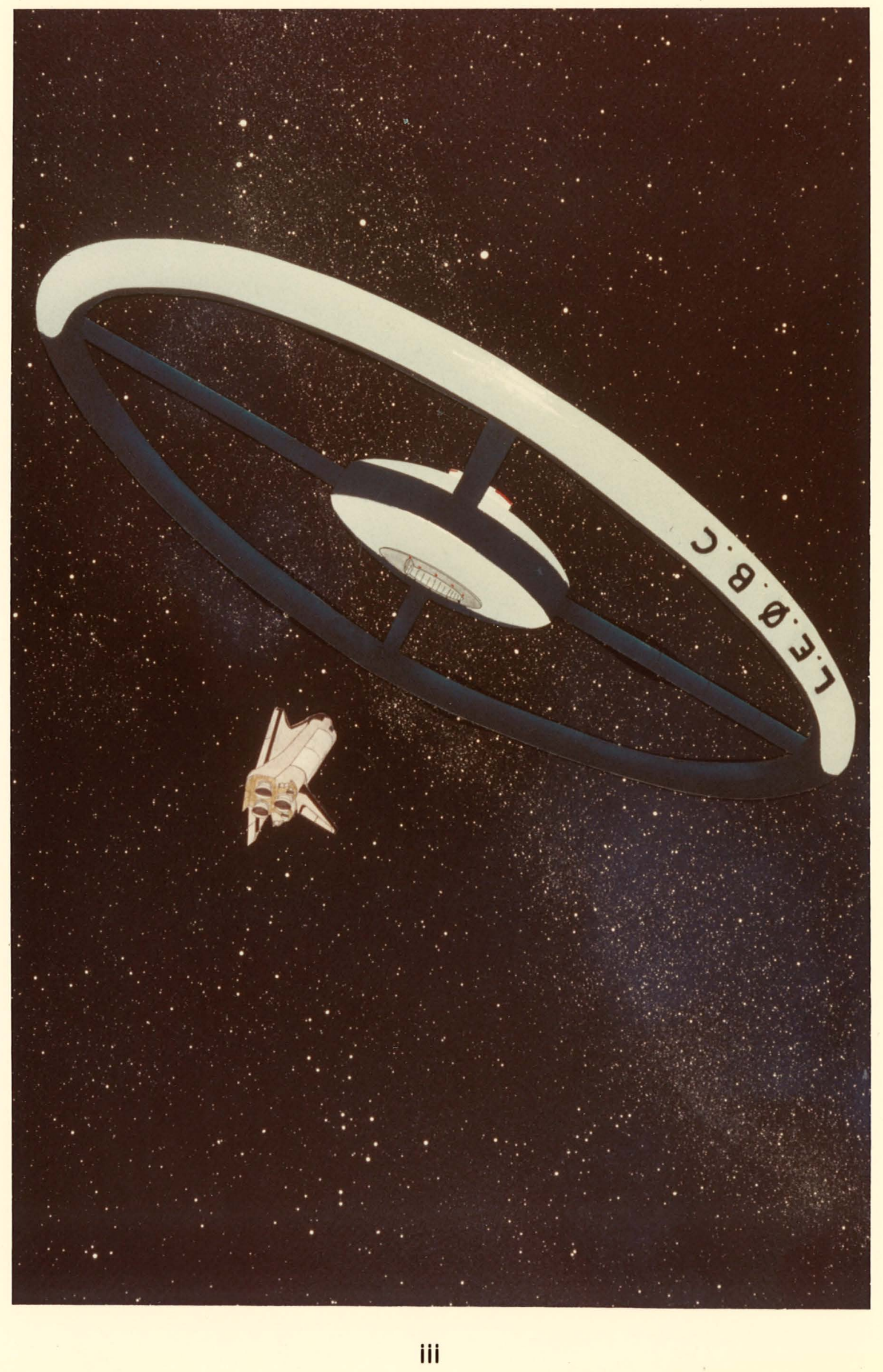




\section{ACKNOWLEDGEMENTS}

I wish to express my gratitude to those who have helped me over the years to complete this thesis by providing encouragement, prodding and understanding: ny advisor, Tim Fox, Chair of Mechanical and Chemical Engineering; Dr. B. J. Bluth for her excellent comments on human factors; Dr. B. J. Campbell for improving the clarity; Richard Swaim, design engineer at Rocketdyne Division of Rockwell International for providing excellent engineering drawings of LEOBC; Mike Morrow, of the Advanced Engineering Department at Rockwe11 International who provided the Low Earth Orbit Business Center panel figures; Bob Bovill, a commercial artist, who did all the artistic drawings because of his interest in space commercialization; Linda Martin for her word processing skills; my wife, Yolanda, for egging me on without nagging; and finally Erik and Danielle for putting up with the excuse, "I have to work on ny paper," for too many years. 
PREFACE

The Low Earth Orbit Business Center (LEOBC) was initially conceived as a modular structure to be launched aboard the space Shuttle, it evolved to its present configuration as a result of research, discussions and the desire to increase the efficiency of space utilization.

Although the idea of placing space stations into Earth orbit is not new, as is discussed in the first chapter, and the configuration offers nothing new, LEOBC is unique in its application. Previous concepts and current justification cited for space stations were and are based on scientific need. LEOBC, on the other hand, is proposed as a speculative project. It is to be placed in low Earth orbit for the same reason a developer builds a shopping mall or a warehouse on property which appears to be out of the way -- speculation.

As more companies explore the possibilities of operating in space and NASA's Space Station becomes a reality, there will soon become a shortage of habitable volume in space. Most visionaries foresee space cities and lunar cities as a result of economic expansion into space. LEOBC can be a needed intermediate step in this process. 
TABLE OF CONTENTS

Chapter

Page

FRONTISPIECE

iii

ACKNOWLEDGEMENTS

iv

PREFACE

$\mathrm{v}$

LIST OF TABLES

vii

LIST OF FIGURES

viii

LIST OF SYMBOLS

xi

ABSTRACT

xiv

1. INIRODUCTION

1

2. THE NEXT S'TEP 11

$\begin{array}{ll}\text { 3. INIERNAL ENVIRONMENT } & 19\end{array}$

$\begin{array}{ll}\text { PSEUDOGRAVITY } & 19\end{array}$

$\begin{array}{ll}\text { ATMOSPHERE } & 25\end{array}$

4. LOW EARTH ORBIT BUSINESS CENTER CONFIGURATION 31

5. INTERIOR DESCRIPTION AND ARRANGEMENT 47

6. LEOBC CONSTRUCTION CONS IDERATIONS 59

7. CLOSING REMARKS 81

$\begin{array}{ll}\text { BIBLIOGRAPHY } & 85\end{array}$

APPENDICES

A SPACE/STATION HABITAT CONCEPTS 99

$\begin{array}{ll}\text { B SPACE STATION MISSIONS } & 102\end{array}$

$\begin{array}{ll}\text { C SHAPE EQUATIONS DEVELOPMENT } & 107\end{array}$

D SHELI THICKNESS ESTIMATES 136

E LEOBC INTERNAL MASS CALCULATIONS 


\section{LIST OF TABLES}

Table

Page

$1 \quad$ Shape Description Summary

2 Shape Comparison Equation Summary

$3 \quad$ Key for Figures 13-23

40

4 Shape Evaluation Table

46

$5 \quad$ LEOBC Geometric Specifications

53

6 LEOBC Space Allocation (Torus Only)

54

7 LEOBC Structural And Floor Panel Description

67 Summary

8 LEOBC Structural And F1oor Pane1 Launch Data

68 Summary

9 Revised Launch Data Summary Due To Payload Mass

73

Considerations

$10 \quad$ Subsystem Options

I1 Historical Listing of Manned Satellite Concepts

12 Additional Manned Satellite Concepts 101

13 Skylab Missions 102

14 Missions To Salyut Stations 103 
LIST OF FIGURES

\begin{tabular}{|c|c|c|}
\hline Figure & & Page \\
\hline 1 & Hermann Noordung's "WOHNRAD" & $\Xi 3$ \\
\hline 2 & Dr. W. von Braun's "Space Wheel" & 4 \\
\hline 3 & Location of Lagrangian Points & 5 \\
\hline 4 & Dr. Krafft Ehricke's "Star City" & 7 \\
\hline 5 & STS Mission Duration Versus Power Use Rate & 16 \\
\hline 6 & Pseudogravity Limits & 20 \\
\hline 7 & Coriolis Acceleration Effects & 23 \\
\hline 8 & Allowable Pseudogravity Design Envelope & 24 \\
\hline 9 & $\begin{array}{l}\text { Body Nitrogen Pressure For Tissues With A } \\
\text { Half-Saturation Time of } 240 \text { Minutes For Two } \\
\text { Pre-Breathe Air Mixtures }\end{array}$ & 27 \\
\hline 10 & Sea Level Equivalent Atmosphere Composition & 28 \\
\hline 11 & Impact Rates of Meteoric Material & 29 \\
\hline 12 & LEOBC Shape Candidates & 38 \\
\hline 13 & Shapes' Volumes & 41 \\
\hline 14 & Shapes' Habitable Volumes & 41 \\
\hline 15 & Shapes' Surface Areas & 41 \\
\hline 16 & Shapes' Projected Areas & 41 \\
\hline 17 & Shapes' Floor Areas & 43 \\
\hline 18 & Shapes' Habitable Volume/Volume & 43 \\
\hline 19 & Shapes' Volume/Surface Area & 43 \\
\hline 20 & Shapes' Habitable Volume/Surface Area & 43 \\
\hline 21 & Shapes' Projected Area/Surface Area & 44 \\
\hline 22 & Shapes' Floor Area/Volume & 44 \\
\hline 23 & Shapes' FIoor Area/Surface Area & 44 \\
\hline
\end{tabular}




\section{LIST OF FIGURES (CONTINUED)}

Figure

Page

24

LEOBC Top and Side Views

48

25

LEOBC Torus Cross-Section and Elevation

49

26 Typical Efficiency Floor Plan 51

27 LEOBC Efficiency Elevations 52

28 Artist's Concept of LEOBC Recreation Court 56

29 LEOBC Cross Section $\quad 57$

30 Torus Structural Panels $\quad 61$

31 First- and Second-Floor Floor Panels 62

32 LEOBC Hub Structural Panels 63

33 Hub Structural Panels H1 Through H6 64

34 Hub Structural Panels 47 Through H9 65

35 LEOBC Thickness for Various Pressures and Altitudes70 with Constant Radiation Exposure Levels

36 Structural Panel Mass 72

37 LEOBC Panels Per STS Launch 72

38 LEOBC Telescopic Spoke 74

39 LEOBC Design, Fabrication and Construction Schedule77

40 Spherical Habitat Characteristics 109

41 Dumbbe11, Beaded Torus Habitat Characteristics 114

42 Cylindrical Habitat Characteristics 119

43 Toroidal Habitat Characteristics 122

44 Crysta1 Palace Habitat Characteristics 127

45 Two-Axis-Stretched Ellipse Characteristics 130

46 Differential Element ds in $x-y$ Plane 133

47 LEOBC Hub Pressure Resolution 139 


\section{LIST OF FIGURES (CONTINUED)}

Figure

48

LEOBC Potable Water Tank
Page

147 
$\mathrm{b}$

ds

F

$F A_{s, d, m d, b t, c, t, c t, c p, e}$

g

$H V_{S, d, m d, ~ b t, c, t, c t, c p, e}$

$\mathrm{k}$

1

L

m

$\mathrm{m}_{\mathrm{c}}$

m

M

n

$\mathrm{N}$

N1

P

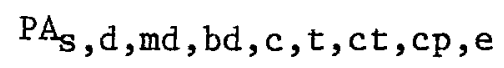

$y$ - intercept of a straight line.

Arc length.

Axial load per unit length.

Floor area of a sphere, dumbbel1, multiple dumbbel1, beaded torus, cylinder, torus, cylindrical torus, crystal palace and two-axis-stretched ellipse.

Gravitational acceleration; pseudogravity acceleration.

Habitable volume of a sphere, dumbbell, multiple dumbbell, beaded torus, cylinder, torus, cylindrical torus, crystal palace, and two-axis-stretched ellipse.

Time constant related to body tissue nitrogen saturation half-time.

Crystal palace radial hoop number.

Number of radial hoops in crystal palace.

Meters; gram-mole mass.

Slope of a curve.

Slope of a normal to curve.

Number of dumbbells in a beaded torus.

Floor number.

Maximum number of floors; maximum number of axial hoops in crystal palace.

Number of floors with a rotational radius greater than the shape's major radius.

Pressure at time $t$.

Projected area of sphere, dumbbell, multiple dumbbell, beaded torus, cylinder, torus, cylindrical torus, crystal palace, and two-axis-stretched ellipse. 


\begin{tabular}{|c|c|}
\hline$P_{f}$ & Floor design mass load. \\
\hline$P_{i}$ & $\begin{array}{l}\text { Axial load per unit length along inner } \\
\text { circumference. }\end{array}$ \\
\hline$P_{N}(t)$ & $\begin{array}{l}\text { Body tissue nitrogen partial pressure at } \\
\text { time t. }\end{array}$ \\
\hline$P_{N}(0)$ & $\begin{array}{l}\text { Initial body tissue nitrogen partial } \\
\text { pressure. }\end{array}$ \\
\hline $\mathrm{P}_{\mathrm{N}-\operatorname{mix}}$ & $\begin{array}{l}\text { Nitrogen partial pressure of pre-breathe } \\
\text { air mixture. }\end{array}$ \\
\hline $\mathrm{P}_{\mathrm{o}}$ & $\begin{array}{l}\text { Initial pressure; Axial load per unit } \\
\text { length along outer circumference. }\end{array}$ \\
\hline $\mathrm{R}$ & Major radius; universal gas constant. \\
\hline$\overline{\mathrm{R}}$ & Average or weighted-average radius. \\
\hline $\mathrm{R}_{1}$ & Radius of cuvature of a meridian. \\
\hline $\mathrm{R}_{2}$ & $\begin{array}{l}\text { Line length of normal to curve to axis of } \\
\text { rotation. }\end{array}$ \\
\hline$R_{i}$ & Inner radius. \\
\hline$R_{n}$ & Radius of floor $n$. \\
\hline $\mathrm{R}_{\mathrm{o}}$ & Outer radius. \\
\hline${ }^{\mathrm{R}} \gamma$ & Habitable volume minimum radius. \\
\hline $\mathrm{SA}_{s, d, \mathrm{md}, \mathrm{bd}, c, t, c t, c p, e}$ & $\begin{array}{l}\text { Surface area of sphere, dumbbel1, } \\
\text { multiple dumbbell, beaded torus, } \\
\text { cylinder, torus, cylindrical torus, } \\
\text { crystal palace and two-axis-stretched } \\
\text { ellipse. }\end{array}$ \\
\hline $\mathrm{t}$ & Time; thickness. \\
\hline $\mathrm{T}$ & Temperature - Degrees Kelvin. \\
\hline V & Volume \\
\hline
\end{tabular}




\begin{tabular}{|c|c|}
\hline$\nabla_{s, d, m d}, b d, c, t, c t, c p, e$ & $\begin{array}{l}\text { Volume of sphere, dumbbell, multiple } \\
\text { dumbbell, beaded torus, cylinder, torus, } \\
\text { cylindrical torus, crystal palace and } \\
\text { two-axis stretched ellipse. }\end{array}$ \\
\hline$W_{\mathrm{n}}$ & Width of floor $n$. \\
\hline$w_{\gamma}$ & $\begin{array}{l}\text { Width at minimum radius of habitable } \\
\text { volume. }\end{array}$ \\
\hline$\alpha$ & $\begin{array}{l}\text { Ratio of cylinder length to radius, ratio } \\
\text { of cylindrical torus length to minor } \\
\text { radius, ratio of two-axis-stretched } \\
\text { ellipse offset from latitudinal axes to } \\
\text { radius. }\end{array}$ \\
\hline$\beta$ & $\begin{array}{l}\text { Ratio of two-axis-stretched ellipse } \\
\text { offset from rotational axis to radius. }\end{array}$ \\
\hline$\gamma$ & $\begin{array}{l}\text { Variation of centripetal-acceleration in } \\
\text { habitable volume, ratio of specific heats. }\end{array}$ \\
\hline$\delta$ & $\begin{array}{l}\text { Ratio of two-axis-stretched ellipse } \\
\text { semi-major radius to hub radius. }\end{array}$ \\
\hline$\varepsilon$ & $\begin{array}{l}\text { Ratio of two axis stretched ellipse of } \\
\text { semi-minor radius to hub radius. }\end{array}$ \\
\hline$\eta$ & Ratio of minor radius to major radius. \\
\hline$\rho$ & Material mass density. \\
\hline$\sigma_{\mathrm{W}}$ & $\begin{array}{l}\text { Working stress of material (ultimate } \\
\text { stress divided by factor of safety). }\end{array}$ \\
\hline$\Sigma$ & Summation. \\
\hline$\tau$ & Pressure decay time constant. \\
\hline
\end{tabular}




\author{
ABSTRACT \\ LOW EARTH ORBIT BUSINESS CENTER \\ by \\ Dallas Gene Bienhoff \\ Master of Science in Engineering
}

The need for a business park in low earth orbit may be generated as manufacturers discover and implement the benefits of operating in space to produce cheaper and create new products. What configuration should this Low Earth Orbit Business Center have, what sort of environment should it offer and how long will it take to become operational? These questions are addressed and results presented in this paper. Comparisons are made for various gravity-oriented configurations to determine what shape is best suited for the living areas. Artificial gravity and associated problems are discussed as is atmospheric composition and pressure. An interior design for the living area is presented. The Low Earth Orbit Business Center offers 
a 0.5 earth gravity environment in a toroidal structure with a standard sea level atmosphere. Inside the torus are living quarters, recreational facilities, and office and laboratory areas. A large hub provides for low-g laboratory areas, mechanical equipment and consumable stores location. Estimates based on structural panel sizing, thickness estimates and STS launch capabilities indicate that the Low Earth Orbit Business Center can be placed into orbit over a period of 20 years. 
CHAPTER 1

INTRODUCTION

The concept of man living aboard an earth satellite was introduced slightly more than a century ago. Since then, various concepts have been presented in novels, short stories and scientific articles. These concepts have become increasingly larger and more complex, but, to date, only three true space habitats have been launched and utilized for extended space operations. A review of these concepts and actual space habitats is presented below.

Descriptions of man-made habitats have been around since 1865 when Edward Everett Hale wrote the Brick Moon. ${ }^{1}$ In this short nove1, several families are accidently launched into Earth orbit inside a brick sphere. Under construction to be launched into polar orbit, it was to become a longitudinal navigation aid, similar to Polaris' aid in fixing latitude. Due to the untimely launch, its intended use was never realized. However, the families on board survived due to retention of an atmosphere. Evolution, the vogue of these times, quickly provided the residents with various and sundry plant and animal life for their long term survival needs. In this manner, the brick moon became a self-sufficient space colony. With the publication of this novelette, the seed was sown for a continuous stream of ideas regarding permanent habitation in Earth orbit aboard man-made worlds.

The next proposed habitat description appeared in Russian science fiction 1iterature in $1895 .^{2}$ Written by Konstantin Tsiolkovsky, whom $R$. Hutton described as the founder of the science of space travel, ${ }^{3}$ this story described a space station in engineering 
detail. This description was revised eight years later to include added features such as artificial gravity, solar energy and a greenhouse. This became the first serious proposal for living in space. Initial presentation may have occurred in science fiction as that may have been the only vehicle for publication of such ideas at the time.

Twenty years after Tsiolkovsky revised his station concept, the first engineering concept for a space station was proposed by Hermann oberth. ${ }^{4}$ In this conceptual description, oberth presented methods for supplying artificial gravity and orbital construction techniques. In the following years, many additional proposals for space station designs were published. The most notable of these were Hermann Noordung's "Whonrad" in 1928, the first design placed on paper, and Dr. von Braun's "Space Wheel" in 1951, the most popular concept of modern times. ${ }^{5,6}$ These two concepts are shown in Figures 1 and 2 .

The latest space habitat concepts are not mere stations, but large cities capable of supporting populations in excess of 10,000 people. These concepts have been studied by senior research workers and college students in two summer sessions sponsored by NASA. ${ }^{7 \& 8}$ The proposed locations for these large cities are the L-4 and I-5 positions in the Earth-Moon system. These are two of five stable orbital locations in a two-body system first defined by the 18th century mathematician and astronomer J. L. Lagrange and are illustrated in Figure $3 .^{9}$ The $\mathrm{L}-4$ and $\mathrm{L}-5$ locations are located sixty degrees fore and aft of the smaller body, along its orbital path. Even larger structures than those studied in these summer sessions have been proposed for travel through and beyond the solar system. 


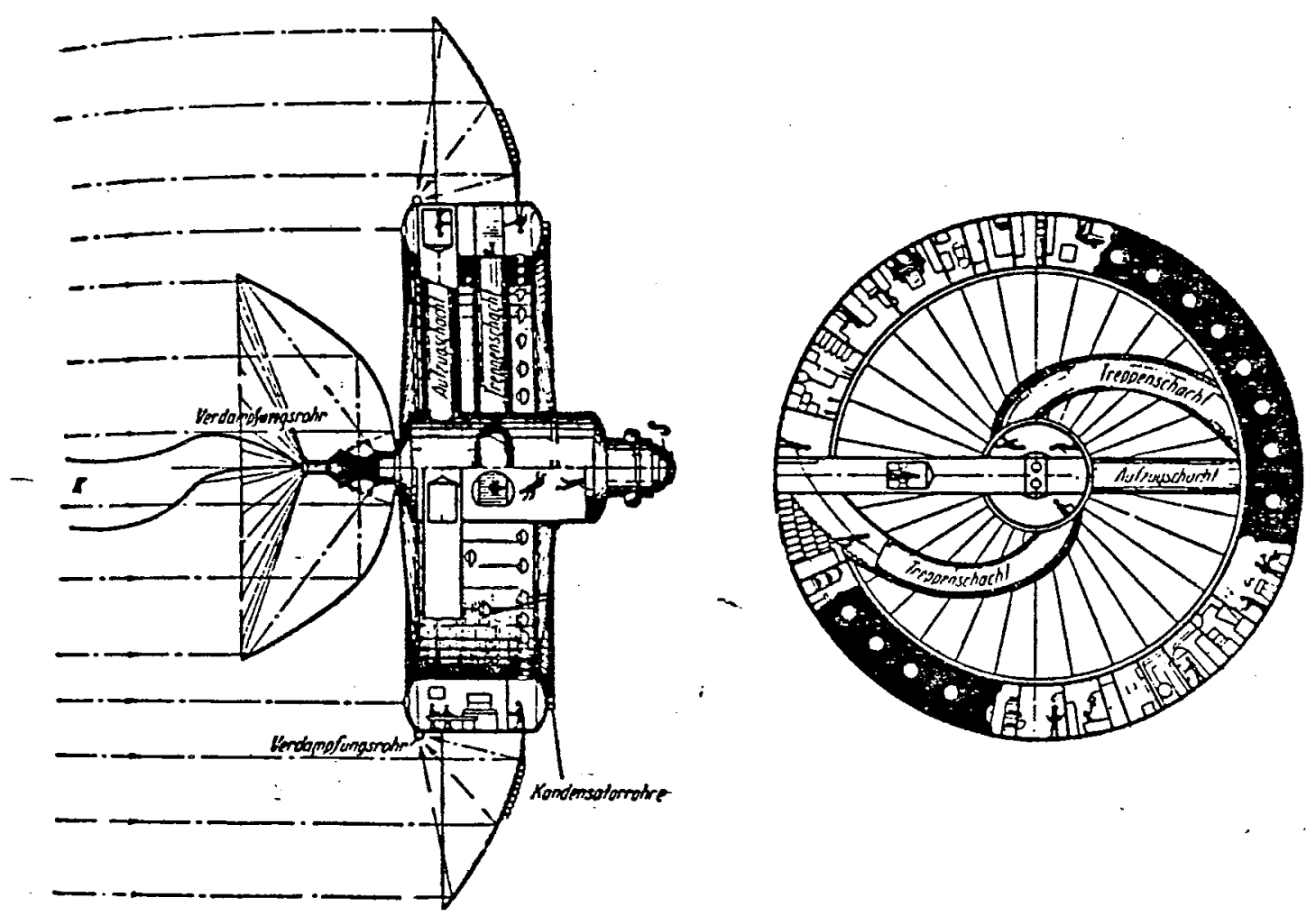

Spat station designed in 1929 by Hermann Noordung. $\mathrm{K}$ is the electric cable to an external obwriutory; $\mathrm{S}$ is the airlock; Kondensatorrohre are condenser pipes; Verdampfungsrohr are boiler pipis: Treppenschacht is a stainvell: Aufzugschacht is an elevator shaft. The design calls for power to tr supplied by mirrors concentrating sunlight onto the boiler pipes. (Courtesy the Millikan Library, (“lifornia Institute of Technology)

Heppenheimer, T. A. Colonies in Space. Stackpole Books, 1977

Figure 1. Hermann Noordung's "WOHNRAD" 


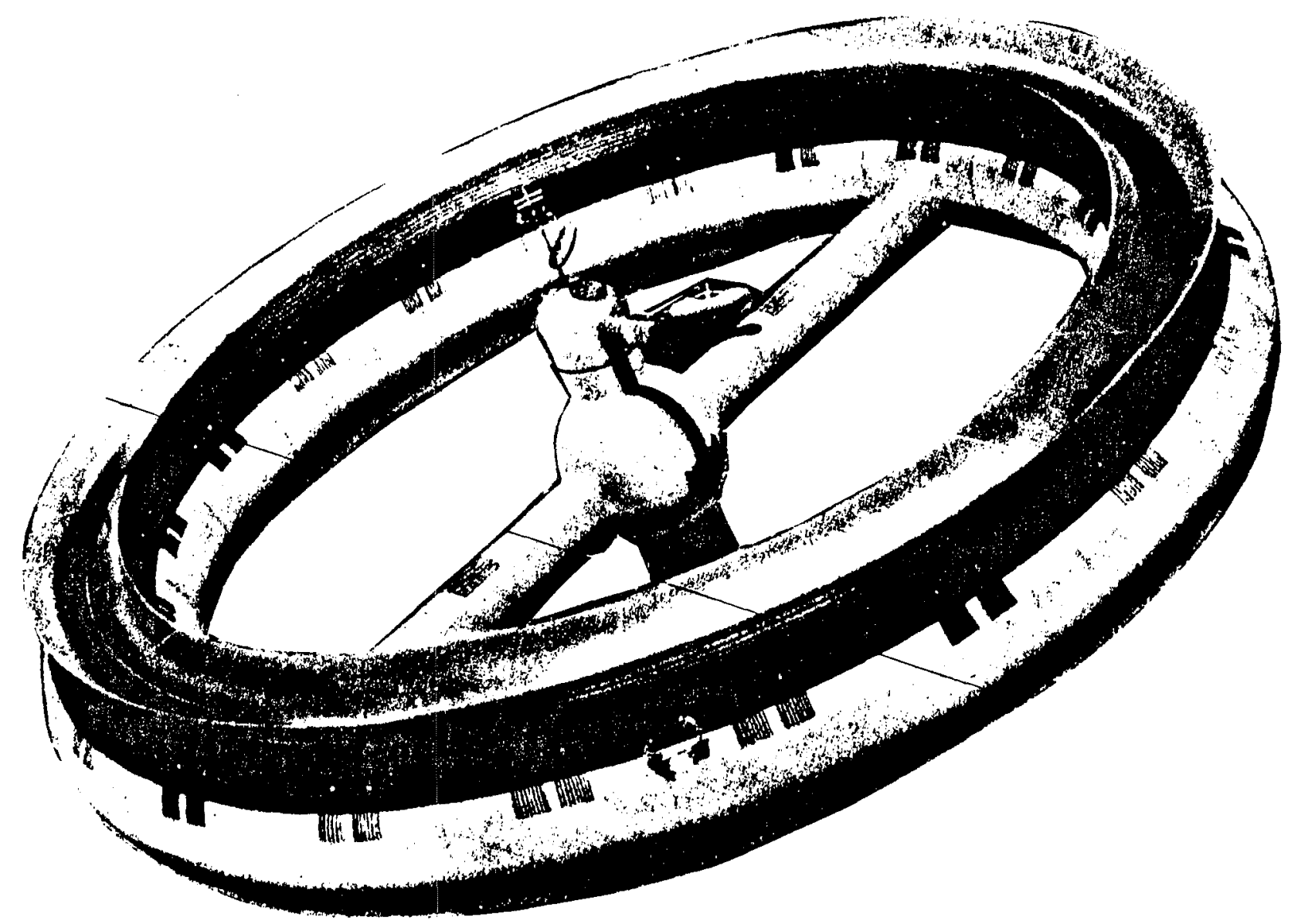

Dr. W. von Braun. "Crossing the Last Frontier." Colliers. 22 March 1952.

Figure 2. Dr. W. von Braun's "SPACE WHEEL" 


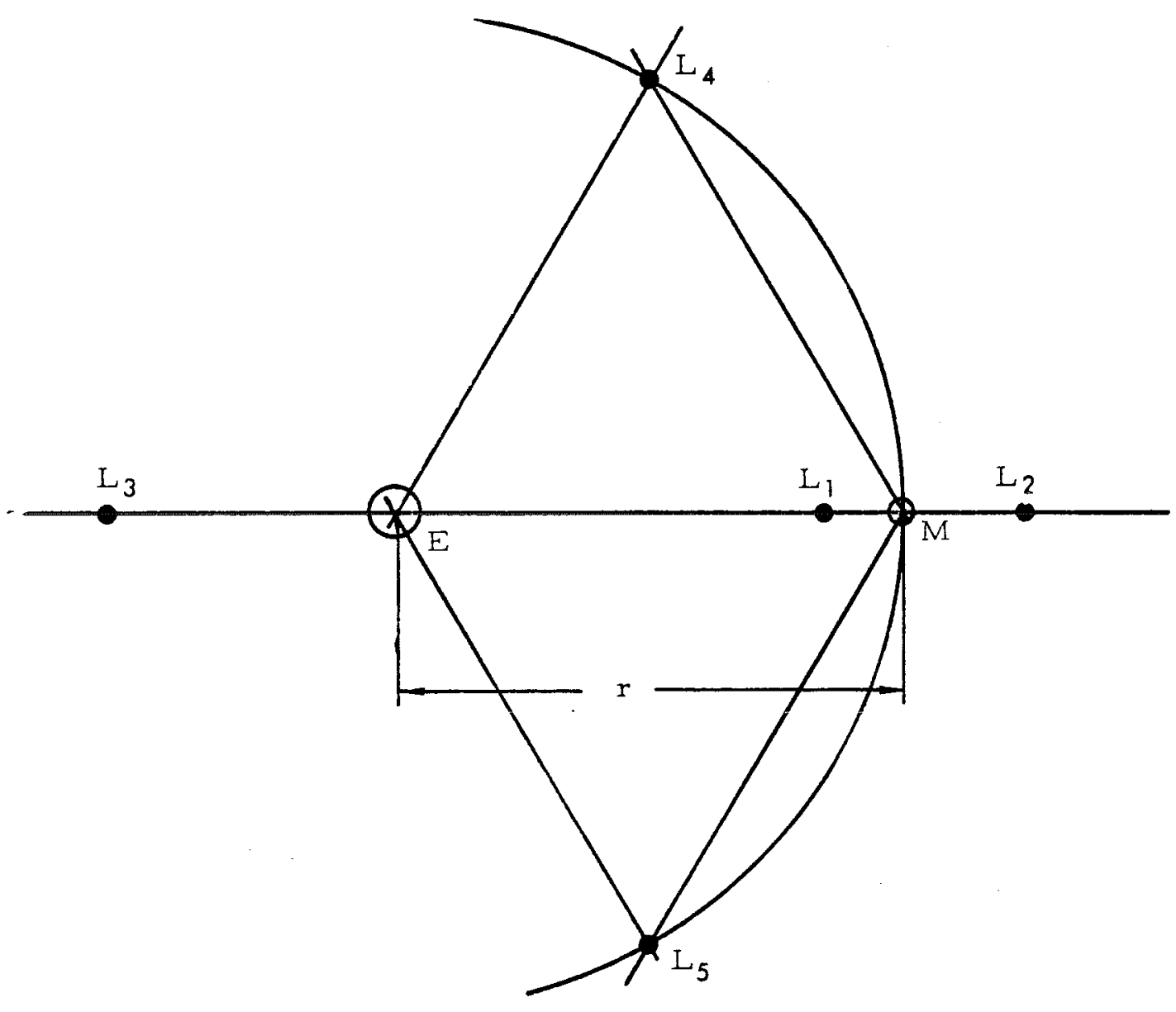

Figure 3. Location of Lagrangian Points 
The latest of these was proposed by Dr. Krafft Ehricke in $1976 .^{10}$ Known as Astropolis, this modular, rotating system is capable of simulating other-world environments in its various modules (Fig. 4). There is no set time for this type of system to be built, for its existence is dependent on expansion into space for economic rather than explorative reasons. This is the same driving force that led to rapid development of the North American continent in the 18th and 19th centuries .

The concepts for space habitats mentioned above, and others, are tabulated in Appendix A. Table 11 is taken from a paper by Koelle. ${ }^{11}$ Table 12 was compiled by this author. ${ }^{2,7,8,10-18}$ other concepts have been pursued by the National Aeronautics and Space Administration (NASA) and the Air Force but are so numerous they are not included in the 1isting. Suffice it to say that the stations studied by these two agencies of the U.S. Government were compatible with launch vehicles available at the time of the specific study. In general, they were not built-up structures but placed into orbit by a single launch and were capable of supporting from two to five crew members. Since the advent of the Space Transportation System (STS)*,

* The Space Transportation System consists of two solid rocket boosters, an external tank, the Space Shuttle Orbiter, and a manned maneuvering unit. The design goal is that it be capable of placing a 65,000 pound payload into circular orbit 150 nautical miles above the Earth's surface at 28.5 degrees inclination to the equator (due East launch out of Kennedy Space Center). Maximum payload volume is 15 feet in diameter by 60 feet long. ${ }^{19}$ 


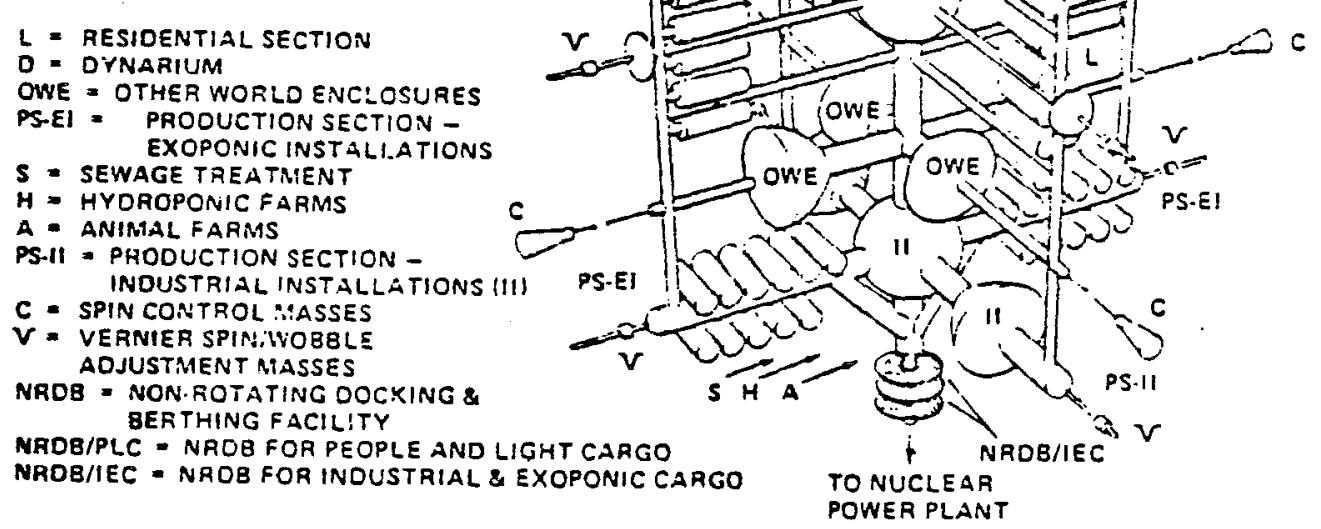

\section{Astropolis - Conceptual Arrangement}

Dr. K. Ehricke. "A Long Range Perspective and Some Aspects of Interstellar Evolution." Journal of the British Interplanetary Society. Vol. 28, April 1975.

Figure 4. Dr. K. Ehricke's "STAR CITY" 
these studies have taken on a modular, expandable theme, requiring multiple launches of the Space Shuttle Orbiter for construction capable of supporting up to 10 personnel.

Thus, since the first mention of earth orbital space habitats by Hale over 100 years ago, concepts have ranged from small 10-foot diameter cylinders to large toroidal cities more than a mile in diameter to modular, multi-g, multi-world structures capable of traveling through and beyond our solar system. Each concept had its own purpose for existence, from proving man's ability to survive and work in zero-g, to being complete environmental niches in which generations could travel through space, exploring and perhaps settling on planets in other stellar systems. In spite of these many concepts, only three true space stations have been placed in orbit: Skylab, Salyut 6 and Salyut 7 .

Skylab was launched in May 1973, and housed three 3-man crews for 28, 59 and 84 days from May 1973, through February 1974. 20-26 These visits are listed in Table 13 of Appendix B. However, Skylab was not designed to be a permanent station and could not be readily resupplied or reboosted to a higher orbital altitude. As a result, it was deactivated after the third crew departed and five years later, it reentered the Earth's atmosphere and was destroyed in July 1979. 27

Using a different approach, perhaps due to a more deliberate program for space utilization, Soviet space stations Salyut 6 and 7 were designed for resupply. Launched in September, 1977, Salyut 6 was

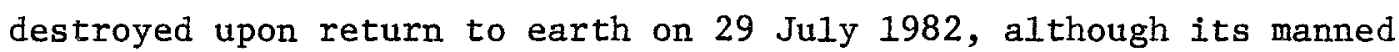
activities ended in $1981 . .^{28-78}$ During its nearly five years in service, 15 of the 17 crews sent to Salyut 6 successfully docked with 
and occupied it for periods up to 185 days. In addition, 12 Progress tankers were periodically sent to the station with fresh supplies of consumables. A second station, Salyut 7, was launched April 19, 1982. As with Salyut 6, various crews and resupply missions have been made to Salyut $7 .^{79-118}$ The latest occupants were launched on February 8, 1984 and returned October 2, 1984. ${ }^{117}$ For a complete list of flights to the Skylab and Salyut stations, please refer to Table 14 in Appendix B.

The next step in mankind's move into space is the placement of permanent, continuous1y occupied stations in Earth orbit. The USSR plans to accomplish this by using their 1960's design of a Saturn class vehicle. The USSR station will be carried into orbit by a single launch and be capable of supporting 12 cosmonauts. It will be used to aid Soviet military activities and continue the work begun on both Salyuts. ${ }^{63,119}$ A different approach is planned by the United States NASA. In 1980, NASA's plans called for the construction of a Space Operations Center (SOC) ${ }^{120-123}$ from several modules placed in orbit by the Space Transportation System. No 1onger called the SOC, it is now known as Space Station. NASA's Space Station will be used for logistical support of on-orbit activities such as commercial material processing operations, satellite servicing and repair, sortie support for manned geosynchronous flights, as a staging point for assembly of satellites or planetary probes that cannot be orbited by a single STS launch, materials processing and various scientific experiments. These support tasks are similar to those performed by the 01d West Cavalry Forts for early settlers in North America. 
For all the concepts proposed for space habitation in the past century, only three have become a reality. The next step, which is currently in the concept definition phase and should be on-orbit by 1992, is NASA's Space Station. The Soviet Union also has plans for stations larger than the Salyuts currently in use. The next generation space habitats appear to be those presented by NASA's special study groups. These are a giant step from what is currently in the planning stages. The Low Earth Orbit Business Center (LEOBC) is a proposed commercial space station which can fill the gap between the current generation of space stations and the space cities of the next century as seen by $0^{\prime} \mathrm{Nei11}$ and others. 


\section{CHAPTER 2}

THE NEXT STEP

Operational limitations of current space hardware and the means of support for commercial operations in space are discussed to illustrate why there is a need for something more than the Space Transportation System and the upcoming space station and how a commercial site in space may be financed.

Following the plans of the United States NASA and visions of Gerard $0^{\prime}$ Neill, Krafft Ehricke and others, the evolutionary expansion into space leads from the Space Transportation System to logistical support centers in low Earth orbit followed by Lunar mining communities and cities in the L-5 1ocation of the Earth-Moon system. Beyond that, a modular rotating structure, known as Astropolis, is seen traveling about the solar system and interstellar space. It is difficult to visualize a sudden step from small 8-12 man stations in low Earth orbit to cities on the Moon and at L-5 with tens of thousands of inhabitants without any intermediate steps. LEOBC is proposed as one of these intermediate steps.

Current space programs are funded by federal tax dollars appropriated by Congress. However, lunar and space cities, as envisioned by Ehricke and $0^{\prime} N e i 11$, are expected to be paid for by profits generated from commercial space activities. Whether or not this happens will only be answered in time.

Incentives to develop space could follow a path similar to that used to develop the North American frontier and the satellite communications industry. The biggest problem in settling the West was inadequate transporation. This was overcome with large land grants 
along rights-of-way to companies that built the railroads, thus lowering the financial burden of construction. Satellite communications was an undeveloped technology in the early 1960's when Comsat was established by the U.S. Congress to provide research dollars and industry regulation needed to develop satellite communications and ensure a return on investment. Today, companies are beginning to build communication satellites on a venture basis and are selling transponders, rather than leasing them under government regulation. 124 This opens up the market to supply and demand price setting, rather than controlled income fixed by government regulations.

To open other markets in space, it may be necessary for NASA to provide incentives of lower transportation or research funding as was done for the railroads and satellite communications industries. Then, once profitability is proven, each endeavor can compete in free markets. Placing a facility on orbit such as LEOBC could be an incentive needed to spur space development.

In 1981, the chairman of American Institute of Aeronautics and Astronautics' Space Processing Committee, R. A. Weiss, was asked by this author about the prospects of material processing in space. His response indicated that private sources were finding the high development cost and long lead time necessary for return on investment to be major deterrents to investment in space processing. As a result, he indicated that it may be necessary for NASA to place the needed facilities in space for early phases of space commercialization. This position is echoed in a paper presented by Waltz at the 1981 AIAA Annual Meeting showing the need for funding and 
promotion of material processing in space. ${ }^{125}$ Eventually, as "market pul1" exceeds "technology push", more private money should become available and government support can be decreased or eliminated. NASA realizes the need to aid initial steps toward exploitation of space and is offering joint endeavor agreements (JEA) with companies wishing to explore possibilities of operating in space. ${ }^{126}$ With a JEA, the principal investigator develops a proof-of-concept experiment and NASA provides several free launches aboard the Space Shuttle Orbiter.

McDonne11 Douglas and Johnson \& Johnson have signed such an agreement and are developing hardware for electropheretic separation of biological materials. This process plays a key role in drug purification for medical research. To date, the process, which was flown on STS-4, STS-6, STS-7, STS-8, and STS mission 41D (STS-14), has shown dramatic improvements in electropheretic separation efficiency. Four to seven hundred percent improvement in the separation rate has been reported by McDonnell Douglas. ${ }^{127-132}$

In addition to the McDonnel1 Douglas and Johnson \& Johnson team, in a recent study for NASA, Booz, Allen and Hamilton surveyed 60 companies concerning possibilities in space industrialization. ${ }^{133}$ Of these, 10 were identified as possible JEA signers within the next 12 months, some of which may result in STS flight activity and thirty-five are still actively examining commercial applications of space. In addition, 17 investment firms have expressed a desire to finance such activities.

In order to fully realize the benefits of operating in space, it is necessary to overcome the basic limitations inherent in the Space 
Transportation System, and possibly, the Space Station. One of the key reasons for transferring a process to earth orbit is use of benefits derived from being in a microacceleration environment, commonly called zero-g. However, with the Space Shuttle Orbiter, flight duration is now limited to less than two weeks. Current studies are under way which will extend this to 30 days or longer. By adding Space Station to NASA's inventory, mission time can be extended to the maximum allowable time defined by operational or medical limits. Available power in earth orbit is another concern to any who desire to manufacture products in orbit. Just as on the surface of this planet, there is a power shortage in space. The Space Shuttle Orbiter has a limited electrical power generating capacity on board at 1ift-off. As mission duration is extended to seven days, usable payload power drops to $50 \mathrm{kw}-\mathrm{hr} .^{19}$ As stay time is shortened, available power increases as shown in Figure 5. Eventually, a power extension package, in the form of a solar array, may be added to the Orbiter to increase payload usable power to as much as $25 \mathrm{kw}$ continuously. 134

The McDonnel Douglas Electrophoresis Operations in Space (EOS) Program is an example of the need for additional power in space. Currently being operated in the Orbiter mid deck region, EOS operations will eventually move into the payload bay and then onto a free-flying platform. While in the payload bay, EOS will need to draw $3.5 \mathrm{kw}$ during operation. ${ }^{135}$ This 1imits Orbiter mission duration to a maximum of five and a half days, unless power usage rate is decreased (Fig. 5). This, however, will reduce the operational efficiency of the EOS. The solar array addition to STS hardware would 


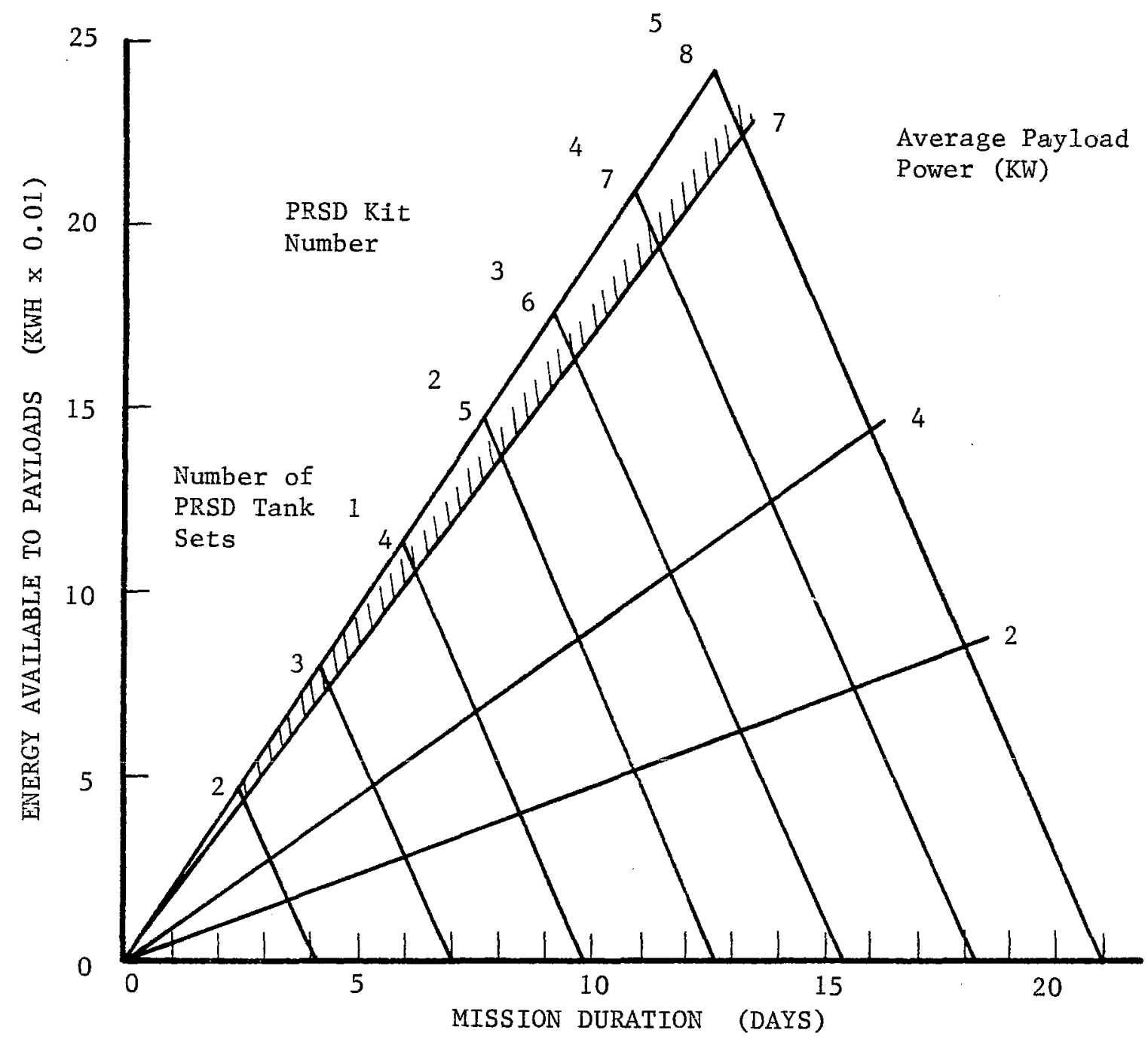

Figure 5. Payload Average Power Impact on STS Mission Duration Space Shuttle System Summary, SSV80-1, Rockwell Internaltional, May 1980, pp. 24-85. 
make long duration missions possible for power intensive activites such as EOS. Even with this Orbiter capability extension, McDonnell Douglas is pursuing permanent on-orbit operation with a free-flyer or in conjunction with Space Station. 136

The third of three important factors limited by the Space Shuttle Orbiter is usable volume. On the Orbiter, a user is limited to a maximum payload bay volume of 300 cubic meters. This cannot be increased without placing permanent structures in orbit. As of this writing, current plans for Space Station will actually provide less internal volume per module than is available in the Space Shuttle Orbiter payload bay because each module will be carried into orbit inside the payload bay. Volume per module can be increased by carrying the external tank into orbit and using it as the basic building block for a station. By using only the hydrogen tank, a habitat that is over 8 meters in diameter and 29 meters in length would be available, providing a usable volume in excess of 464 cubic meters per module. However, this approach may not be cost effective. Without using this tank and by following current plans, maximum size of any equipment utilized in an enclosed environment on orbit is limited to an envelope of less than 15 feet in diameter and 60 feet in length since each module is viewed as an isolatable volume.

Although not necessary for man's survival in space, a pseudogravitational environment may be extremely advantageous from a medical and human factors viewpoint. A key reason for providing an acceleration field for long periods of stay-time on orbit is to counteract mineral losses that are associated with zero-g. These losses, which can amount to as much as $0.3-0.4$ percent per month, 
remain unexplained. As shown in the 84-day Skylab mission, neither vigorous exercise nor special diet had an effect on the rate of heel bone deterioration. ${ }^{137-139}$ However, the longer flights aboard the Soviet Salyuts indicate that these mineral losses become asymptotic.

A gravitational environment may also be desirable to preclude changes in personalities during long missions. The negative impact on productivity and safety that these personality changes have had on space flights and in other confined environments has been documented by $\mathrm{Dr}$. B. J. Bluth in her studies on the physiological and psychological aspects of space flight. ${ }^{140}$ Weightlessness has been pointed to as a possible source of these changes. ${ }^{141}$

An additional advantage associated with an acceleration field is the elimination of the need for special equipment designed for zero gravity in the laboratory and living areas. Also, by living in a pseudogravity environment while on orbit, the time necessary to readjust to a one-g acceleration field upon return may be shortened or eliminated.

The major disadvantage to a gravity-oriented habitat is that it forces processes which require micro-g levels to be housed in counter-rotating or non-rotating co-orbiting facilities. This will impact either the LEOBC design or the operational logistics for these processes.

The proposed LEOBC will overcome the operational limitations associated with the STS and the upcoming Space Station. It will also provide experience in space construction and operation of rotating facilities before implementation of larger programs such as the space cities proposed by the NASA-Ames studies of 1975 and 1977 . 
CHAPTER 3

INTERNAL ENVIRONMENT

Prior to evaluating geometric configurations for LEOBC, parametric limits on pseudogravity and atmospheric pressure and composition will be presented. The pseudogravity limits are taken from various studies on rotation rate and radius of rotation effects on crew performance. Atmospheric pressure and composition are related to current and future space hardware, decompression sickness and equivalent sea-level composition.

\section{PSEUDOGRAVITY}

In order to create an artificial gravity for LEOBC, the structure must be rotated about its longitudinal axis at some angular velocity. Several studies and experiments have been conducted on this subject resulting in various limits that should be considered when establishing a gravity-oriented environment through rotation. These limits were established or reinforced by testing in a ground-based rotating test facility. These test were conducted by North American Rockwell Corporation, Space Division (NR/SD), in cooperation with NASA Langley Research Center to determine the effects of rotational rates, acceleration levels and radius of rotation on several test subjects. 142

Referring to Figure 6 , the rotational limits suggested by these past tests and studies are plotted as a function of radius. Those combinations of rate and radius eliminated by each upper or lower boundary are covered by diagonal lines.

For design purposes, a value of one-g was set as a pseudogravity maximum and was chosen as an upper limit as it is man's natural 

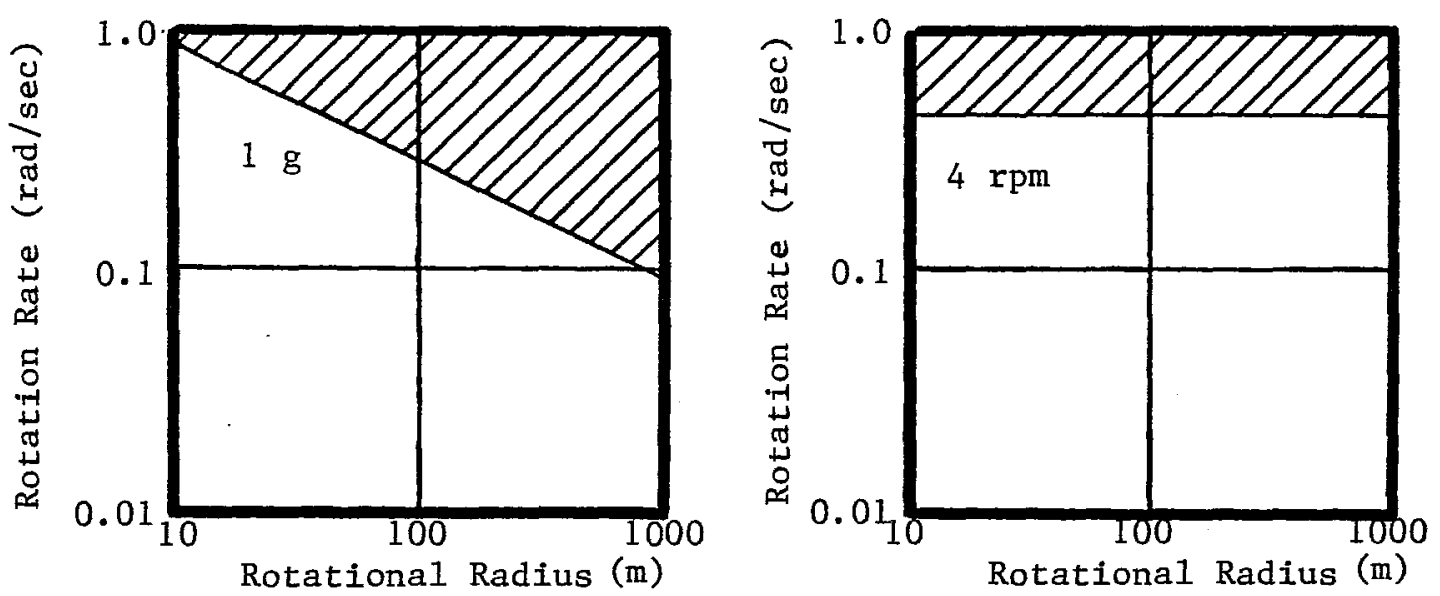

(a) Upper G Limit

(b) Upper Rate of Rotation Limit
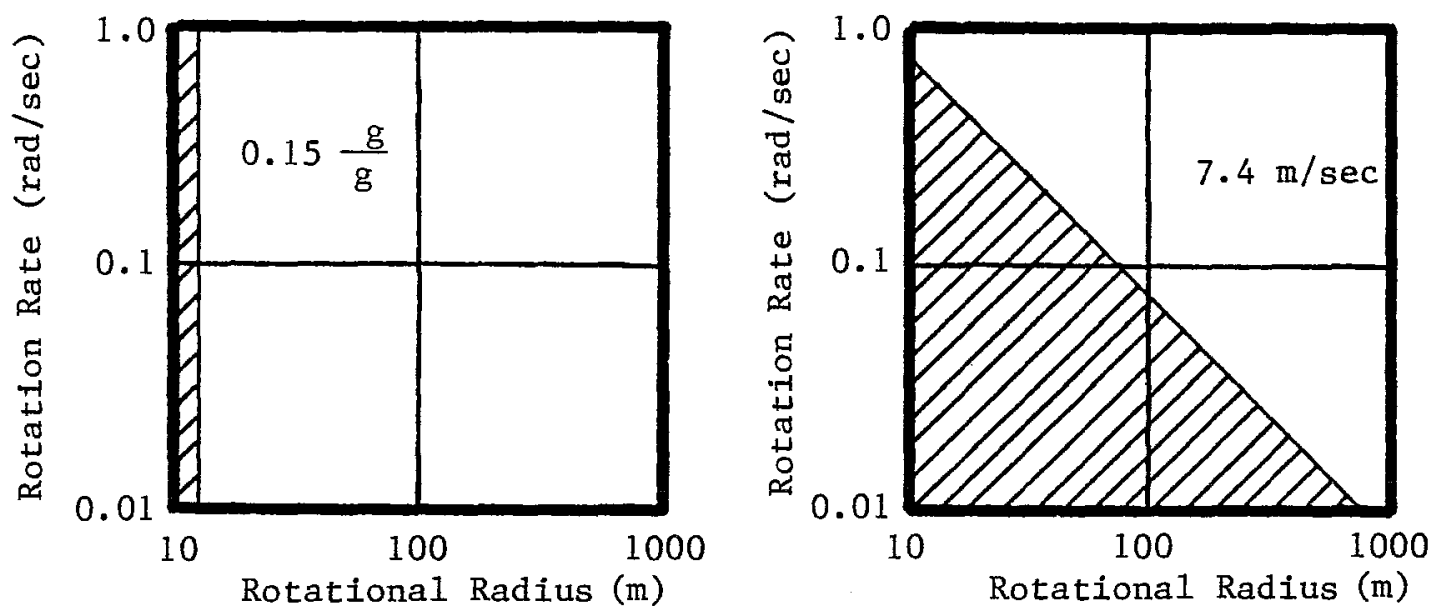

(c) Upper Gravity

Gradient Limit

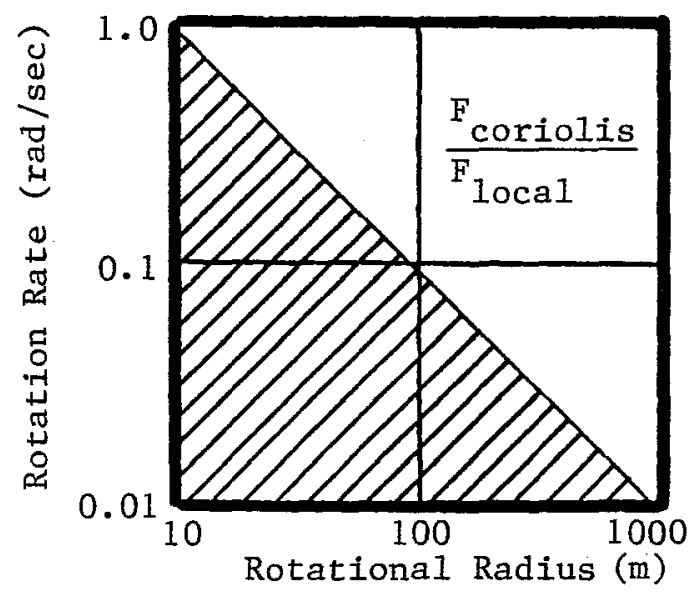

(d) Rim Velocity Lower Limit

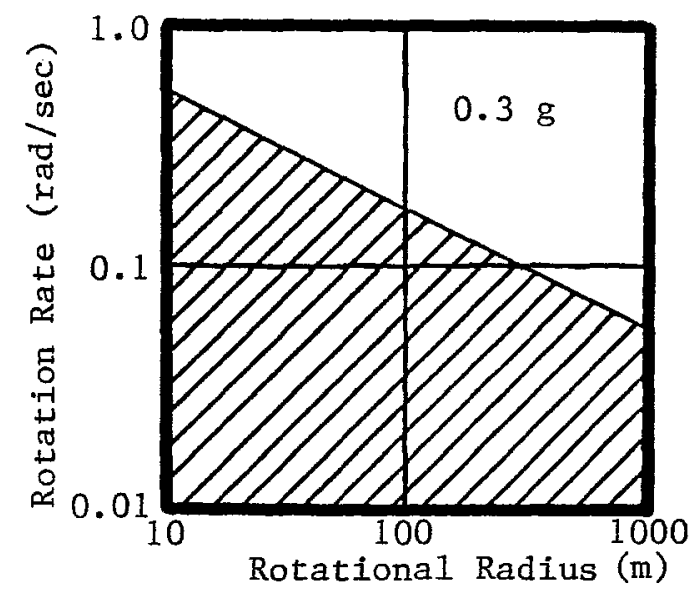

(e) Ratio of Coriolis

Force to Local Force $=0.25$

(f) Lower G Limit

Figure 6. Pseudogravity Design Limits 
environment. This upper limit removes all combinations of rotation rates and radii as shown in Figure $6 a$.

Studies on the effect of rotation rates on selected individuals have shown that a limited number can adjust to rotation rates as high as $1.05 \mathrm{rad} / \mathrm{sec}(10 \mathrm{rpm}) .^{143}$ However, a maximum rotational rate of $0.42 \mathrm{rad} / \mathrm{sec}(4 \mathrm{rpm})$ is usually quoted as an upper limit. The tests performed by NR/SD show that performance improves as induced g-levels increase from $0.1 \mathrm{~g}$ with a plateau achieved between 0.3 and $0.4 \mathrm{~g}$ 's They also showed that performance improved as rotation rates were increased from $0.31 \mathrm{rad} / \mathrm{sec}$ to $0.52 \mathrm{rad} / \mathrm{sec}$ for radii of less than 18.29 meters. Indications are that performance increases as rotation rates decrease for radii above 18.29 meters. ${ }^{142}$ To ensure adaptability by the general population, the 1975 summer study group used an upper 1imit of $0.105 \mathrm{rad} / \mathrm{sec}(1 \mathrm{rpm}) .^{144}$ Since LEOBC staff will be from a select population, tolerance to rotation rates may be checked. Therefore, the limit suggested by Green, et al of 0.42 $\mathrm{rad} / \mathrm{sec}$ has been established as the upper limit on rotation rates. ${ }^{143}$ Figure $6 \mathrm{~b}$ shows those rate-radii combinations eliminated by this limit.

For objects in a uniform gravitational field, such as earth's surface, hydrostatic force varies linearly with height. However, in a rotating structure the centripetal acceleration also varies with radius or height. As a result, hydrostatic pressure varies as the square of the height. This change in acceleration levels with height is called gravity gradient. An arbitrary upper limit on gravity gradient of $15 \%$ has been recommended. $142,143,145$ This ensures that the ratio of hydrostatic pressures of the heart and feet for a six 
foot tall individual is similar on a rotating structure and the earth's surface. This sets a lower limit on the rotational radius at 12.2 meters, as seen in Figure 6c.

Side forces generated by motion in a rotating structure can inhibit locomotion if they are too great. These coriolis accelerations are cross-products of the rotational rate and the velocity of an object. Inside a rotating structure such as LEOBC, effects caused by coriolis accelerations include apparent weight change when motion is in the pro- or anti-spin direction or when motion is in a radial direction, an apparent force is generated in the pro- or anti-spin direction. This is illustrated in Figure 7.146 Two different limits have been proposed to minimize effects of coriolis accelerations in the living area. One limit establishes a maximum rim velocity of $7.4 \mathrm{~m} / \mathrm{sec}$ (Fig. 6d) in order to reduce the apparent weight loss or gain while moving either opposed or parallel to the direction of spin. ${ }^{145}$ The second criterion suggested that side forces generated when an object moves radially be limited to $25 \%$ of an object's weight. ${ }^{143}$ Since this is both a function of radius and velocity, a representative limit can be found by using walking speed $(1.34 \mathrm{~m} / \mathrm{sec})$ as the velocity at which side forces are generated. This limit is illustrated in Figure 6e.

The final limit places a lower bound on acceptable pseudogravity acceleration levels and were established by walking tests conducted by NR/SD. ${ }^{142}$ They found that mobility, as defined by walking speed, fell drastically as induced g-levels dropped below $0.3 \mathrm{~g}$ 's. Figure $6 \mathrm{f}$ depicts the radii-rotation rate combinations eliminated by this lower limit. 


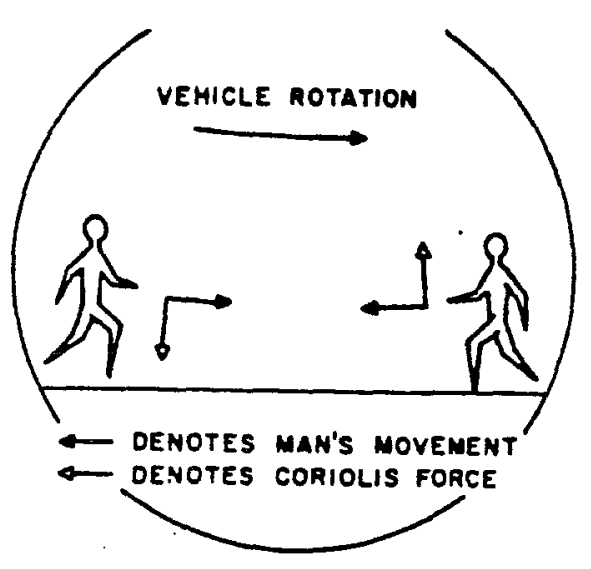

A - In Plane of Rotation
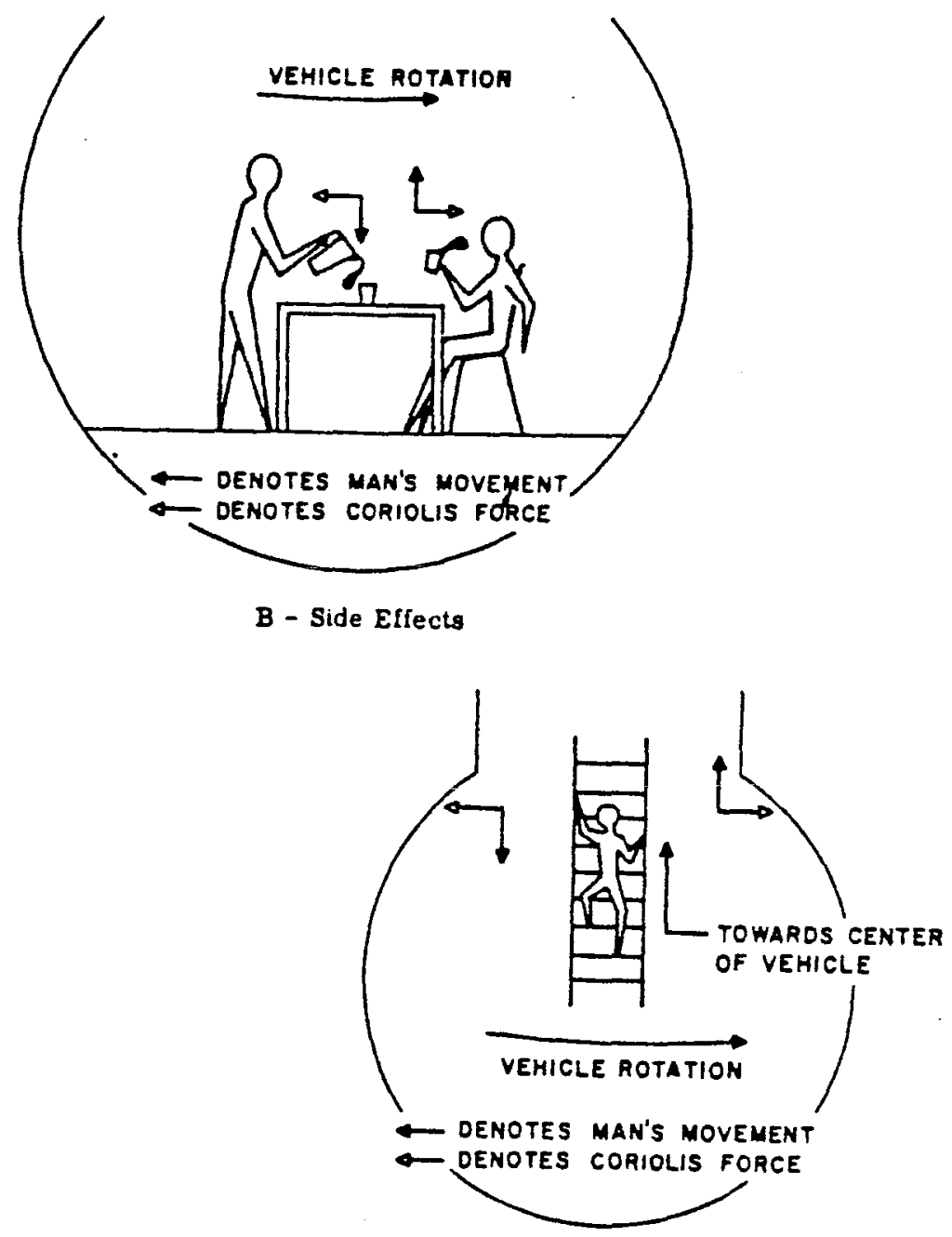

C - For Radial Motion

Kramer \& Byers. "A Modular Concept for a Multimanned Space Station." Proceedings of the Manned Space Station Symposium. IAS, 1960

Figure 7. Coriolis Acceleration Effects 
By combining all limits discussed above and show in Figure 6, an overall design envelope is defined for rotation rate versus radius and is shown in Figure 8. This envelope indicates that the smallest radius that should be considered for a rotating structure is 20 meters. It also shows that there is no rotational speed limit for any structure larger than 50 meters in radius except that set by the maximum desired $\mathrm{g}$ level. The rotational radius for LEOBC will be targeted for the mid point of rotation versus radius envelope to provide on acceleration of $16.1 \mathrm{ft} / \mathrm{sec}^{2}$.

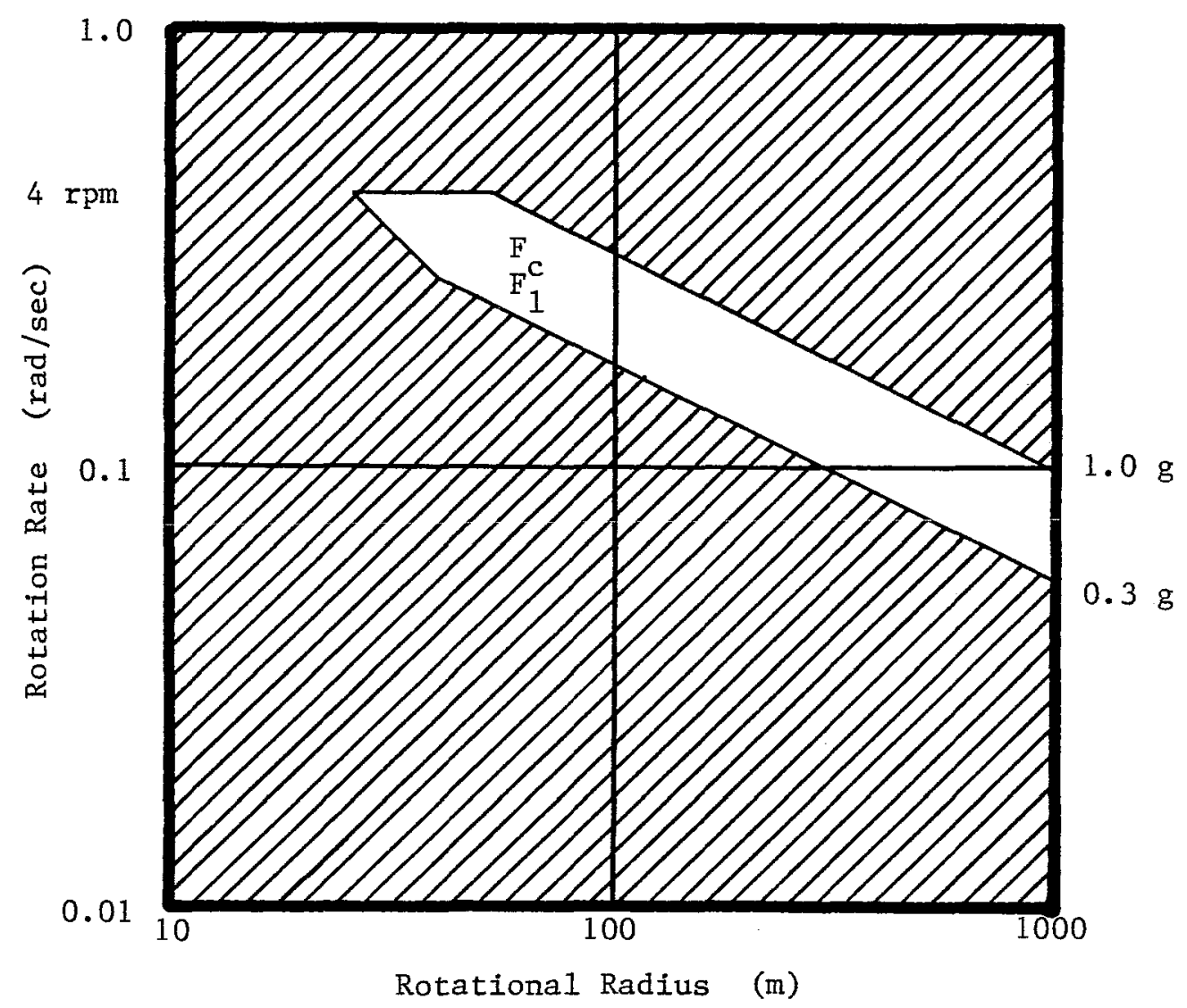

Figure 8. LEOBC Pseudogravity Design Envelope 


\section{INTERNAL ATMOSPHERE}

LEOBC's atmospheric minimum design point is driven by current STS orbiter cabin pressure, STS spacesuit pressure, baselined space station suit pressure, oxygen partial pressure in the lungs and caisson's disease or the bends.

Current Space Shuttle Orbiter cabin and spacesuit atmospheres are not conducive to immediate extravehicular activity (EVA) because of pressure and composition differences. The orbiter operates at standard sea-level pressure and composition while the EVA suit contains $100 \%$ oxygen at a pressure of 0.2925 atm ( 4.3 psi). 124,147 Since decompression sickness occurs whenever the nitrogen partial pressure in the body is greater than 1.5 times the new ambient pressure and STS cabin nitrogen partial pressure is greater than twice the suit pressure, astronauts must eliminate nitrogen from their body before attempting an EVA. This imposes a time-consuming operational constraint for the purpose of removing nitrogen from the body. This can be accomplished by either prebreathing a nitrogen-poor mixture or by reducing the cabin pressure. Both of these methods have been used on STS flights. The mathematical relationship between body nitrogen pressure, initial atmospheric nitrogen partial pressure, the nitrogen content of the prebreathing air and time were described by Edel in $1968 .^{148}$ This relationship is given by equation 1 ,

$$
P_{N}(t)=P_{N}(0)+\left[P_{N-M / x}-P_{N}(0)\right]\left[1-e^{-k+}\right] \text { eq. } 1
$$

where $k$ is related to the body tissue nitrogen saturation half-time by the ratio of $0.693 / t_{1 / 2} \min ^{-1}$. Edel states that a value of 240 
minutes proved safe for sea lab decompression schedules. It has been suggested, but not verified, that saturation half-times are longer for women than for men due to higher body-fat content. Typical prebreathing times for half-saturation times of 240 and 300 minutes are show for a breathing air mixture of $25 \% \mathrm{~N}_{2} / 75 \%$ oxygen and $100 \%$ oxygen in Figure 9.

NASA is studying the elimination of this operational constraint for its space station operations by baselining a 0.54 atm ( 8 psi.) suit pressure using a nitrogen/oxygen mixture. It is this suit pressure and the STS cabin pressure which establish the range of pressures considered for LEOBC. Composition will vary as a function of pressure to maintain a sea-level equivalent oxygen partial pressure in the lung as shown in Figure $10^{149}$

As unlikely as it may be (Figure 11), the possibility of being punctured by a meteoroid must be considered. ${ }^{150-151}$ Should LEOBC's skin be punctured, there are two different decay processes that could dominate as defined by Roth..$^{152-153}$ If the puncture is small enough that leakage rates are much less than the ventilation rate, internal temperature will remain constant and the process will follow the isothermal curve. However, should the hole created be large and leakage occur at a very rapid rate, or safety measures require that airtight doors be closed and ventilation shut down, then an adiabatic, isentropic pressure decay will occur.

For an isothermal decay process, pressure change is an exponential process, defined by equation 2 .

$$
\rho=\rho_{0} e^{-t / \tau}
$$




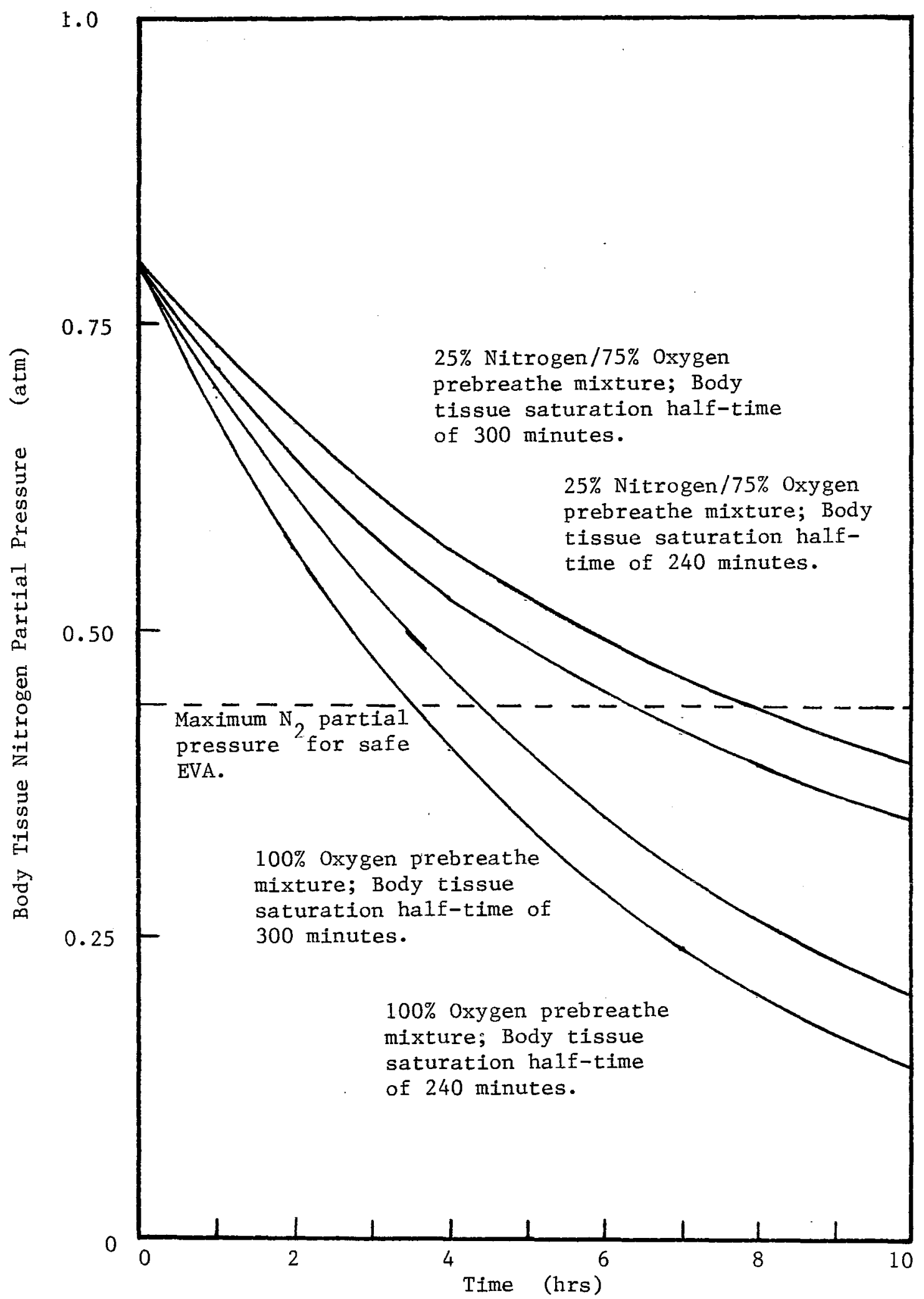

Figure 9. Body Tissue Nitrogen Partial Pressure Versus Time 


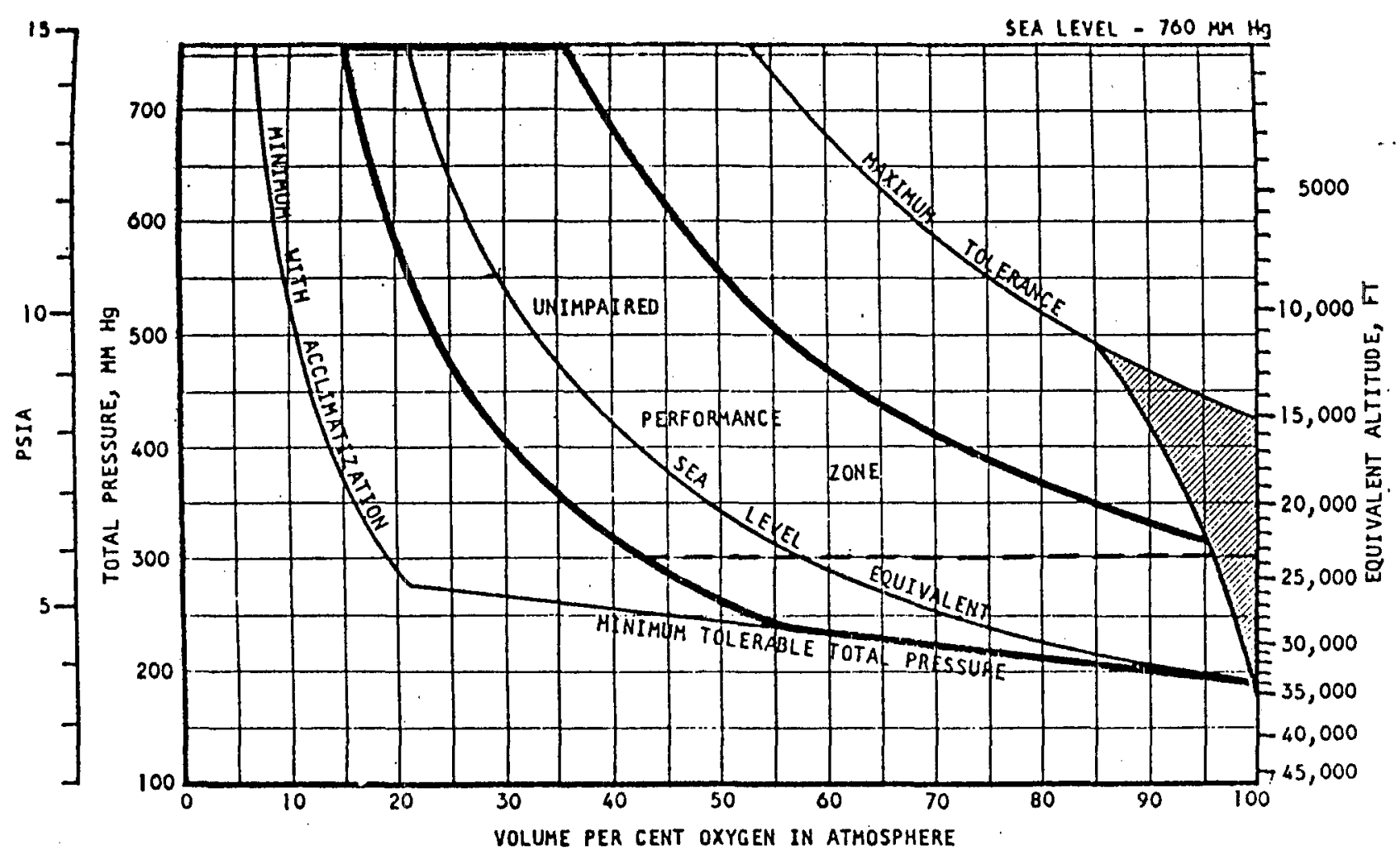

Oxygen-pressure effects; adapted from Luft (1962).

Roth, E. M. Space Cabin Atmosphere Part IV, Engineering Tradeoffs of OneVersus Two-Gas System, A'Literature"Review. Scientific \& Technical Information Office, 1967.

Figure 10. Sea Level Equivalent Atmosphere Composition 


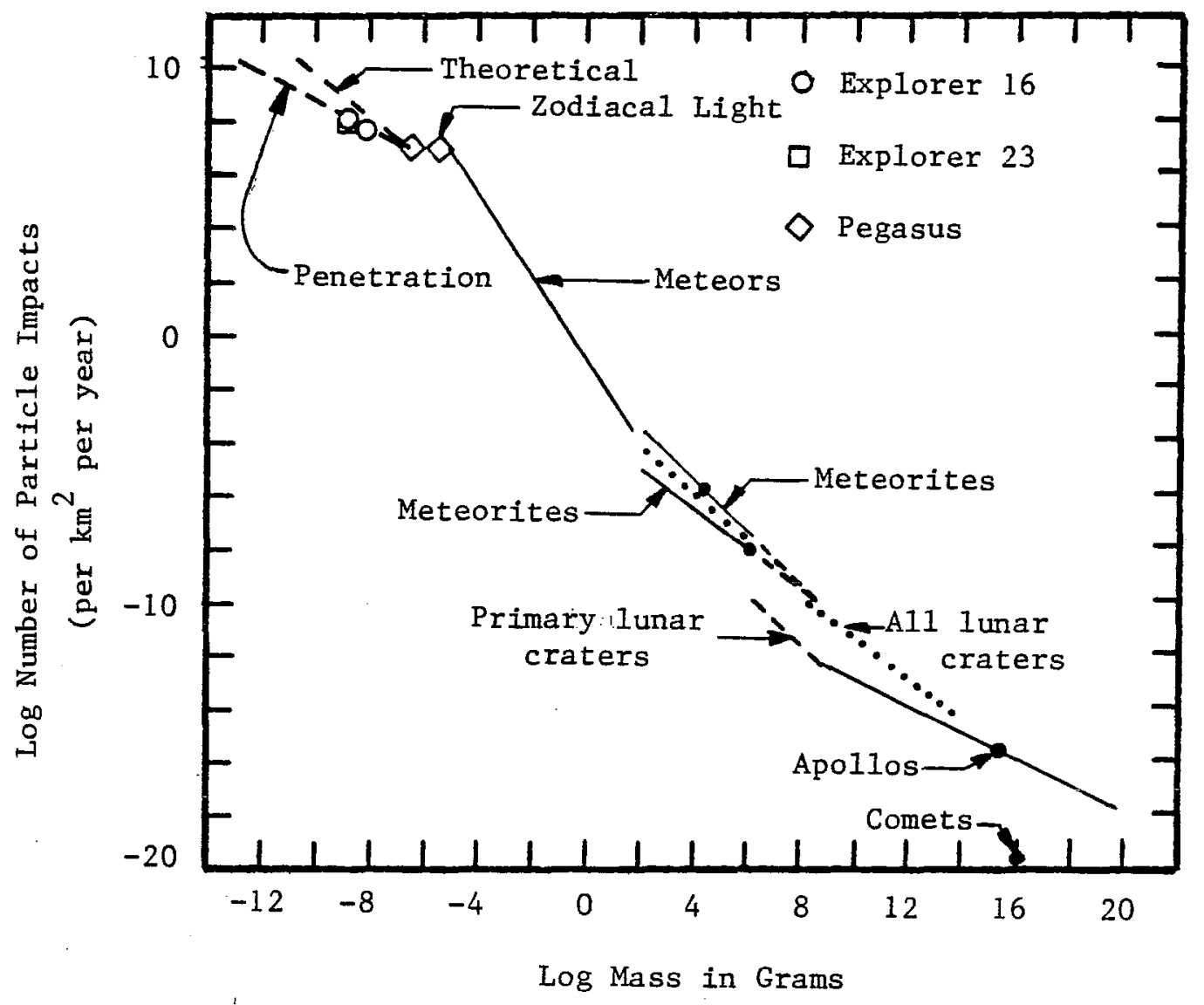

Johnson, R. D. \& Holbrow, C., (ed). Space Settlements A Design Study. NASA SP-143, 1977.

Figure 11. Impact Rates of Meteoric Material 
where $\tau$ is the time constant, defined by equation 3 .

$$
\tau=\frac{V}{A_{e}}\left[\frac{\gamma R T_{0}}{m}\left(\frac{2}{\gamma-1}\right)^{\frac{\gamma+1}{\gamma-1}}\right]^{-1 / 2}
$$

eq. 3

Isentropic pressure decay is slightly faster and produces a pressure drop as defined by Equation $4 . \quad$ ( $\tau$ is defined as before.)

$$
P=P_{0}\left[1+\left(\frac{\gamma-1}{2}\right) \frac{t}{\tau}\right]^{\frac{2 \gamma}{1-\gamma}}
$$

eq. 4

For standard atmospheric conditions, the time constant for any space station is $3.27154 \times 10^{-3} \mathrm{sec}-\mathrm{cm}^{2} / \mathrm{m}^{3}$ times the ratio of station volume to effective hole area. Thus, as stations grow in size, the impact of a meteor puncturing the skin becomes less of an immediate threat.

To prevent personnel from developing the bends due to decompression, airtight doors will be located where necessary. As pressure drops below a preset value, these doors will be automatically closed. The pressure at which this occurs will be based on final pressure, composition and desired margin to preclude the occurence of bends. 
CHAPTER 4

LOW EARTH ORBIT BUSINESS CENTER CONFIGURATION

If commercial activities in space justify a space business park, questions regarding its configuration and internal environment need to be answered.

Prior to selecting a geometric configuration for LEOBC, consideration must be given to user needs. These needs are defined by volume requirements, mass-to-orbit 1imitations, pseudo-gravity needs, expandability, and floor area requirements. Studies by industry and educational institutions that have proposed space station designs have included trade studies to determine the optimum configuration. The selection in these studies were driven by a particular launch vehicle, population density, ease of construction, total station mass based on radiation shielding requirements and cost. Most studies, however, were conducted for station populations less than 100 or greater than 10,000 personnel per habitat. Since LEOBC is expected to accommodate up to 200 personnel, a new look at configuration comparisons will be made.

The following definitions were used in generating the necessary equations for LEOBC candidates shape comparisons:

Surface Area - Total area required to enclose the pressurized volume.

Projected Area - Maximum habitable volume width multiplied by its circumference.

Habitable Volume - The volume within a specified radial acceleration differential $(\gamma=0.15)$

Floor Area - Floor space which has a minimum overhead clearance of 2 meters. 
The first step is to define the means of comparison. For all rotating structures, the following comparisons are basic: 1) volume, 2) habitable volume, 3) surface area, 4) projected area and 5) floor area as functions of rotational radius. In addition, six ratios of geometric parameters will be compared. These are 1) habitable volume/total volume, 2) total volume/surface area, 3) habitable volume/surface area, 4) projected area/surface area, 5) floor area/total volume, also as functions of radius. These parameters will be compared for each of the following configurations: 1) sphere, 2) cylinder, 3) dumbbell, 4) torus, 5) crystal palace and 6) a two-axis-stretched ellipse of revolution. Each smooth-curved body of revolution is defined in Table 1 and depicted in Figure 12.

It should be pointed out that all but the last configuration discussed in this paper have been previously compared. ${ }^{154}$ In fact, two study groups under the same sponsorship and guidance came to two different conclusions. In 1975, the NASA-AMES study group under 0 'Neill developed a space city concept for 10,000 inhabitants. The torus was chosen as the best configuration over other shapes based on various comparisons. This has become known as the Stanford Torus. Subsequent to this, 0 'Neill developed a new configuration, ${ }^{155}$ which he called the "Crystal Palace", after the London World's Fair exposition hall built in $1880 .^{8}$ This new structure, in conjunction with a change in radiation shielding application to the Stanford Torus, became the preferred choice.

Table 2 lists the equations used to compare the various shapes of Figure 12. Full development and explanation of each equation is presented in Appendix C. By reviewing the graphical presentation, it 
Sphere

1) A shell of radius $R$

2) Curve $A$ revolved about $x$-axis

3) Most efficient structure for given pressure and volume

Cylinder

1) Shell of radius $R$ and length $\alpha$ with hemisperical endcaps

2) Curve $B$ revolved about $x$-axis

3) Offers more "land area" for given radius than sphere

Dumbbe11.

1) Two spheres of radius $R$ separated by distance $2 R-\gamma R$

2) Curve $C$ and $D$ revolved about $x$-axis

3) Most efficient structure for given pressure and volume plus rotational radius independent of structural radius

Torus

1) Circular or cylindrical cross section of radius $R$ and length $2 R(1+\alpha)$

2) Curve $E$ or $F$ revolved about z-axis

3) Rotational radius independent of structural radius

Crystal Palace 1) Series of semi-circular shells of radius $R$ and $R / 2$ joined together to allow expansion along axis of rotation

2) Curve $G$ revolved about $z$-axis

3) Choice of 1977 NASA Ames study session

Ellipse

1) Volume of revolution of ellipse quadrant offset from $x$ - and $z$-axis

2) Curve $H$ revolved about $z$-axis

3) Proposed LEOBC Hub design

Legend 1) Description

2) Curve from Figure 4

3) Reason for inclusion 
TABLE 2. SHAPE EQUATIONS

I. SPHERE

Volume: $\quad V_{5}=\frac{4}{3} \pi R^{3}$

Habitable Volume: $H V_{5}=\frac{4}{3} \pi R^{3}\left(2 \gamma-y^{2}\right)^{3 / 2}$

Surface Area: $\quad S A_{3}=4 \pi R^{2}$

Projected Area: $\quad P A_{S}=4 \pi R^{2}(1-y)\left(2 q-y^{2}\right)^{1 / 2}$

Floor Area:

$F A_{5}=4 \pi \sum_{n=1}^{N}[R-3 n+2]\left[R(6 n-4)-(3 n-2)^{2}\right]^{1 / 2}$

II. DUMBBELL

Volume: $\quad V_{d}=\frac{8}{3} \pi \eta^{3} R^{3}$

Habitable Volume: $H y_{d}=\frac{8}{3} \pi \eta^{3} R^{3}$

Surface Area: $\quad S A_{d}=8 \pi \eta^{2} R^{2}$

Projected Area: $\quad P A_{d}=2 \pi \eta^{2} R^{2}$

Floor Area:

$$
\begin{aligned}
F A_{d}=2 \pi & \left\{\sum_{n=i}^{N}\left[\eta R(\operatorname{lon}-4)-(3 n-2)^{2}\right]\right. \\
& \left.+\sum_{n=N+1}^{N}\left[\log n R-9 n^{2}\right]\right\}
\end{aligned}
$$

* Equations for multiple dumbbell stations are the same as those presented for the dumbbell except the multiplier $M$ is added, which represents the number of dumbbells in the station.

+ For the beaded torus $M$ is defined as: $M=\ln t\left[\frac{\pi}{2 \sin ^{-1} \eta}\right]$ 
35

TABLE 2. SHAPE EQUATIONS (CONTINUED)

III. CYLINDER

Volume: $\quad V_{c}=\frac{4}{3} \pi R^{3}\left(i+\frac{3 x}{4}\right)$

Habitable Volume: $H V_{C}=\frac{4}{3} \pi R^{3}\left[\left(2 \gamma-\gamma^{2}\right)^{3 / 2}+\frac{3 \alpha}{4}\left(2 \gamma-\gamma^{2}\right)\right]$

Surface Area: $\quad S A_{C}=4 \pi R^{2}\left(1+\frac{\alpha}{2}\right)$

Projected Area: $\quad P A_{c}=4 \pi R^{2}(1-\gamma)\left[\left(2 \gamma-\gamma^{2}\right)^{1 / 2}+\frac{\alpha}{2}\right]$

Floor Area:

$$
\begin{aligned}
F A_{C}=4 \pi \sum_{n=1}^{N}(R-3 n+2 ; j\{ & \left.R(\operatorname{lon}-4)-(3 n-2)^{2}\right)^{\frac{1}{2}} \\
& \left.+\frac{B_{x}}{2}\right\}
\end{aligned}
$$

IV. TORUS (CIRCULAR CROSS-SECTION)

Volume:

$$
v_{t}=2 \pi^{2} \eta^{2} R^{3}
$$

Habitable Volume: $\quad H V_{t}=2 \pi^{2} \eta^{2} R^{3}$

Surface Area: $\quad S A_{t}=4 \pi^{2} \eta R^{2}$

Projected Area: $\quad P A_{t}=4 \pi \eta R^{2}$

Floor Area:

$$
\begin{aligned}
F A_{t}=4 \pi\{ & \left\{\sum_{n=1}^{N 1}[R(1+\eta)-3 n+2]\left[R(6 n-4)-(3 n-2)^{2}\right]^{\frac{1}{2}}\right. \\
& \left.+\sum_{n=N+1}^{N}[R(1+\eta)-3 n+2]\left[4 q n R-9 n^{2}\right]^{1 / 2}\right\}
\end{aligned}
$$


TABLE 2. SHAPE EQUATIONS (CONTINUED)

V. TORUS (CYLINDRICAL CROSS-SECTION)

Volume:

$$
V_{c t}=2 \pi^{2} \eta^{2} R^{3}\left[1+\frac{2 \alpha}{\pi \eta}\right]
$$

Habitable Volume: $H V_{i t}=2 \pi^{2} \eta^{2} R^{3}\left[1+\frac{2 \alpha}{\pi \eta}\right]$

Surface Area: $\quad S A_{c t}=4 \pi^{2} \eta^{2}\left[1+\frac{\alpha}{\eta}\right]$

Projected Area: $\quad P A_{c t}=4 \pi \eta R^{2}\left[1+\frac{\alpha}{2 \eta}\right]$

F1oor Area: $\quad F A_{C t}=4 \pi\left\{\sum_{n=1}^{N 1}[R(1+\eta)-3 n+2] *\right.$

$\left.\left\{\left[R(6 n-4)-(3 n-2)^{2}\right]+x R\right)+\sum_{n=N_{1}+1}^{N}[R(1+\eta)-3 n+2]\left[\left(6 \eta n R-9 n^{2}\right)^{1 / 2}+4 R\right)\right]$

VI. CRYSTAL PALACE

Volume: $\quad V_{c p}=\pi^{2} \eta^{2} N R^{3}(2+3 \eta L)\left(1+\frac{2}{\pi}+\frac{1}{N}\right)$

Habitable Volume: $H V_{C P}=\pi^{2} \eta^{2} N R^{3}(2+3 \eta())\left(1+\frac{2}{\pi}+\frac{1}{N}\right)$

Surface Area: $\quad S A_{C P}=4 \pi^{2} \eta L N R^{2}\left(1+\frac{1}{i \pi}\right)$

Projected Area: $\quad P A_{C P}=\pi \eta N R^{2}\left(2 \div \frac{1}{N}\right) \sum_{l=1}^{L}[2+\eta(1+2 l)]$

Floor Area: $\quad F A_{C P}=2 \pi N \sum_{l=1}^{L}\left[2(R+3 \eta x R-2)(\eta R-1)^{1 / 2}\right.$

$$
\begin{aligned}
& +\left(R+3 \eta l R-\frac{3 \eta R}{2}\right)\left(1+\frac{1}{2 N}\right) \eta R \\
& \left.+2(R+3 \eta R R-9)(6 \eta R-9)^{1 / 2}\right]
\end{aligned}
$$




\section{TABLE 2. SHAPE EQUATIONS (CONTINUED)}

\section{TWO-AXES-STRETCHED ELLIPSE OF REVOLUTION}

Volume:

$$
v_{e}=\frac{2 \pi R^{3}}{3}\left\{3 \beta^{2}(\alpha+\epsilon)+3 \beta(1-\beta)\left[\delta^{2}-(1-\beta)^{2}\right]^{\frac{1}{2}}\right.
$$

$$
\left.+2\left[\delta^{2}-(1-\beta)^{2}\right]^{3 / 2}+3 \delta^{2} \beta \sin ^{-1} \frac{(1-\beta)}{\delta}-\delta^{3}\right\}
$$

Habitable Volume: $H V_{e}=\frac{2 \pi R^{3}}{3}\left\{2\left[S^{2}-(1-\beta)^{\prime}\right]^{i / 2}-2 \delta^{3}\right.$

$$
+3 \beta(1-\beta)\left[\left(\delta^{2}-(1-\beta)^{2}\right]^{1 / 2}+3 \delta^{2} \beta \sin ^{-1} \frac{1-\beta}{\delta}\right\}
$$

Surface Area:

$$
\begin{aligned}
& S A_{e}=4 \pi \alpha R^{2}+2 \pi \beta^{i} R^{2} \\
& +\frac{\pi \epsilon}{S} \sum_{i=1}^{R / \Delta R}\left(x_{1}+x_{2}\right)\left[x_{i}^{2}-x_{2}^{2}+2 \beta R\left(x_{2}-x_{1}\right)^{\frac{1}{2}}\right.
\end{aligned}
$$

Projected Area: $\quad P A_{e}=4 \pi R^{2}(1-\gamma)\left\{\alpha_{0}+\frac{E}{S}\left[S^{2}-(1-\gamma-\beta)^{2}\right]^{\frac{1}{2}}\right\}$

$$
\text { Floor Area: } \quad \begin{aligned}
F A_{e} & =4 \pi \sum_{n=1}^{N}(R-3 n+2,5)\{\alpha R \\
& \left.+\frac{S}{S}\left[S^{2} R^{2}-(R-3 n+2.5)^{2}\right]^{1 / 2}\right\}
\end{aligned}
$$




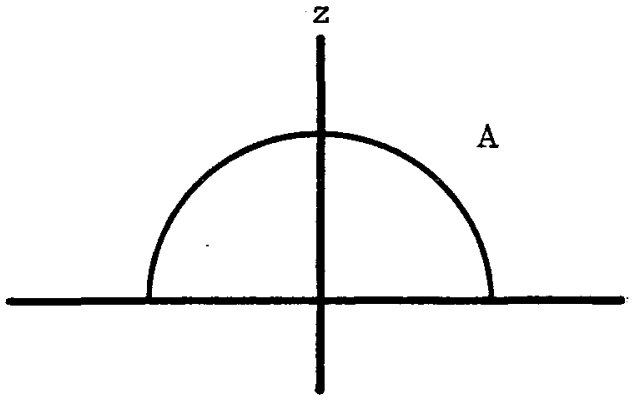

(a) Sphere

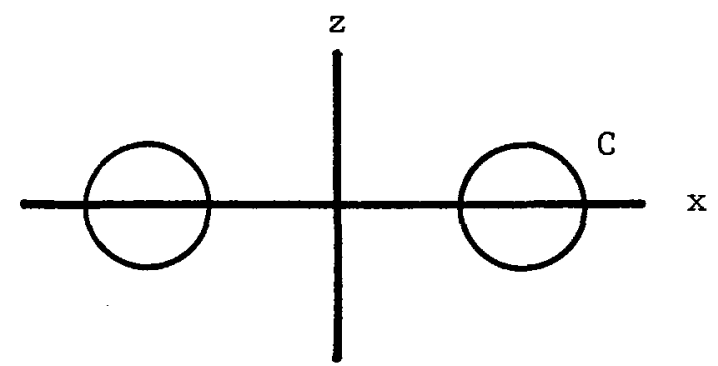

(c) Dumbbell and Beaded Torus

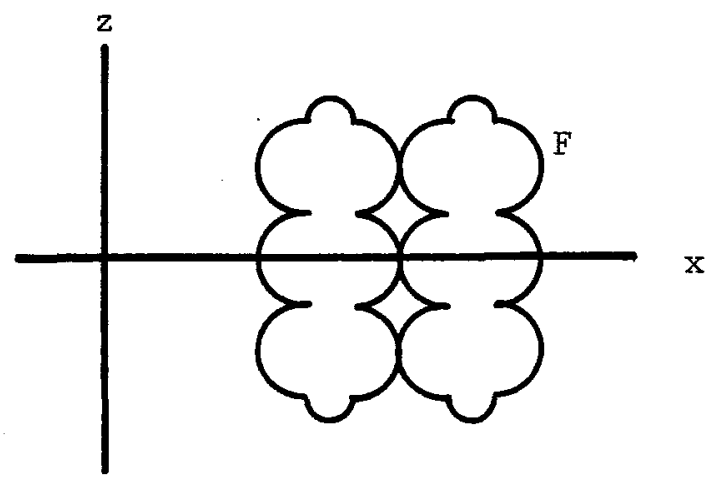

(e) Crystal Palace

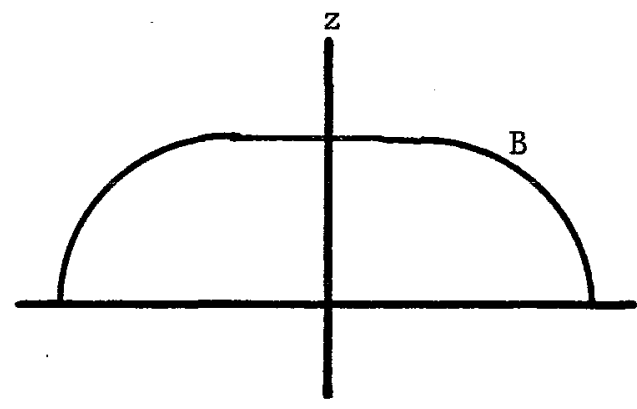

(b) Cylinder

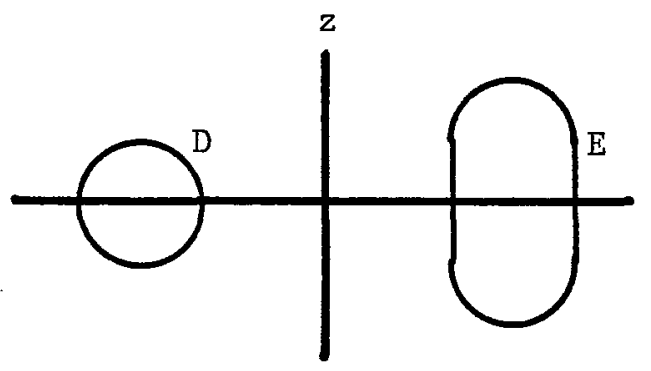

(d) Circular and Cylindrical Torus

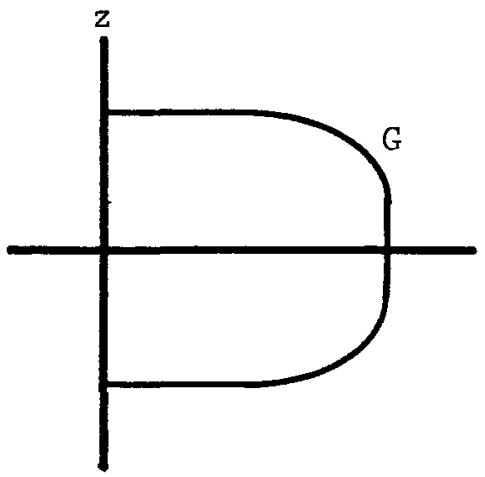

(f) Two-axis-stretched

Ellipse of Revolution

Figure 12. LEOBC Shape Candidates 
is apparent that from strictly a volume consideration (Figure 13), the cylindrical structure with a very large length-to-radius ratio is the most efficient shape for a space city. This shape was the first considered by $\mathrm{O}^{\prime} \mathrm{Neill}$ and his students at Princeton University in 1974. ${ }^{17}$ These cities were to be 20 miles long with a 3 mile diameter. The use of enclosed volume as a governing parameter is important when the intent is to provide inhabitants a feeling of openness as is experienced on earth.

A second volume comparison factor is the amount of habitable volume in a given structure. Habitable volume is that volume which falls within a specified pseudogravity range and establishes the necessary radius to provide a habitable volume for each shape. Habitable volume as a function of radius, or the number of floors, for a pseudogravity range of 0.15 is found in Figure 14.

As surface area of a structure increases, the mass of that structure also increases. For a space station, that higher mass is reflected in an increased number of launches and, hence program costs. For these reasons the surface area of each shape is an important comparison factor, with smaller surface areas being desired. Surface area comparisons are shown in Figure 15.

Real estate acreage is a highly desireable commodity in any location. This will be especially true for the first business locations in space. The projected area of any structure can be considered its real estate, on which laboratories, offices and residences can be placed. Candidate shape projected areas are depicted in Figure 16. 



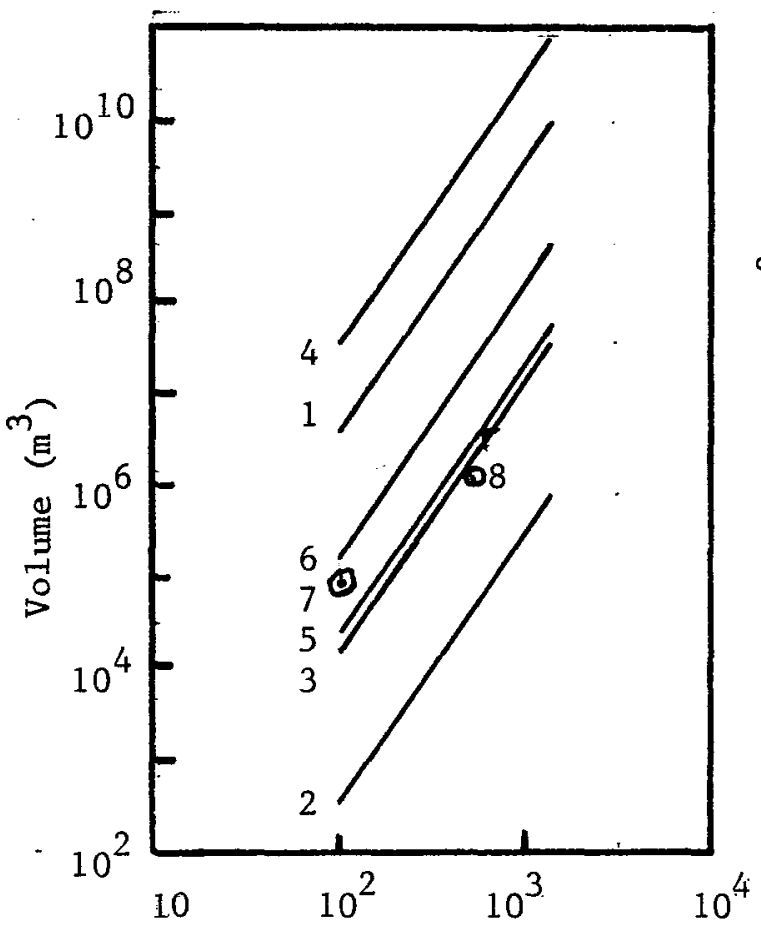

Figure 13. Rąhius ' Volumes

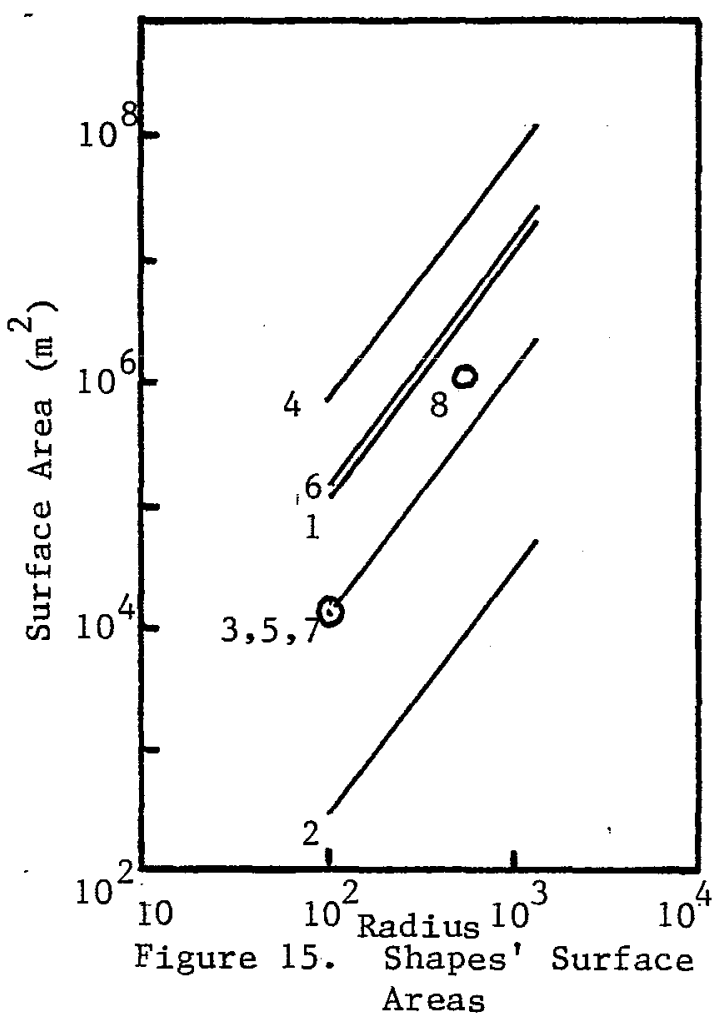

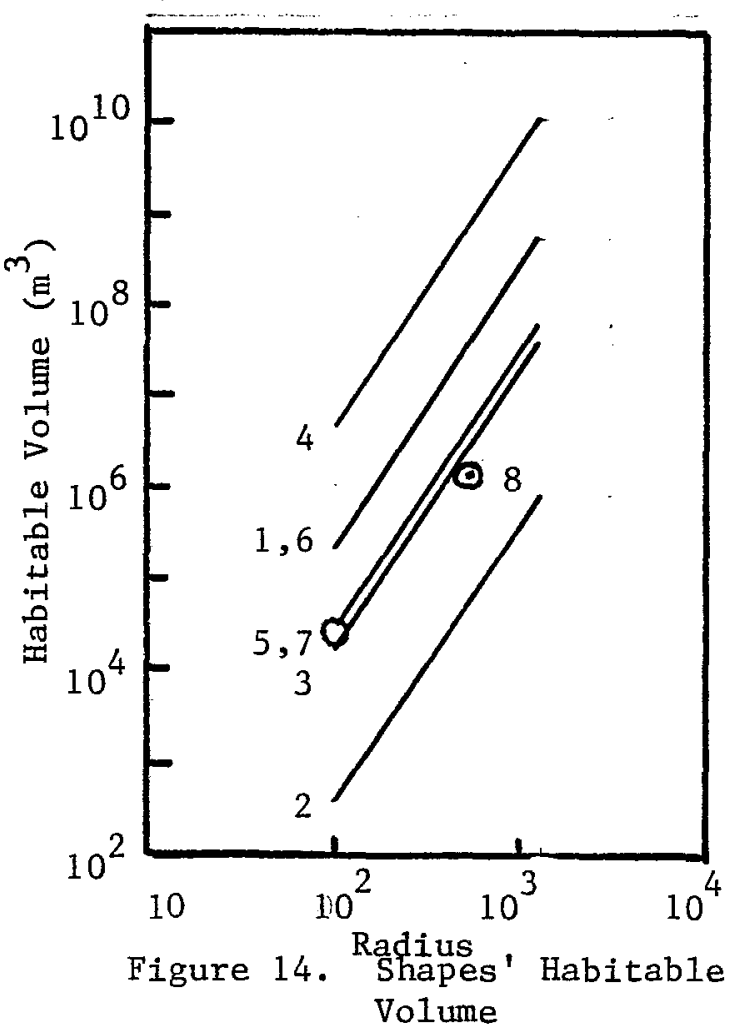

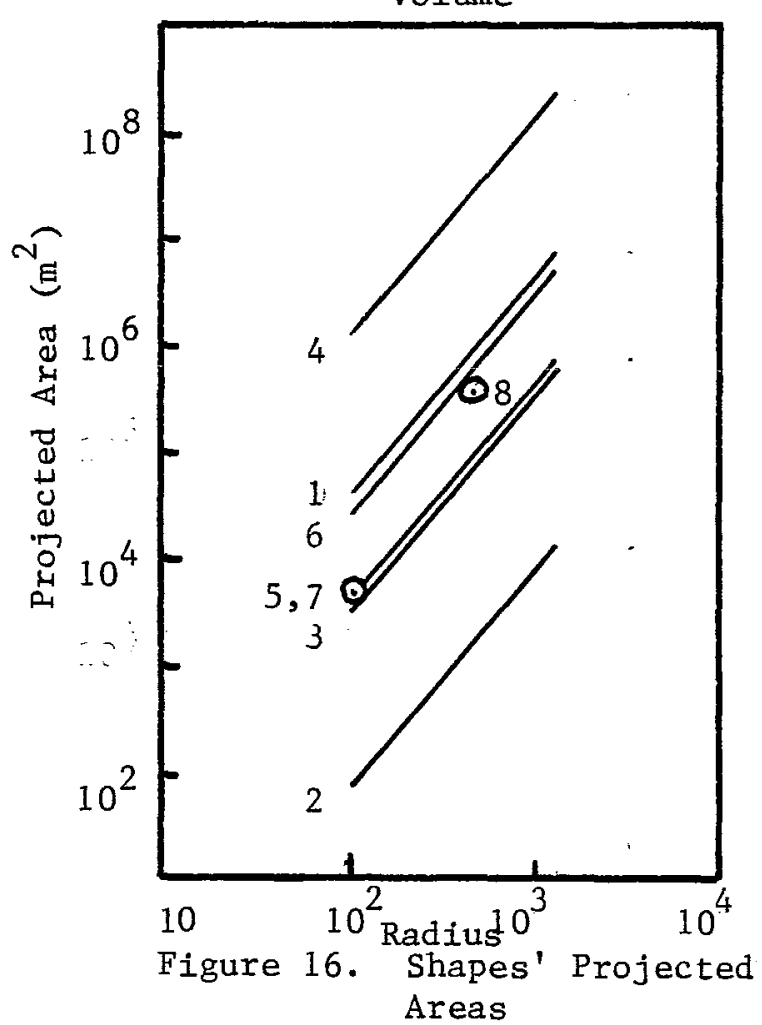


Floor area is an extension of the projected area in that it shows how much usable area is available or how effectively realestate is used in a given structure. This is shown in Figure 17.

Each of the previous parameters indicate how much of a given item each shape has to offer. In order to effectively compare these shapes though, a measure of efficiency is required. Therefore, various ratios were established for this purpose. Figure 18 shows how much of the total volume in a given structure falls inside the desired pseudogravity range. On the negative side, the enclosed volume which is not habitable still needs pressurization and hence increases the launches required to pressurize that structure. Therefore, the closer this ratio is to 1.0 , the better the volume efficiency:

The ratio of surface area to volume or habitable volume are two other measures of efficiency that relay the level of effort necessary to construct a structure of a particular size. The lower the ratio, the fewer launches necessary to enclose a given volume. These ratios are shown in Figures 19 and 20.

The amount of real estate, or projected area, for a given shape as a percentage of surface area indicates how effective a shape is in providing actual working space. These ratios are shown in Figure 21 .

Floor area per unit volume and per unit surface area show how effectively each shpae can be used to provide actual working space. In both these instances, a high value is considered beneficial. These are compared in Figures 22 and 23.

In Comparing each shape, a point system was established where the highest merit is worth 10 points and each lower merit is given 

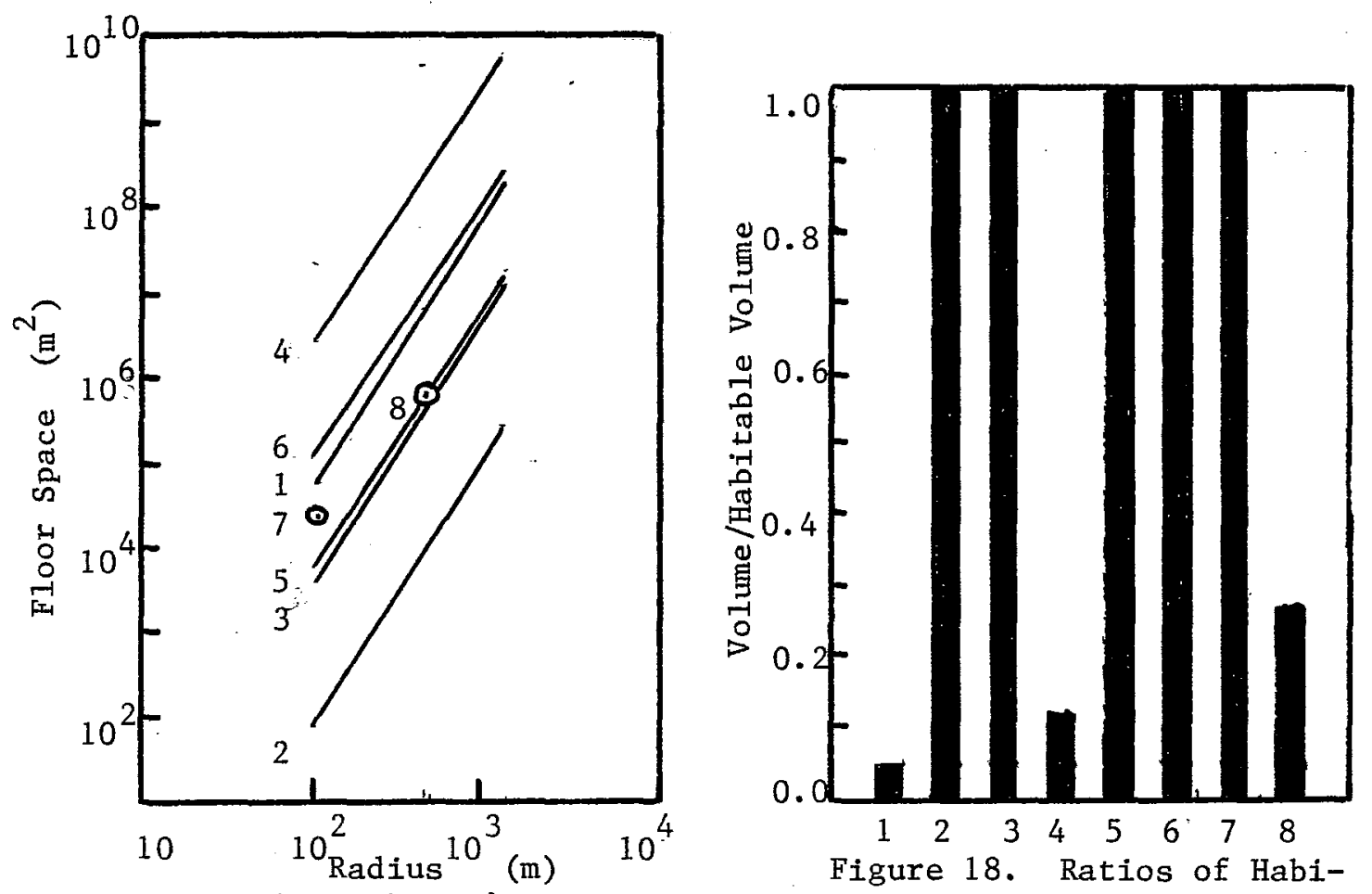

Figure 17. Shapes' Floor

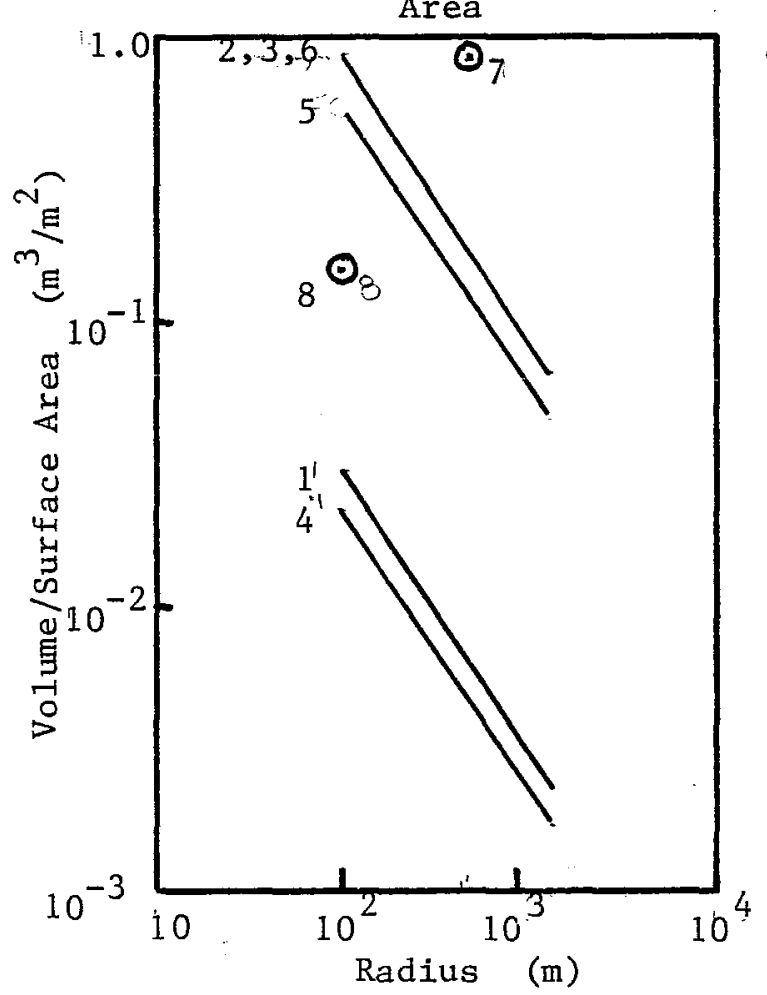

Figure 19. Shapes' Volume/ Surface Area table Volume to: Volume.

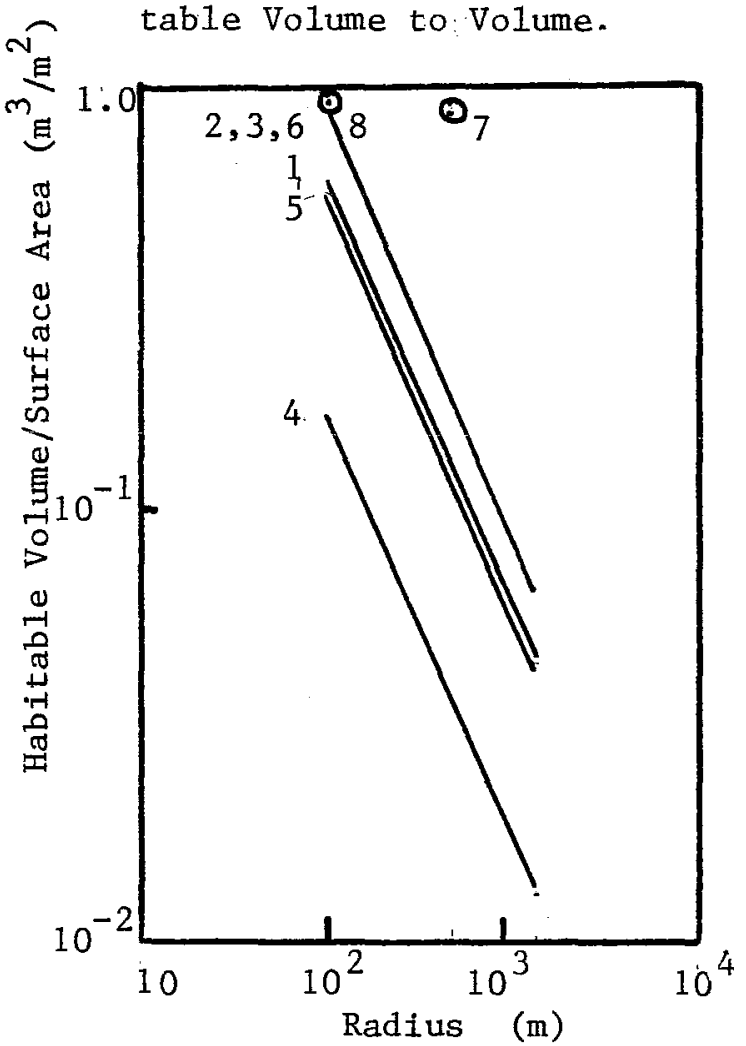

Figure 20. Shapes' Habitable Volume/ Surface Area 


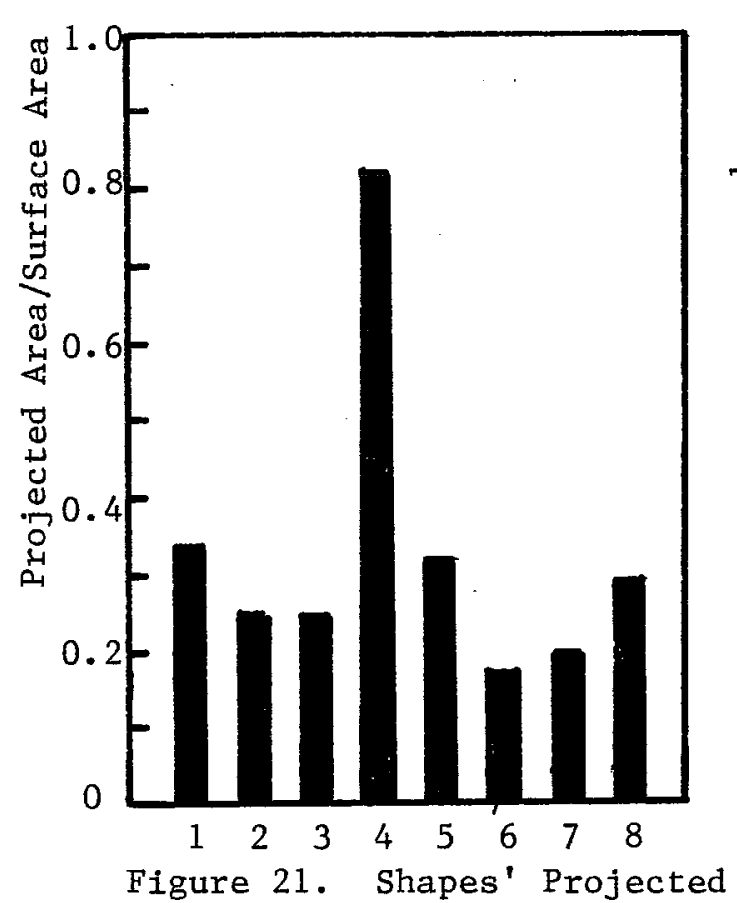

Area/Surface Area

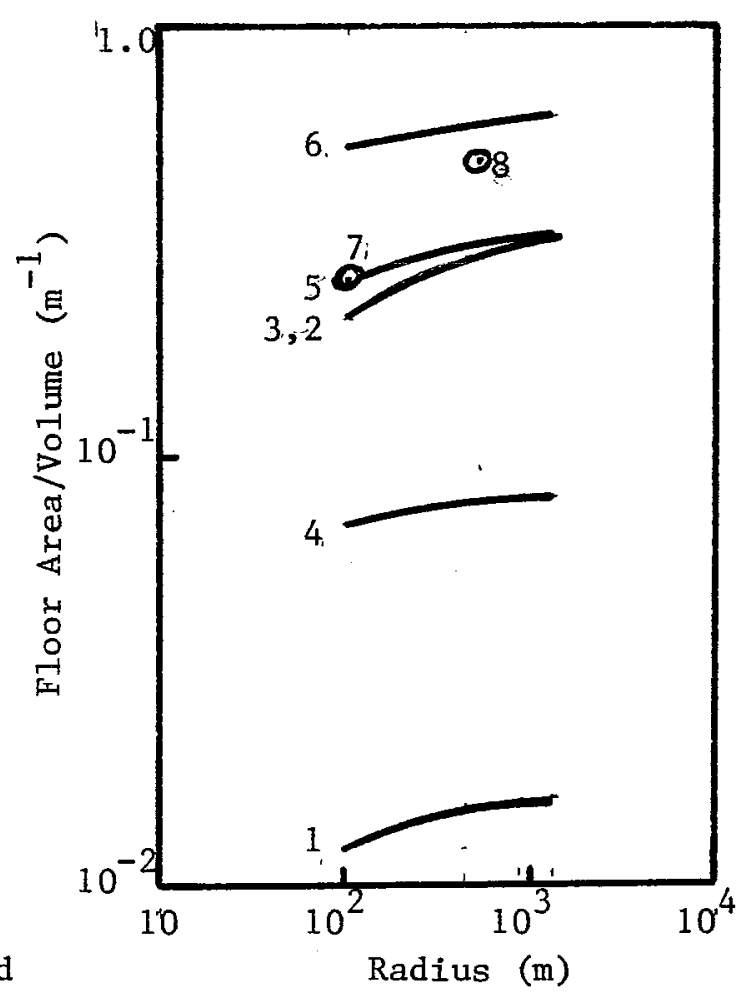

Figure 22. Shapes' Floor Area/Volume

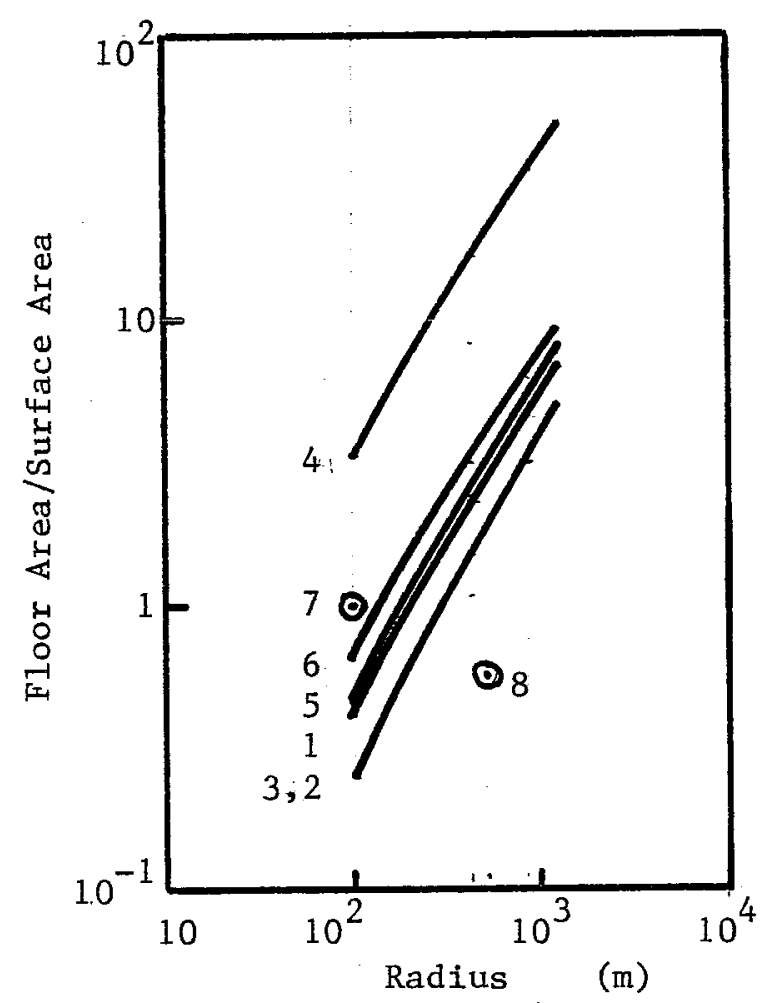

Figure 23. Shapes' Floor Area/Surface Area 
one less point. The lowest merit, with eight shapes being compared, is given a value of three points. In cases where each shape has the same level of merit, a constant value is awarded. However, the next lowest merit is valued such that the worst shape always receives three points. It should be noted that comparisons are made based on the same number of floors and not on rotational radius. Table 4 summarizes the evaluation of each shape and shows their ranking. From this evaluation, the cylindrical torus has the highest rating. However, this shape is eliminated as a candidate due to its susceptability to buckling. ${ }^{153}$ For this reason, the circular torus was chosen as the shape of LEOBC's living and office space volume. 
TABLE 4. SHAPE EVALUATION TABLE

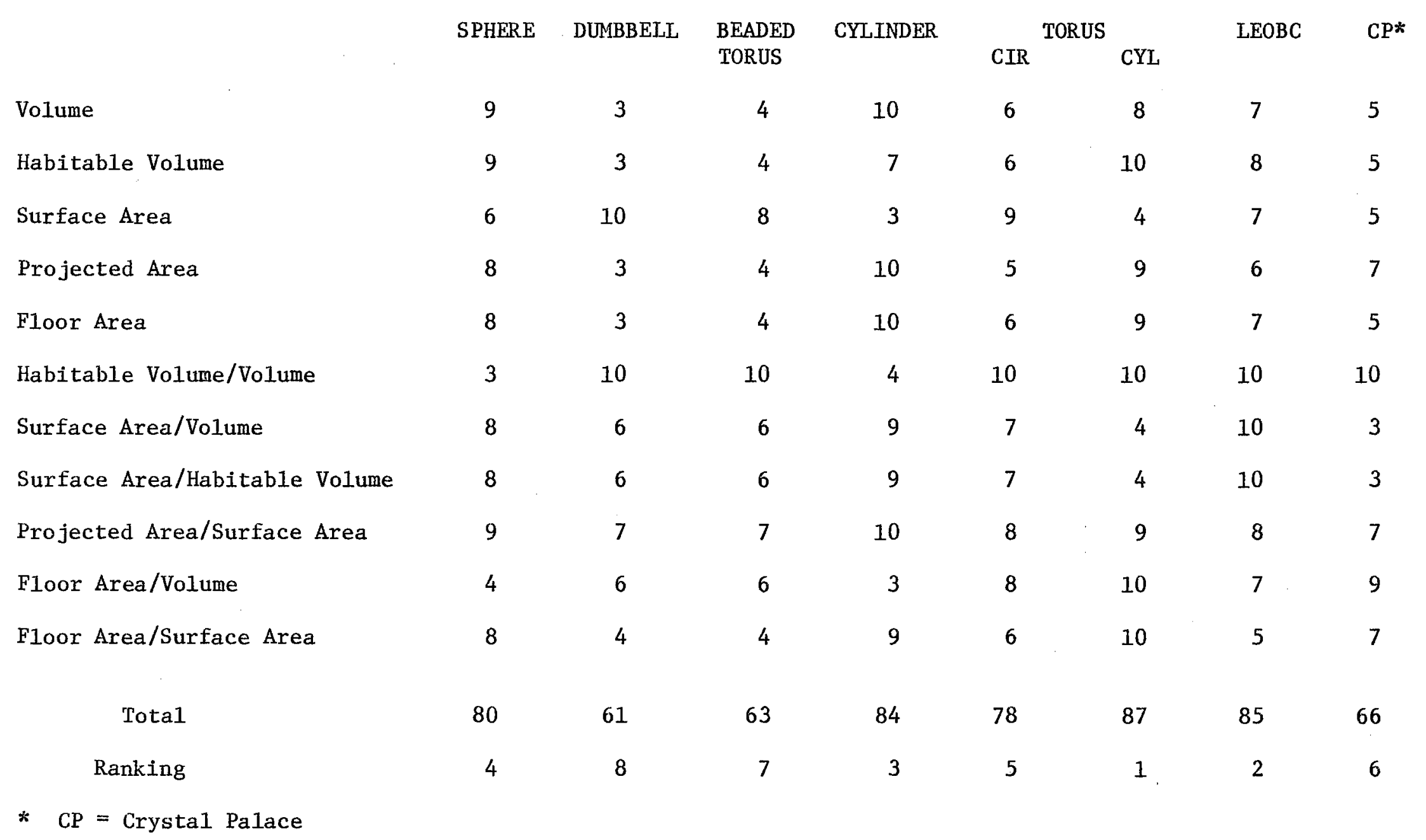


CHAPTER 5

\section{INTERIOR DESCRIPTION AND ARRANGEMENT}

LEOBC is a proposed focal point for low earth orbit business activities in the early years of the 21st century. As such, it offers 0.5 acceleration level in the areas dedicated to living quarters, recreation, offices and laboratories and $10 \mathrm{w} g$ areas for research and manufacturing concerns. It also supports co-orbiting facilities which house processes that require micro-acceleration levels below those available in LEOBC or that could pose a hazard to LEOBC personnel. It can accept the current STS orbiter in the center of its hub to provide completely shielded docking. Three major sections comprise LEOBC: torus, hub and spokes. These are discussed in greater detail below. Top and side views of LEOBC are shown in Figure 24.

T'ORUS

Designed as a two story structure, LEOBC's torus has a seven meter diameter with a 100 meter major radius. A seven meter minor diameter is used as it provides maximum floor space for a two story configuration with floors spaced three meters apart. Each floor has a 2.5 meter ceiling height with a 0.5 meter space between the floors for routing of utility cables and air ducts. Typical cross-sections of the torus are shown in Figure 25a. Bulkheads, shown in Figure 25b, are located approximately every 12 meters around the torus. Spacing at the torus-spoke junction is slightly less to allow for tolerance buildup and bulkhead thickness. Stairways between the first and second floors are located in every third segment, except at the torus-spoke junction. At these segments, an open platform elevator is provided to aid in moving equipment between the two floors. 

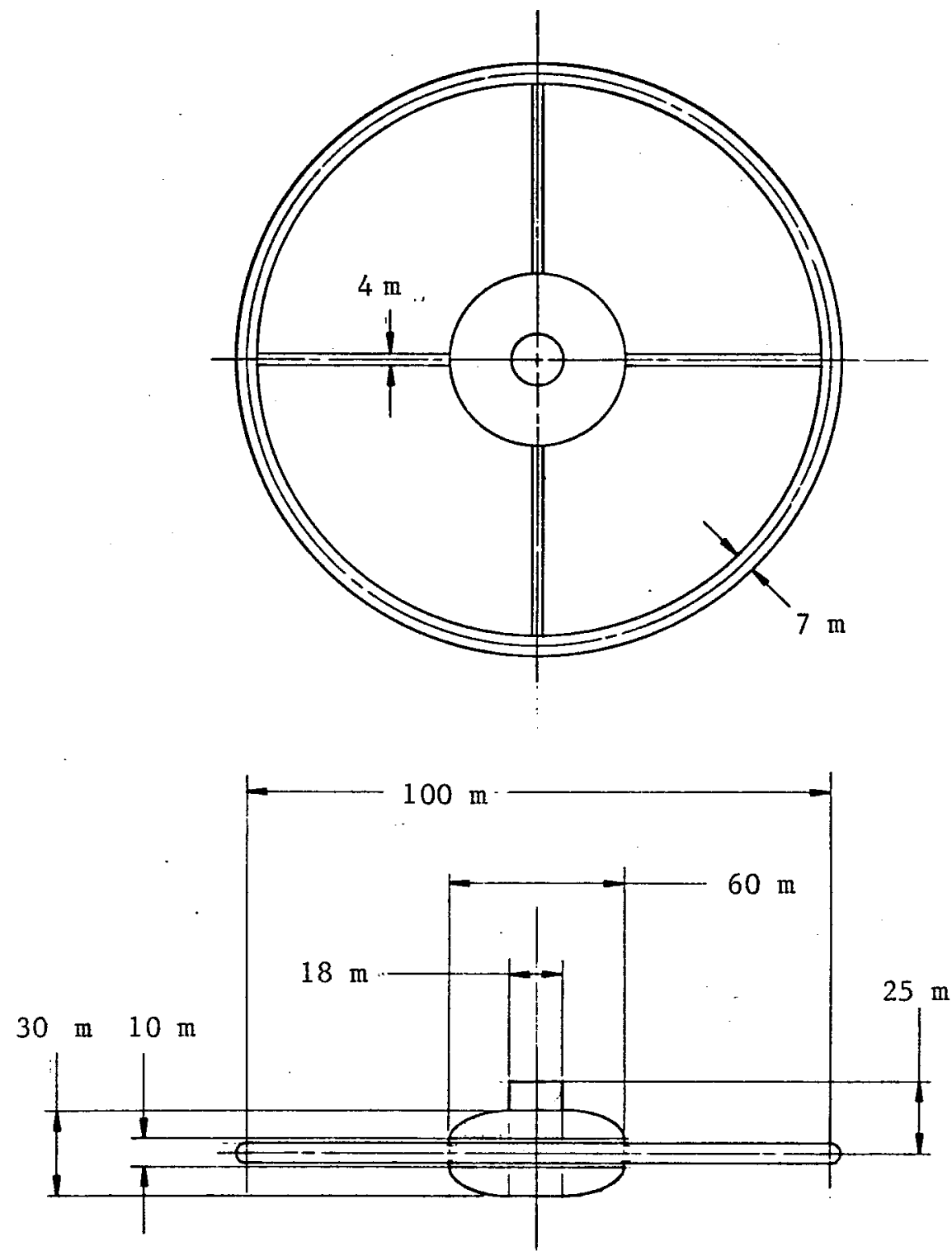

Figure 24. LEOBC Top and Side Veiws 


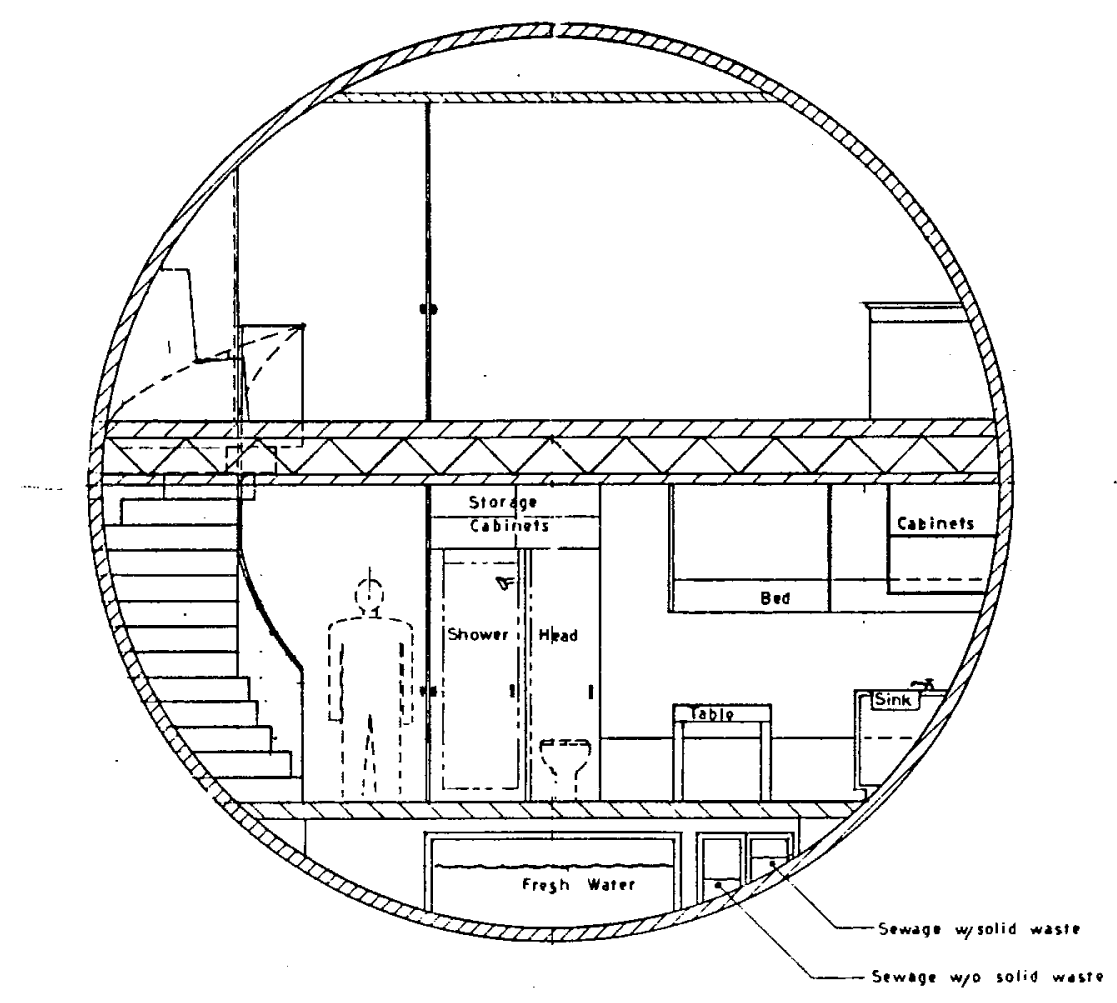

(a) Torus Cross Section

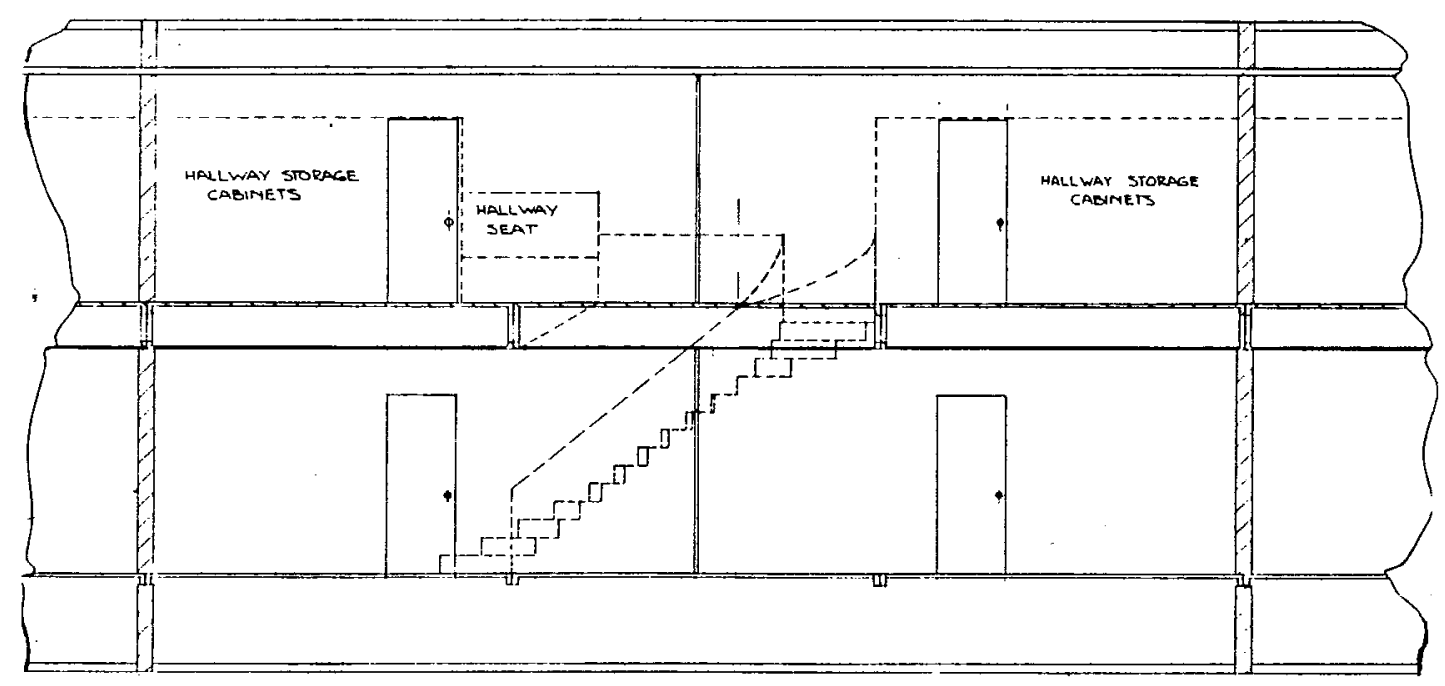

(b) Torus Elevation

Figuure 25. LEOBC Torus Cross Section and Elevation 
Beneath the first floor, integral storage tanks are included in the structural design for potable water and waste material: one for liquid only and one for liquid/solid waste.

One hundred eighty-eight bachelor units are located on the first floor to house the majority of personnel on LEOBC. A possible floor plan and wall elevations are shown in Figures 26 and 27 . Furnishings include a kitchenette, writing desk with chair, a shower and commode, a bureau, closet and storage space. Twelve additional units are located on the second floor.

Single residential units are baselined for LEOBC because of the stated need for privacy from Soviet and American space crews. Additionally, private units may relieve tension and reduce illnesses thought to be increased by a feeling of crowdedness in an isolated and confined environment such as a space station. ${ }^{156}$

As shown in Figure 25, the second floor is not allocated to living quarters but is left as open rooms. This is the area that can be leased for offices and gravity-oriented laboratories where results obtained from zero-g processing can be evaluated. In this manner, basic lab equipment used on Earth can be used at LEOBC without modifications. These labs will help eliminate additional STS flights required to evaluate products under development in low earth orbit. Also found on the second floor are the medical unit, central kitchen and cafeteria, recreational area, maintenance and janitorial supply room and commons areas at each spoke-torus junction. Dimensional information and total space allocation are given in Tables 5 and 6 . With a population of 200 personnel, these dimensions offer an overall area per individual of 112 square meters and a volume of 369 cubic 


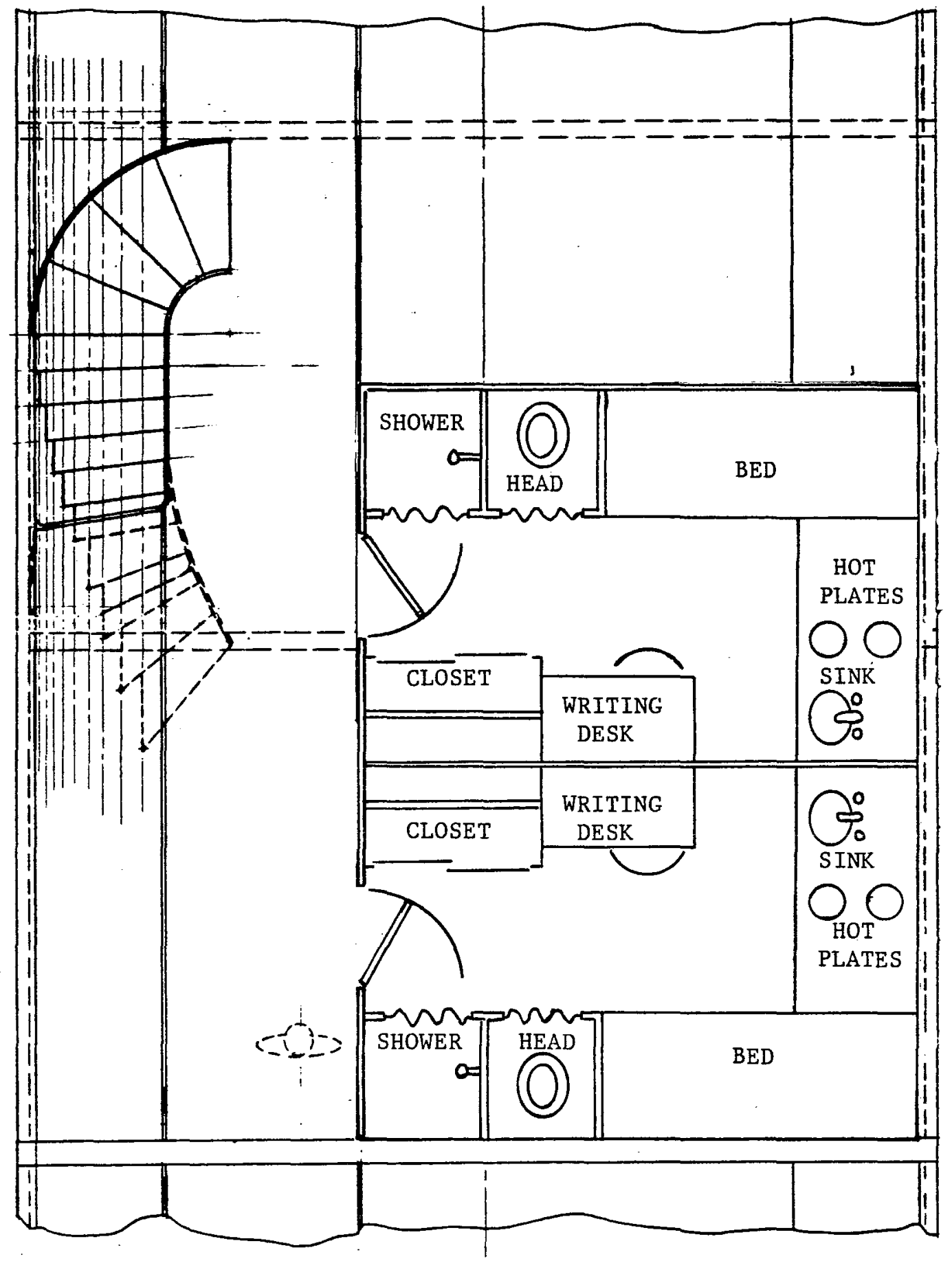

Figure 26. LEOBC Efficiency Floor Plan 


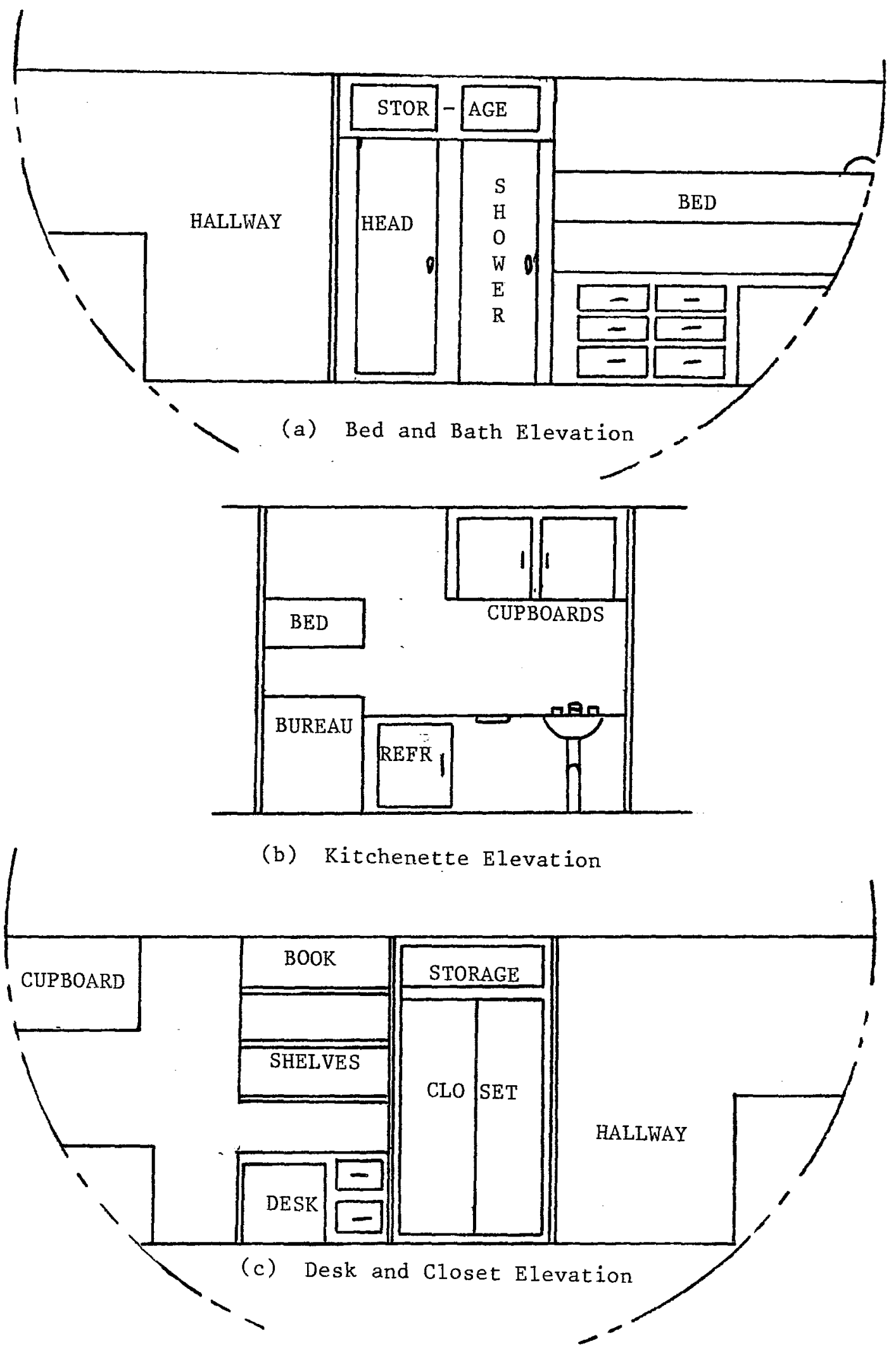

Figure 27. LEOBC Efficiency Elevations 
TABLE 5. LEOBC GEOMETR IC SPECIFICATIONS

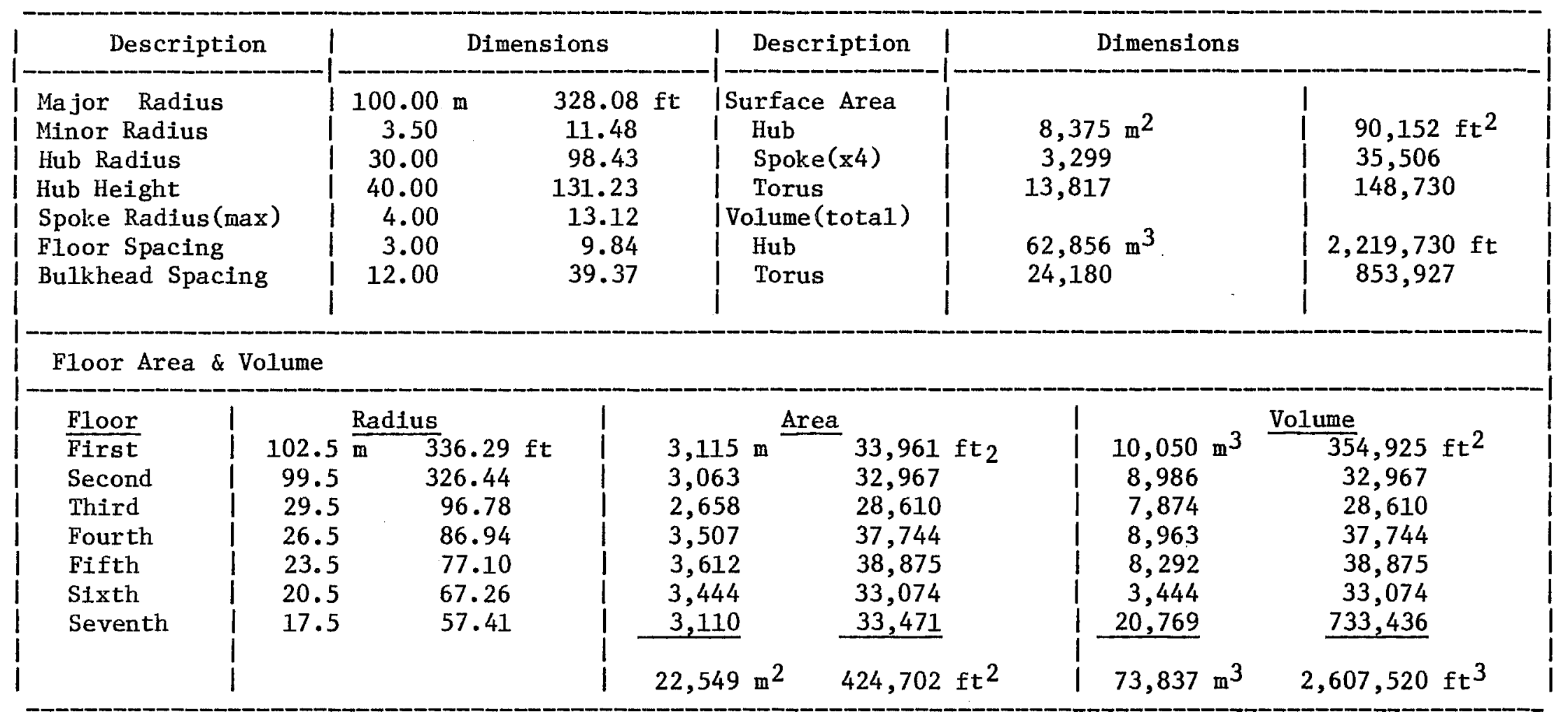


TABLE 6. LEOBC SPACE ALLOCATIONS (TORUS ONLY)

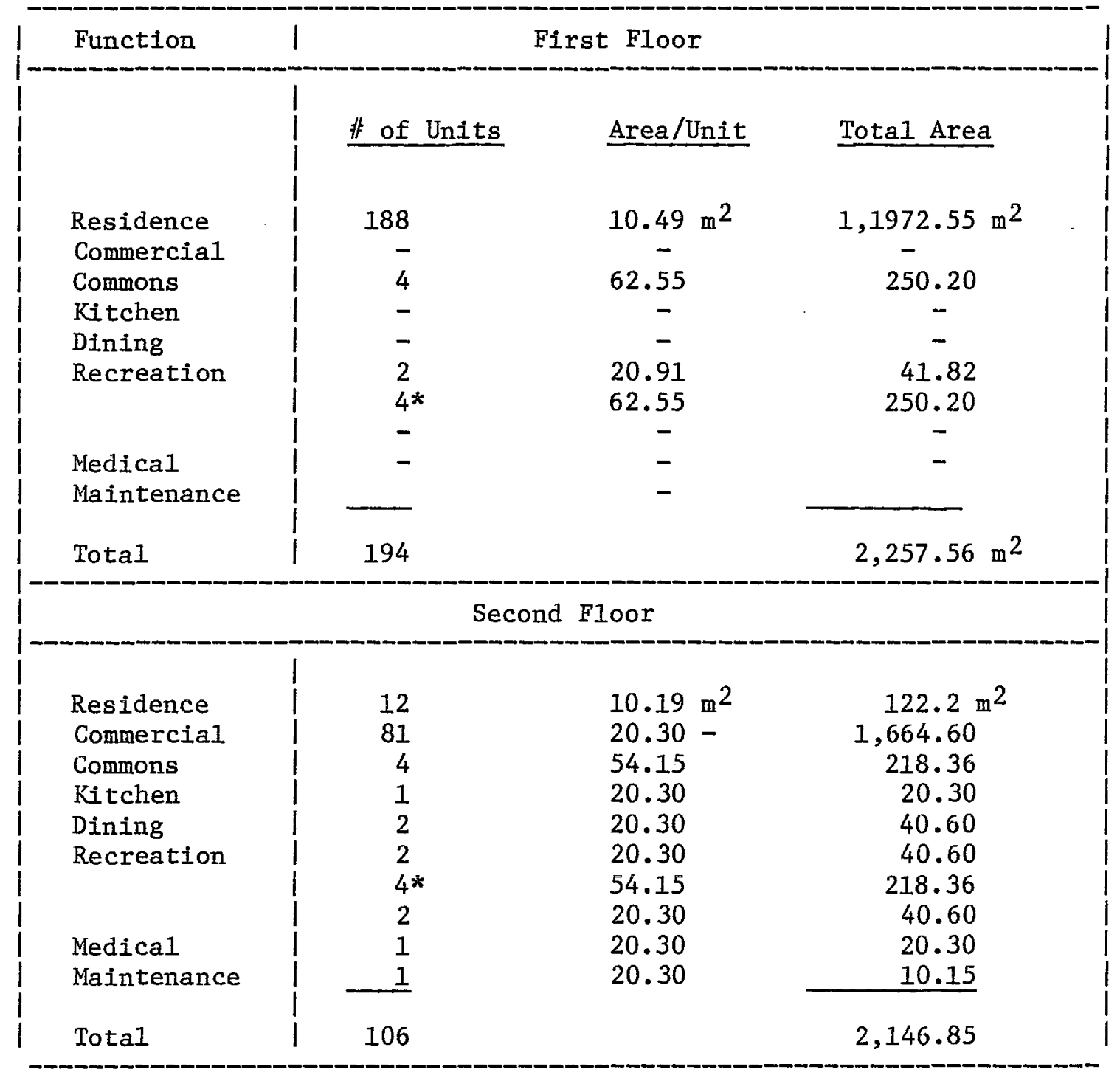

*These are multi-use units, first listed under Commons and Dining. 
meters. This is $42 \%$ more area and $54 \%$ more volume per individual than was recommended by the 1977 Summer Study conducted at the NASA Ames Research Center. ${ }^{153}$ For habitats of 100 people, they recommended $79.1 \mathrm{~m}^{2}$ and $240 \mathrm{~m}^{3}$ when personnel are staying on board for one to two years.

Sports activities in the torus can be conducted in the recreational segment. This is a four-wall, enclosed court, slightly smaller than a regulation racquetball court. It can be adapted for various sports, including basketbal1, racquetball, handball, volleyball, walleybal1 (a four-wall version of volleyball), tennis, badminton or squash. An artist's concept is seen in Figure 28 .

HUB

The hub's primary function is to provide access to the rotating LEOBC and to serve as low $\mathrm{g}$ processing and research areas. It also houses all the mechanical services required for life support on LEOBC. This includes environmental control, waste treatment, power generation, storage facilities and cargo hand1ing.

Extending to a radius of 30 meters, the hub's outer she11 has a 10 meter long cylindrical section with elliptical end caps. These end caps have a 21-meter semi-major axis and a 10-meter semi-minor axis. The origin is located 9 meters from the axis of rotation and 5 meters above the 1ongitudinal axis. The pressurized portion of the hub lies between the 9 meter and 30 meter radius. Inside 9 meters, a cylindrical core is open to space on one end to accept an STS orbiter. A docked orbiter is shown in LEOBC's core in Figure 29. Inside the hub are a total of five floors where plant services, communications, storage and commercial areas are located. Water and 


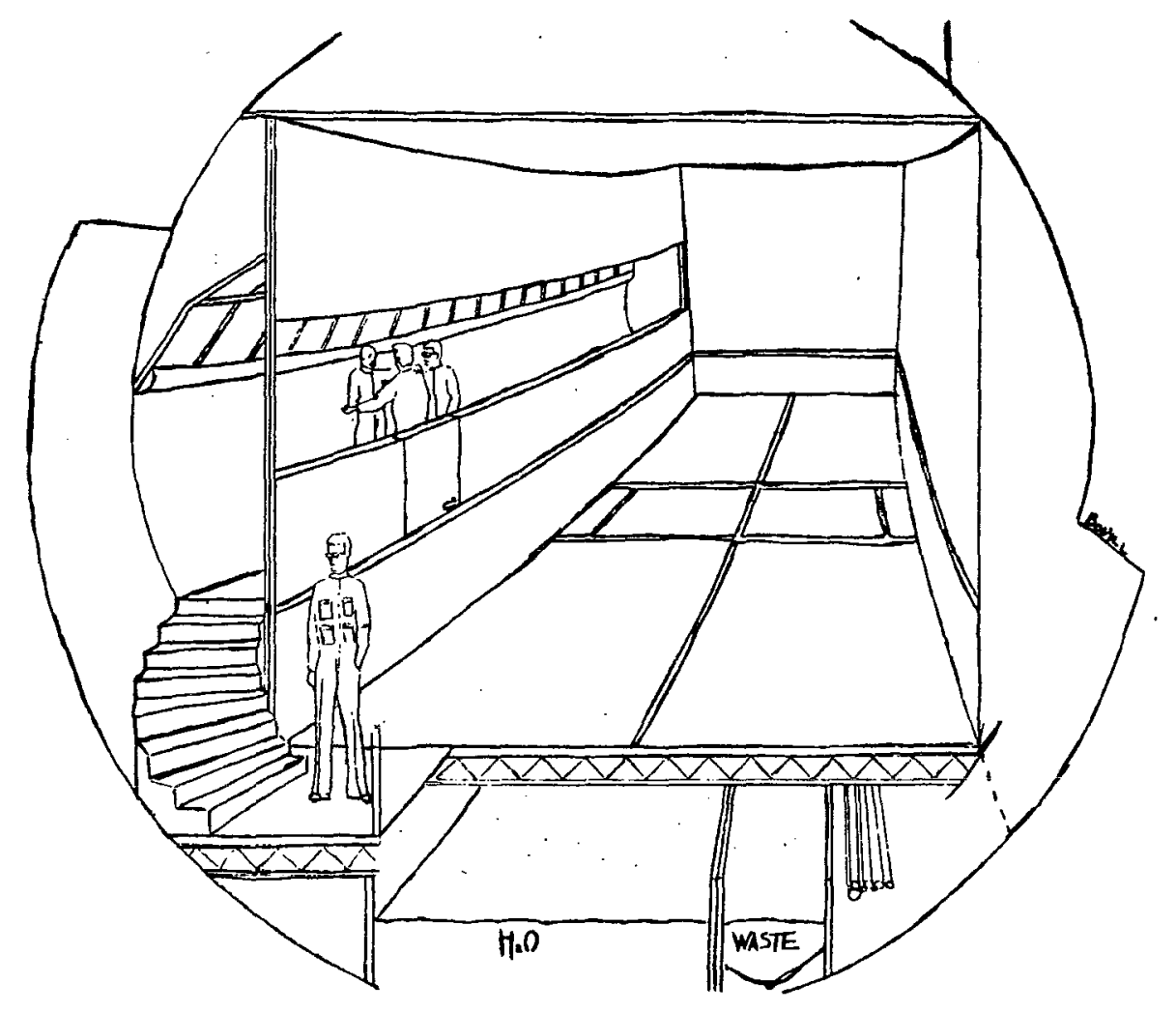

Figure 28. LEOBC Recreation Court 


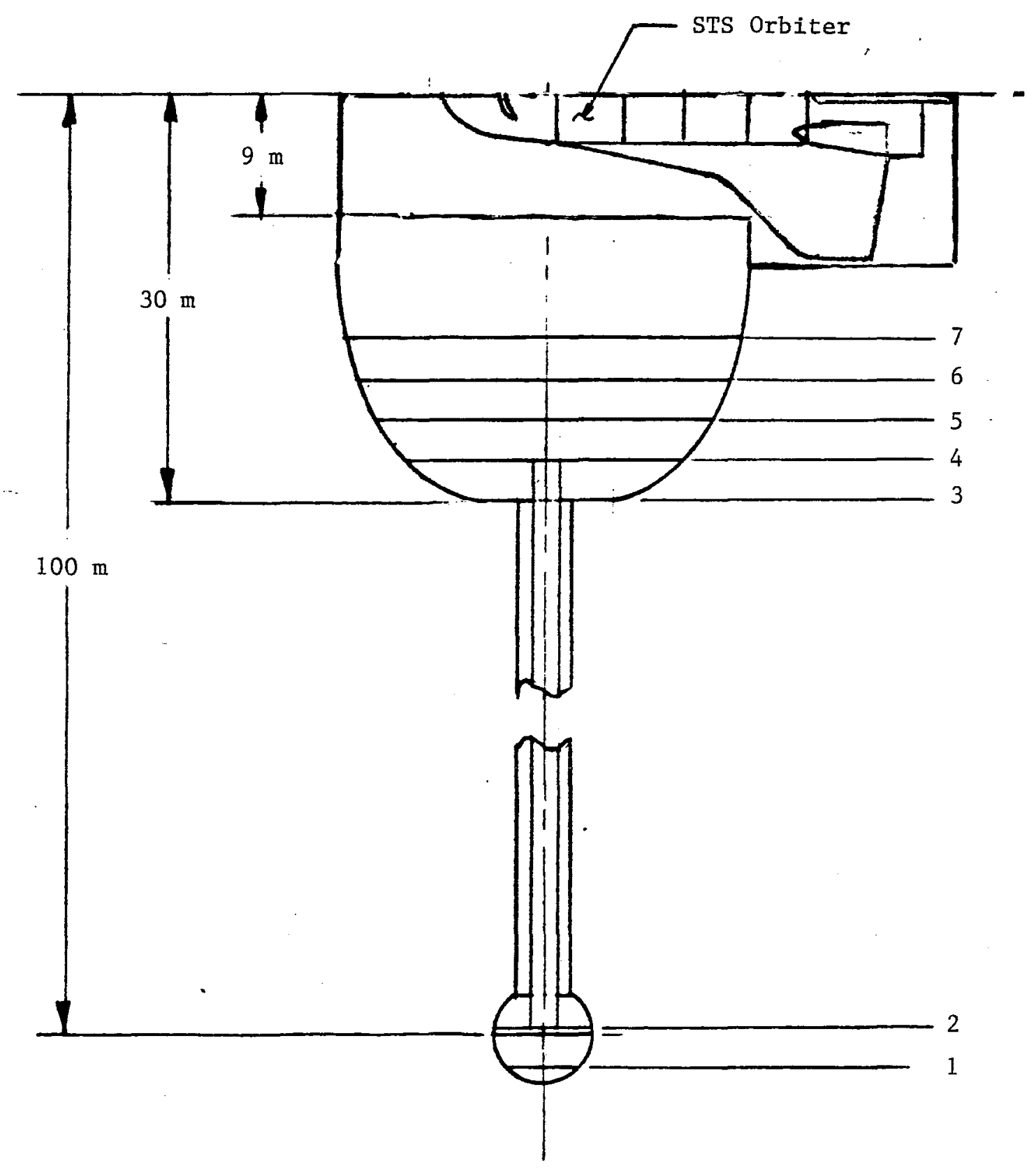

Figure 29. LEOBC Cross Section 
air recycling functions are found on the outermost floor of the hub, or LEOBC's third floor. Power generation and cryogenic storage areas are found on the fourth floor. Consumables stores, maintenance shops and the control center are located on the fifth floor. Floors six and seven, with the lowest acceleration levels, are dedicated to research and manufacturing processes that do not require acceleration levels below $0.1 \mathrm{~g}$. The seventh floor is also used for cargo handing and can be used for satellite repair or initial fabrication processes for orbital or interplanetary vehicles.

\section{SPOKES}

The hub and torus are connected by four spokes located every ninety degrees around the circumference of the hub. These spokes are rigidly attached to the hub and hang like stalactites toward the torus. At the torus, they ride on a suspension system that allows four degrees of freedom: radial displacement and rotation about each axis. With this type of connection, expansion of the torus due to pressurization and rotation will not transmit additional bending loads into the torus.

Inside each spoke are conduits for electricity, air, water, waste and gases required in the torus. Normally, each spoke will carry one fourth of the needs in the torus, but they are designed to handle up to half of the torus' requirements in the event that one or two spokes need to be shut down or are damaged.

In addition to utilities, there is also an elevator system in each spoke for personnel and supplies transfer. These elevators are self-contained units as the spokes are unpressurized. 


\section{CHAPTER 6}

\section{LEOBC CONS TRUCTION CONSIDERATIONS}

Construction of LEOBC will require more launches than any space program previously undertaken. In estimating the number of launches necessary to bring LEOBC to full operational capability the following procedure was employed: 1) establish a baseline launch vehicle, 2) determine the number of pieces necessary to construct LEOBC, 3) assume a packing scheme for payload definition, 4) determine the number of launches necessary if STS payloads are volume-1imited, 5) estimate LEOBC structural mass, 6) determine maximum number of pieces per launch based on component mass, 7) estimate internal mass, and 8) determine number of launches for mass-limited payloads carrying internal mass. These steps will allow a minimum and maximum estimate on the time necessary to contract LEOBC.

The baseline launch vehicle to be used for LEOBC construction and operational support is the current Space Transportation System. This provides the capability to 1 ift $27,500 \mathrm{~kg}$ into low earth orbit in a payload envelope that is 4.572 meters in diameter and 18.288 meters Iong. For volume-1imited launches, usable payload diameter and length are reduced to $4.40 \mathrm{~m}$ and $18.00 \mathrm{~m}$ to allow for airborne support equipment (ASE) needed to hold the payload.

The number of structural and floor panels per launch is defined as the integer value plus one of the height of an inscribed rectangle in the 4.40 meter diameter payload volume divided by a minimum spacing of $15 \mathrm{~cm}$. The base of this rectangle is the width of the particular panel being carried into orbit. Mass-1imited 1aunches carry $90 \%$ of the lifting capacity as payload with the remaining $10 \%$ reserved for ASE. 
In estimating the number of structural and floor panels required to construct LEOBC, payload bay dimensions and ASE allowances mentioned above were used to establish component dimensions. For the torus, structural and floor panel length of 12 meters is set by the 52 bulkheads equally spaced around the major circumference. Six of these panels, with an arc width of $60^{\circ}$, or 3.5 meters across the chord, are needed to complete each segment. These panels are designated T1-T6 and are shown in Figure 30. Also included are dimensions necessary to determine the packing arrangement in the STS payload bay. Four floor panels are needed per segment, two per floor. Al1 are 12 meters long, and are half as wide as the actual floor width. These panels are designated Fla, FIb, F2a and F2b (Figure 31).

Structural panels for the hub fall into one of the following five categories:

$$
\begin{aligned}
& \text { I Outer radius barrel } \\
& \text { II Sma11 radius of curvature } \\
& \text { III Large radius of curvature } \\
& \text { IV Hub Extension } \\
& \text { V Inner radius barre1 }
\end{aligned}
$$

These areas are highlighted in Figure 32. Categories I, III and V require one distinct panel while categories II and IV require three panels for complete definition. Individual hub structural panel planar dimensions necessary to determine payload bay stacking are shown in Figures 33 and 34. Floors in the hub span the distance between the $+z$ and $-z$ elliptical surfaces at radii of $29.5,26.5$, 23.5, 20.5 and 17.5 meters. Each floor, except the one located at a radius of 29.5 meters, requires two sections to span the distance and 

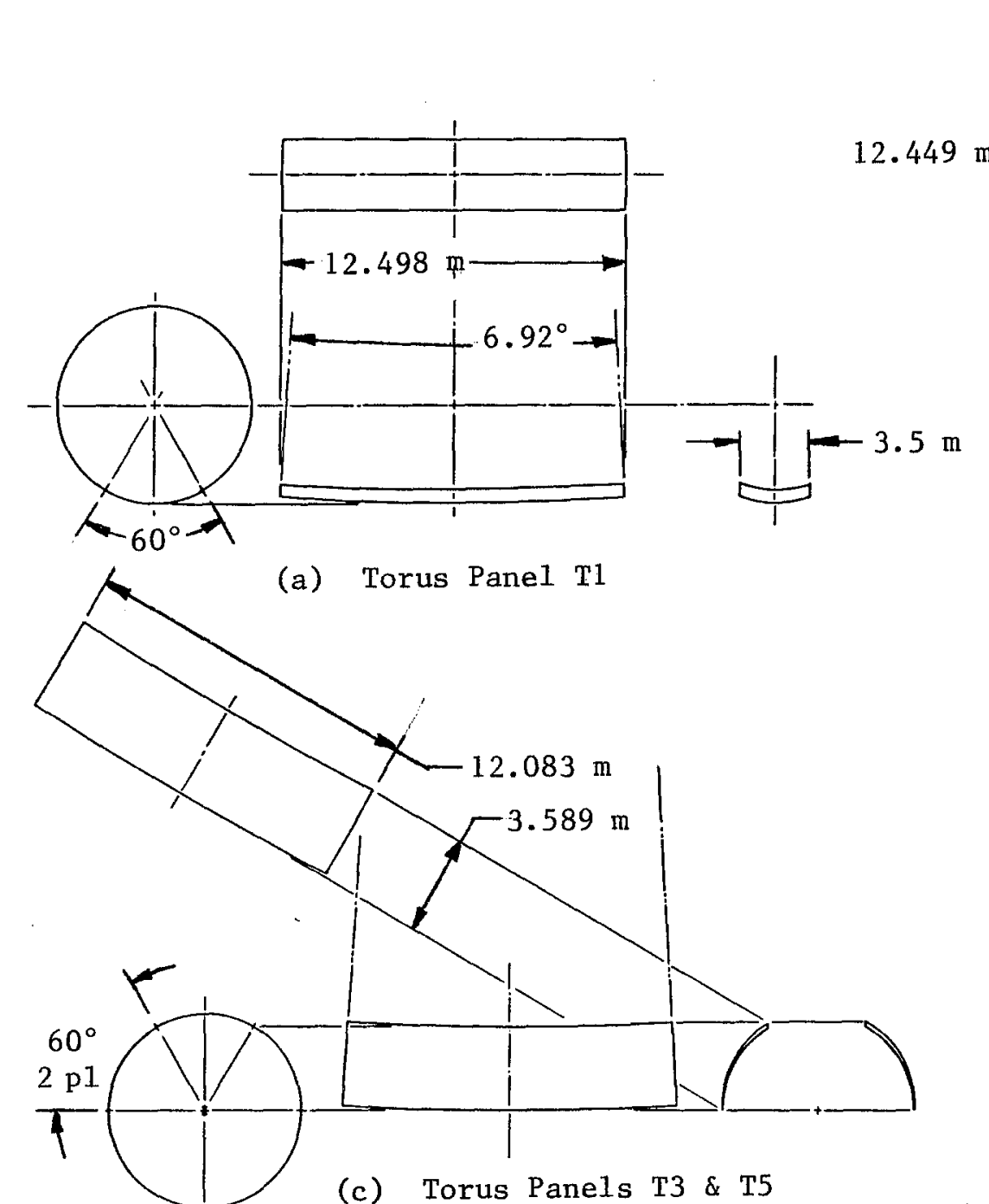

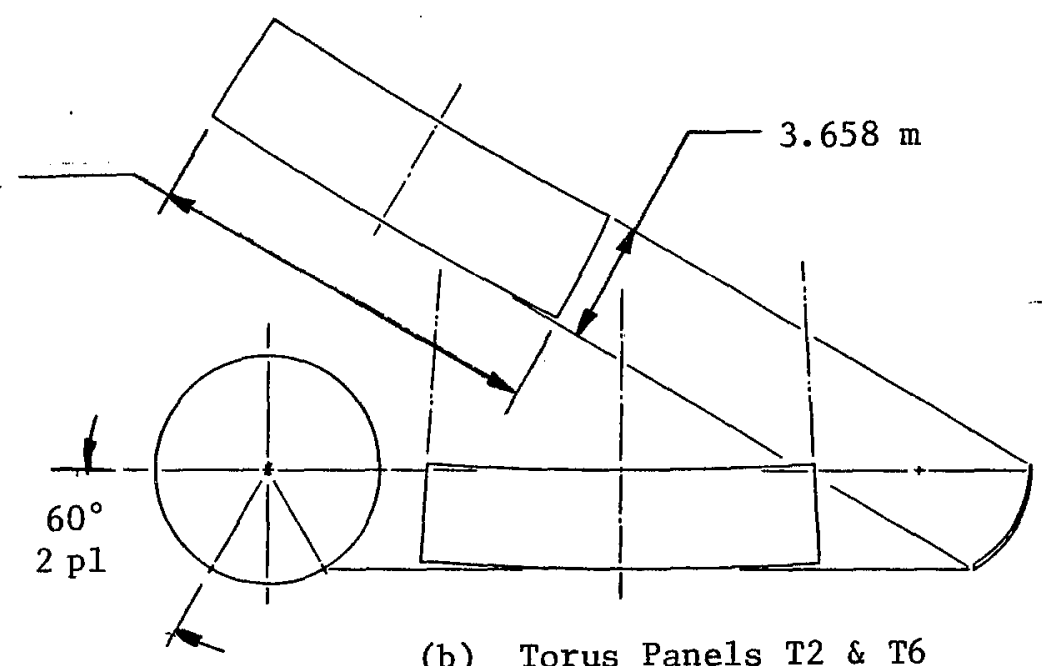

(b) Torus Panels T2\& T6

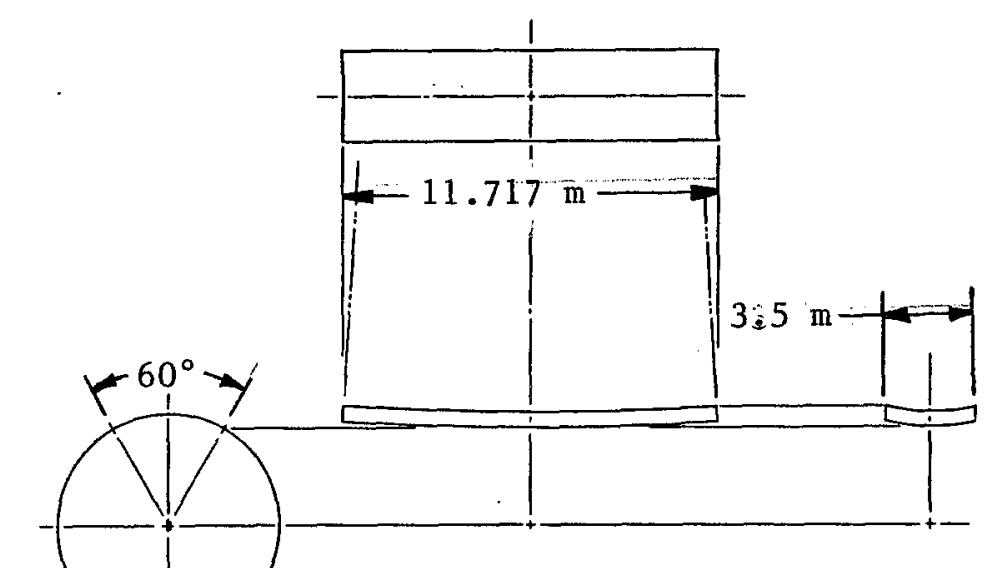

(d) Torus Panel T4

Figure 30. LEOBC Torus Structural Panels 


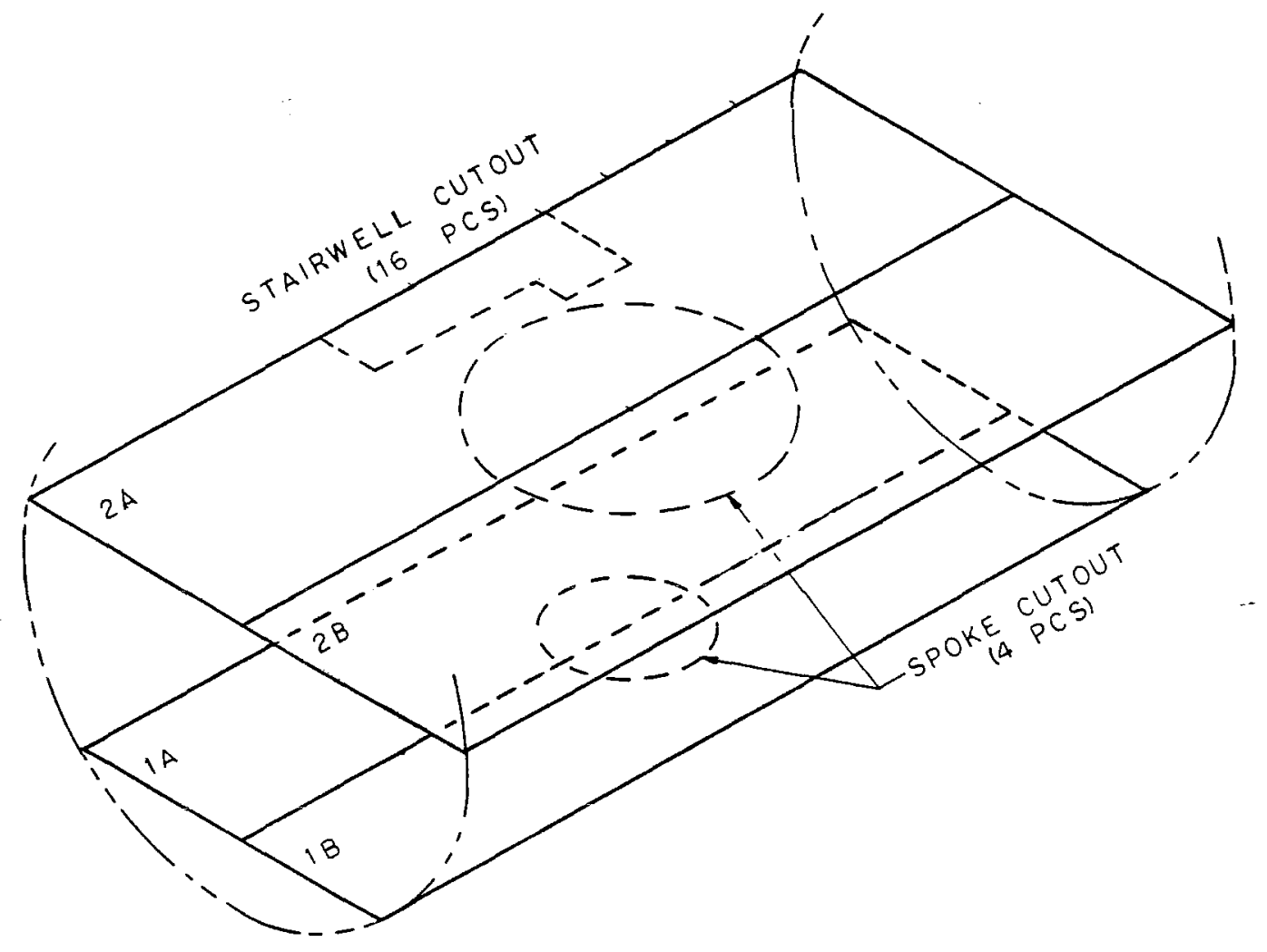

Figure 31. First- and Second-Floor Floor Panels 


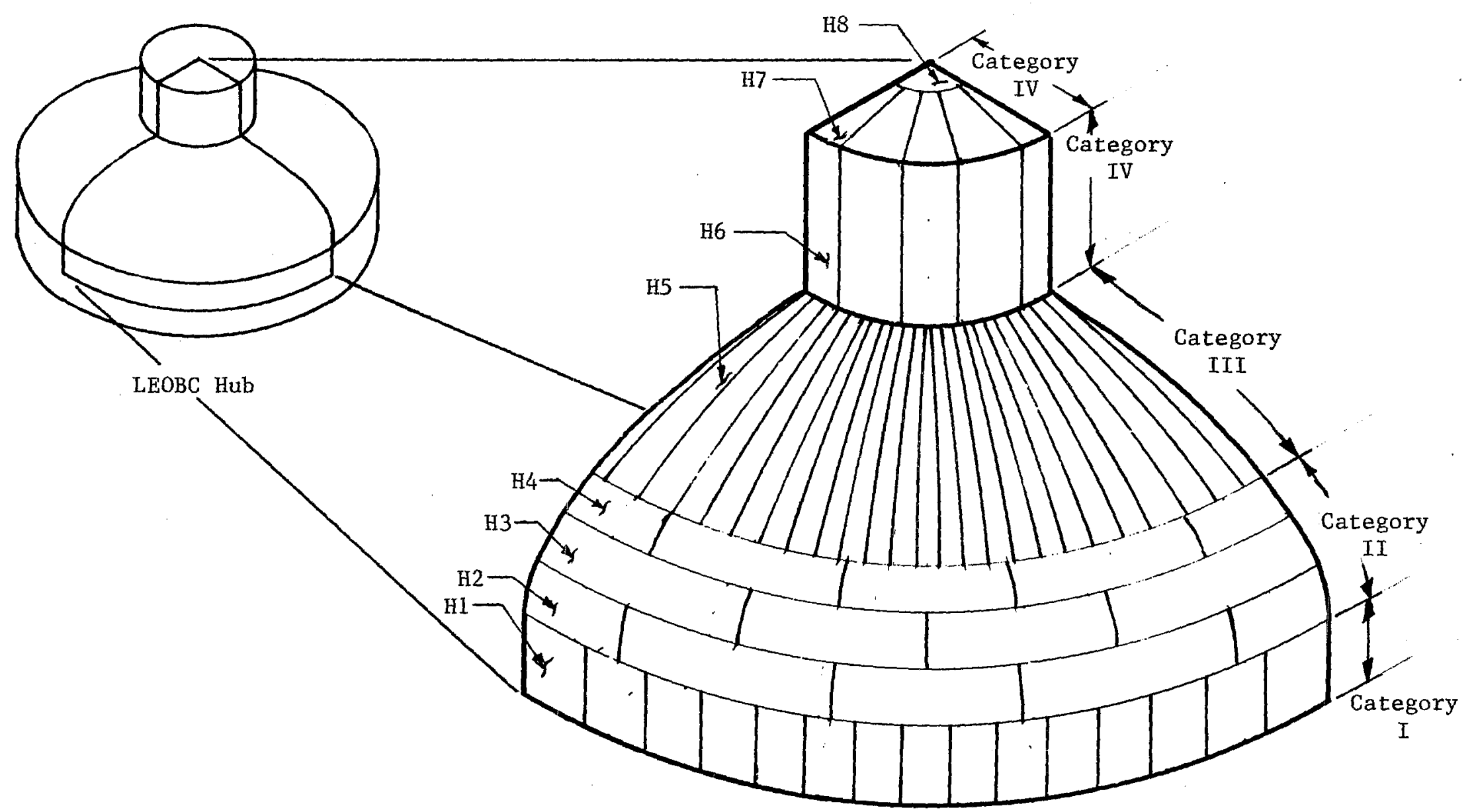

Figure 32. LEOBC Hub Structural Panels 


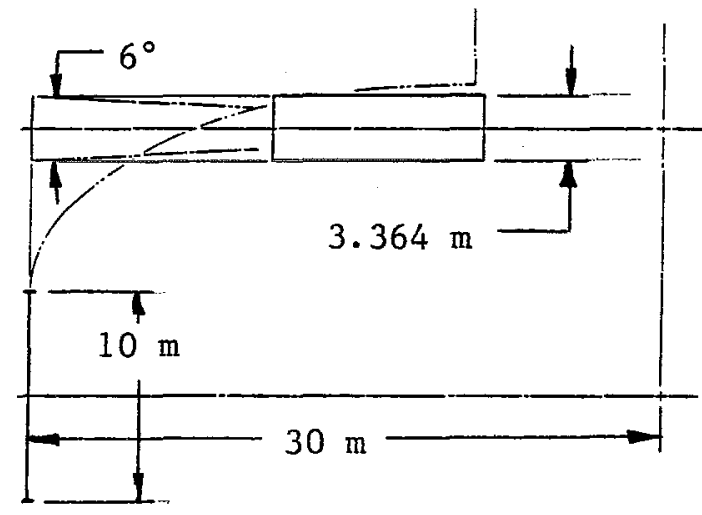

(a) Hub Panel Hl

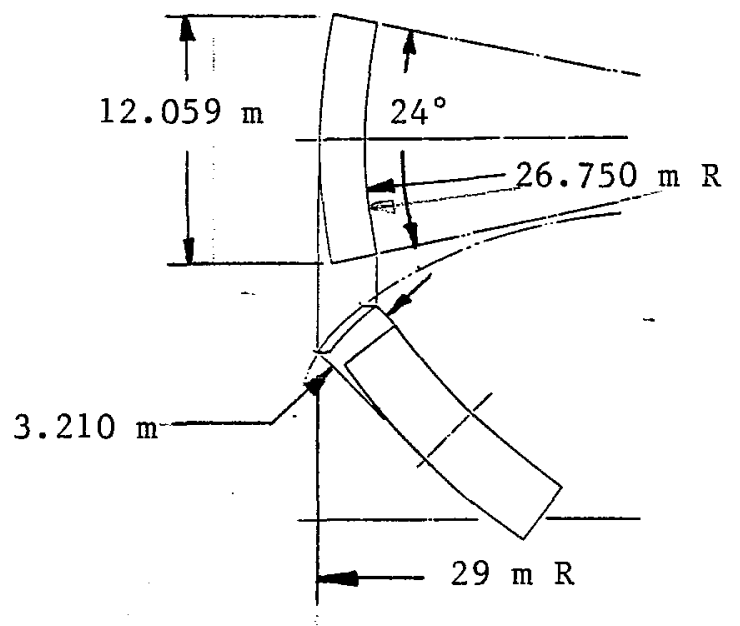

(c) Hub Panel H3

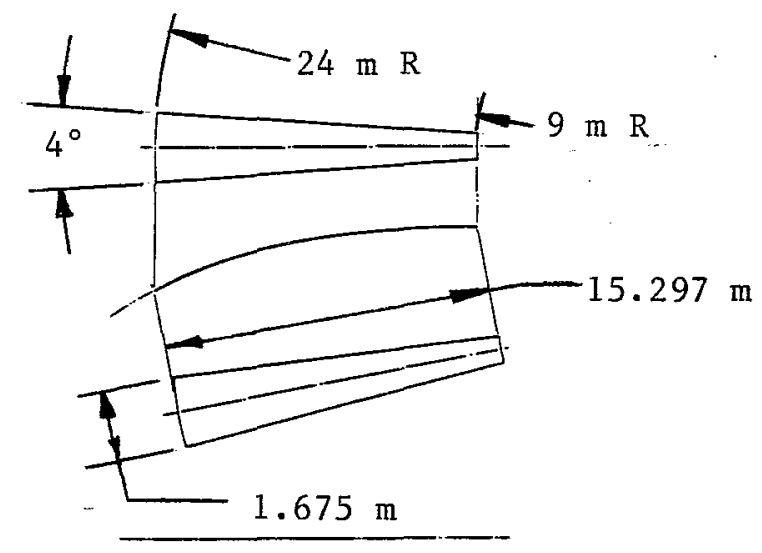

(e) Hub Panel H5

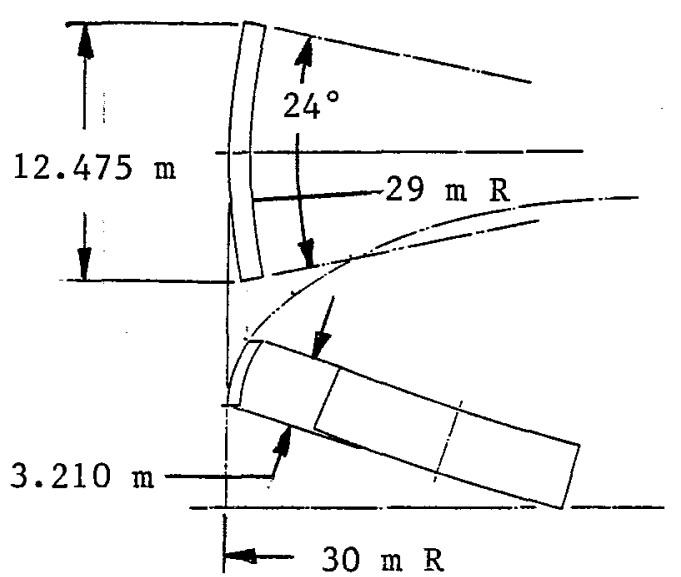

(b) Hub Fanel H2

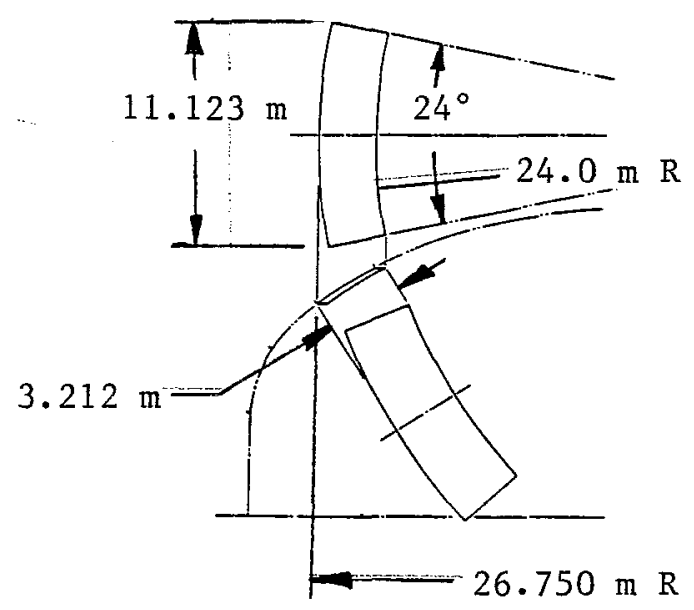

(d) Hub Panel $\mathrm{H}_{4}$

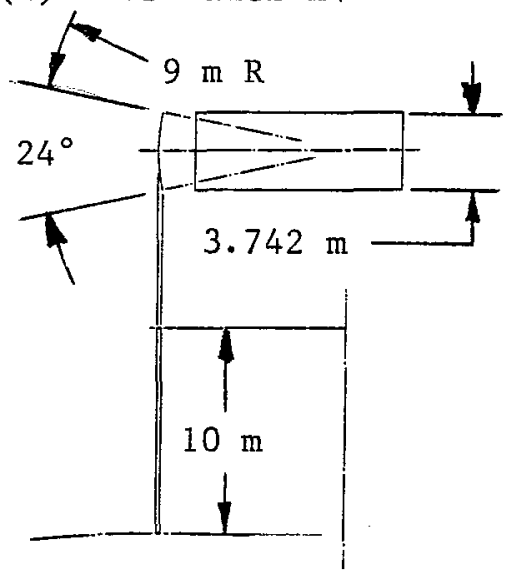

(f) Hub Panel H6

Figure 33. Hub Structural Panels HI through H6 


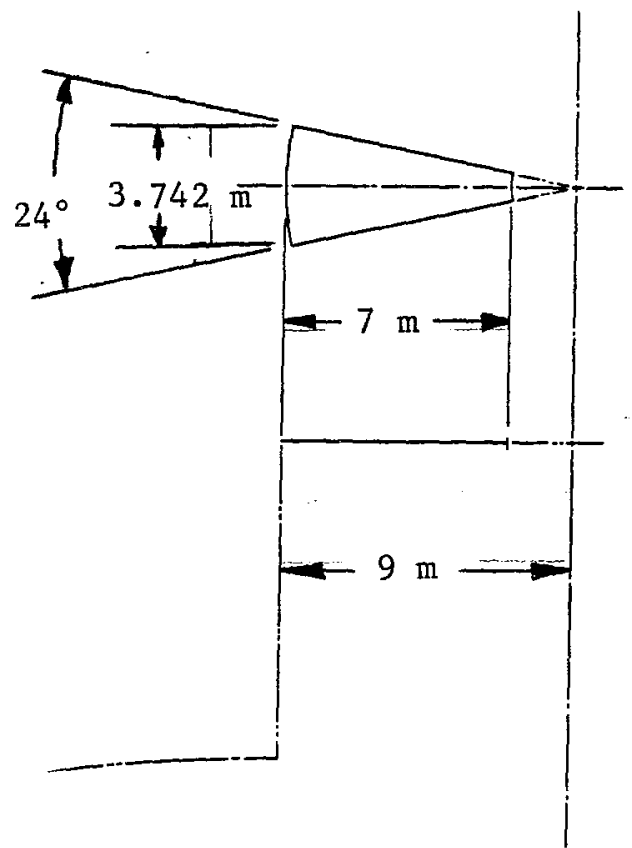

(a) Hub Panel H7

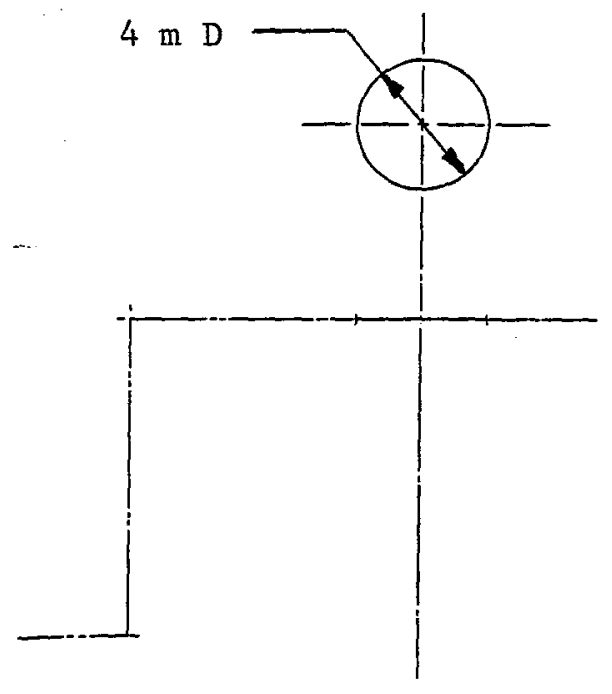

(b) Hub Panel H8

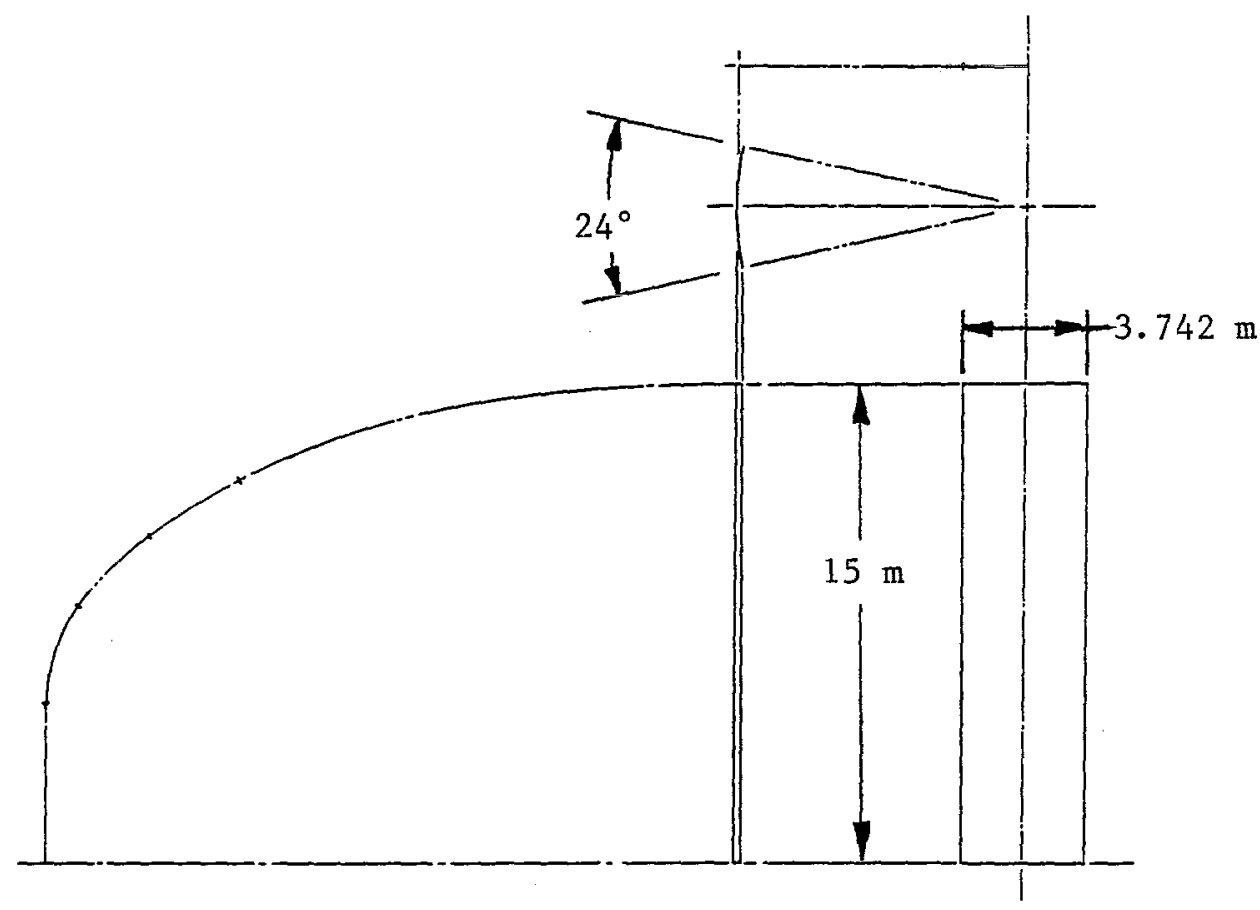

(c) Hub Panel H9

Figure 34. Hub Structural Panels H7 Through H9 
fit in the STS payload bay. Circumferentially, the number of panels needed for each floor varies from 60 to 36 , depending on the floor radius.

A summary of panel dimensions, actual and planar, is given in Tables 7 and 8. Information includes location (radius of centroid), arc lengths, surface area, payload envelope dimensions, quantity required, number of panels per launch, number of dedicated launches required and remaining panels.

The number of panels per STS launch was determined by first assuming that volume in the payload bay was the limiting factor. This assumption should hold for the floor panels but must be validated for the structural panels. For this reason an estimate of shell thickness was made for the torus and hub panels using stress equations for pressure vessels. Wall thickness for the torus was estimated using equation 5 ,

$$
t=\left[\frac{P_{0} \eta}{2}+\frac{P_{f} g}{\pi}\right] \frac{R}{\sigma_{w}-\rho g R}
$$
eq 5

which was used to determine the Stanford Torus she11 thickness. ${ }^{157}$ (The calculations for determining the thicknesses of the torus and hub shells are presented in Appendix E.) Hub thicknesses for the barrel sections at radii of 30 and 9 meters are estimated by using equation 6.145

$$
t=\frac{1}{\sigma_{m}}\left[P_{0} R^{2}+F^{2}\right]
$$
eq 6 
TABLE 7. LEOBC STRUCTURAL AND FLOOR PANEL DESCRIPTION SUMMARY

\begin{tabular}{|c|c|c|c|c|c|}
\hline \multirow{3}{*}{$\begin{array}{l}\text { COMPO- } \\
\text { NENT }\end{array}$} & \multirow{3}{*}{$\begin{array}{l}\text { RADIUS OF } \\
\text { CENTROID }\end{array}$} & \multicolumn{4}{|c|}{ ARC LENGTH } \\
\hline & & CIRCUM- & & & \\
\hline & & FERENTIAL I & RADIAL & AXIAL & AREA \\
\hline & & & & & \\
\hline $\mathrm{TI}$ & 103.342 & 12.506 & 3.665 & & 46.017 \\
\hline $\mathrm{T} 2$ & 102.895 & 11.347 & 3.665 & & 44.957 \\
\hline T3 & 97.106 & 10.983 & 3.665 & & 43.781 \\
\hline T4 & 96.658 & 10.650 & 3.665 & & 42.945 \\
\hline TS & 97.106 & 10.983 & 3.665 & & 43.781 \\
\hline $\mathrm{T} 6$ & 102.895 & 11.347 & 3.665 & & 44.957 \\
\hline $\mathrm{H} 1$ & 30.000 & 3.142 & & 10.000 & 31.416 \\
\hline $\mathrm{H} 2$ & 29.655 & 12.577 & 3.257 & & 40.456 \\
\hline H3 & .27 .954 & 12.147 & 3.228 & & 37.784 \\
\hline H4 & 35.426 & 11.205 & 3.214 & & 34.201 \\
\hline H5 & 17.754 & 3.351 & 15.420 & & 35.773 \\
\hline H6 & 8.925 & 3.770 & & 10.000 & 37.699 \\
\hline $\mathrm{H} 7$ & & 3.770 & & 7.000 & 16.127 \\
\hline H8 & 0.000 & 12.566 & 2.000 & & 12.566 \\
\hline $\mathrm{H9}$ & 8.925 & 3.770 & 10.000 & & 37.699 \\
\hline Fla,b & 102.500 & 12.085 & 2.450 & & 29.608 \\
\hline$F 2 a, b$ & 99.500 & 11.723 & 3.464 & & 40.608 \\
\hline F3 & 29.500 & 3.310 & & 14.338 & 47.457 \\
\hline F4 & 26.5 & 3.330 & & 10.527 & 35.056 \\
\hline F5 & 23.5 & 3.281 & & 12.234 & 40.142 \\
\hline F6 & 20.5 & 3.220 & & 13.367 & 43.044 \\
\hline F7 & 17.5 & 3.054 & & 14.144 & 43.200 \\
\hline
\end{tabular}


TABLE 8. LEOBC STRUCTURAL AND FLOOR PANEL LAUNCH DATA SUMMARY

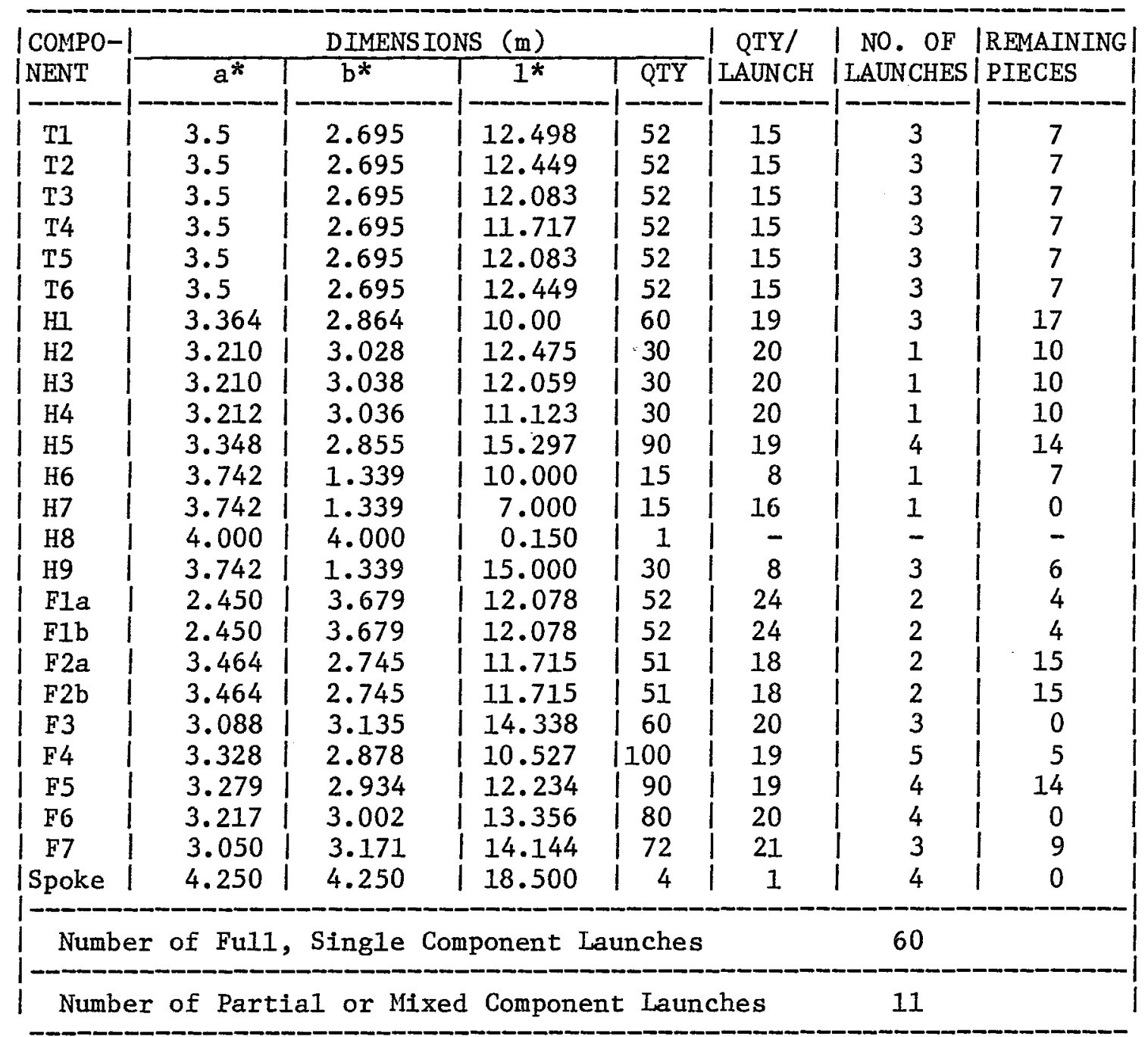


where,

$$
F=\left\{\begin{array}{ll}
\frac{P_{0}\left(R_{0}^{2}-R_{i}^{2}\right)}{2 \bar{R}}\left[\frac{\bar{R}-R_{i}}{R_{0}-R_{i}}\right] & \text { for } R=30 \\
\frac{P_{0}\left(R_{0}^{2}-R_{i}^{2}\right)}{2 \bar{R}}\left\lfloor\frac{R_{i}-\bar{R}}{R_{0}-R_{i}}\right] & \text { for } R=9
\end{array} \quad \text { eq } 7\right.
$$

For the elliptical surface, equation 8 was used. 158

$$
t=\frac{P_{0} R_{2}}{2 \sigma_{w}}\left[s-\frac{4 R_{2}}{R_{1}}+\left(\frac{R_{2}}{R_{1}}\right)^{2}\right]^{1 / 2}
$$

Panel thicknesses versus pressure, as predicted by these equations are plotted in Figure 35. Since the thickness of panels H2 through H5 are a function of radius, an area-weighted average thickness is plotted. Panel H5 is so much thicker than the others because equation 8 does not produce rellable results as the surface in question becomes perpendicular to the axis of revolution. 158

A more detailed analysis of the $H 5$ panel area would utilize finite element analysis to obtain a more accurate thickness profile. Another approach would be to use a skin-stringer construction rather than stressed skin. These alternatives would be explored in the next phase of concept development but are beyond the scope of this paper. For the purpose of estimating the number of launches for construction, a goal of one $H 5$ panel per launch has been established.

In addition to pressure considerations, radiation protection from three sources (Van Allen Belt, solar and cosmic) needs to be considered when establishing a primary structural thickness for any space station. Unfortunately, each type of radiation requires 

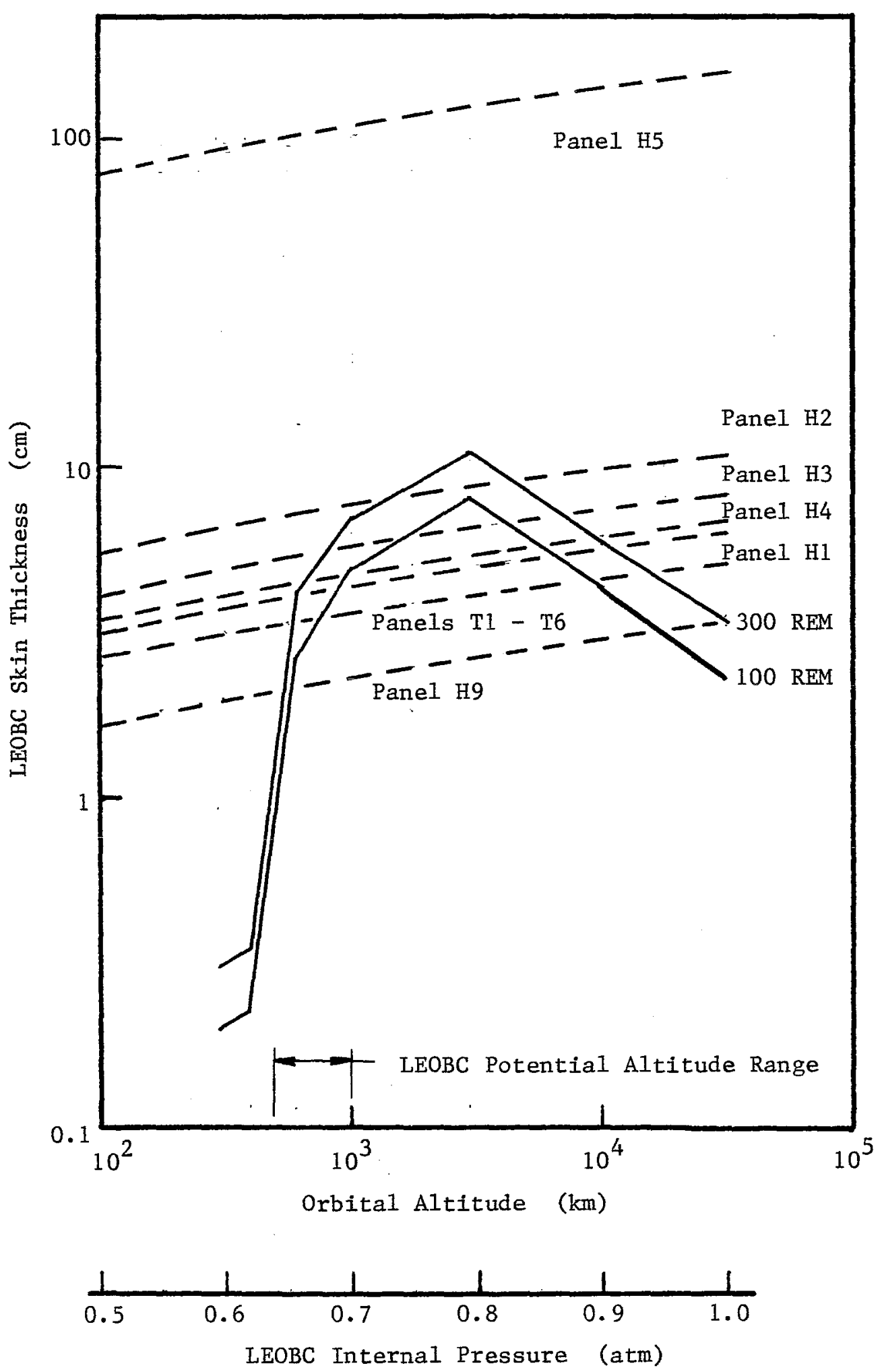

Figure 35. LEOBC Thickness for Various Pressures and Altitudes with Constant Radiation Exposure Levels. 
different counter measures to reduce the hazards. Van Allen Belt radiation is effectively reduced as structural thickness is increased to a point where mass per unit area reaches $10-25 \mathrm{~g} / \mathrm{cm}^{2} .159$ Solar flare particles require much greater thicknesses for protection and may call for a special "storm cellar." Cosmic radiation, however, becomes a greater danger source as thickness increases due to the increased probability of collisions with structural material atoms. The solution to this problem is still an open issue and its resolution is beyond the scope of this paper. However, to illustrate the impact that radiation protection has on station design, aluminum skin thickness as a function of orbital altitude is plotted for two dose limits over six months in conjunction with thickness variation as a function of pressure in Figure 35. From this comparison, it can be seen that, depending on altitude, radiation can be the driving requirement for establishing a minimum structural thickness for some of the LEOBC structural panels. For this reason, panel thickness is based on an internal pressure of 1 atm or a minimum thickness of 7 cm. The exception to this is panel H9, which is an internal panel and not directly exposed to cosmic radiation. Final panel thicknesses and mass per unit area are shown in Figure 36. Number of panels per launch is shown in Figure 37. These thickness estimates increase the number of launches from 61, as estimated by volume-limited payloads, to 254. This data is summarized in Table 9.

Four additional launches will be necessary to place the spokes in orbit. Each spoke is designed to fit into the STS payload bay by telescoping down to 17.5 meters from an extended length of 70 meters (Fig. 38). 


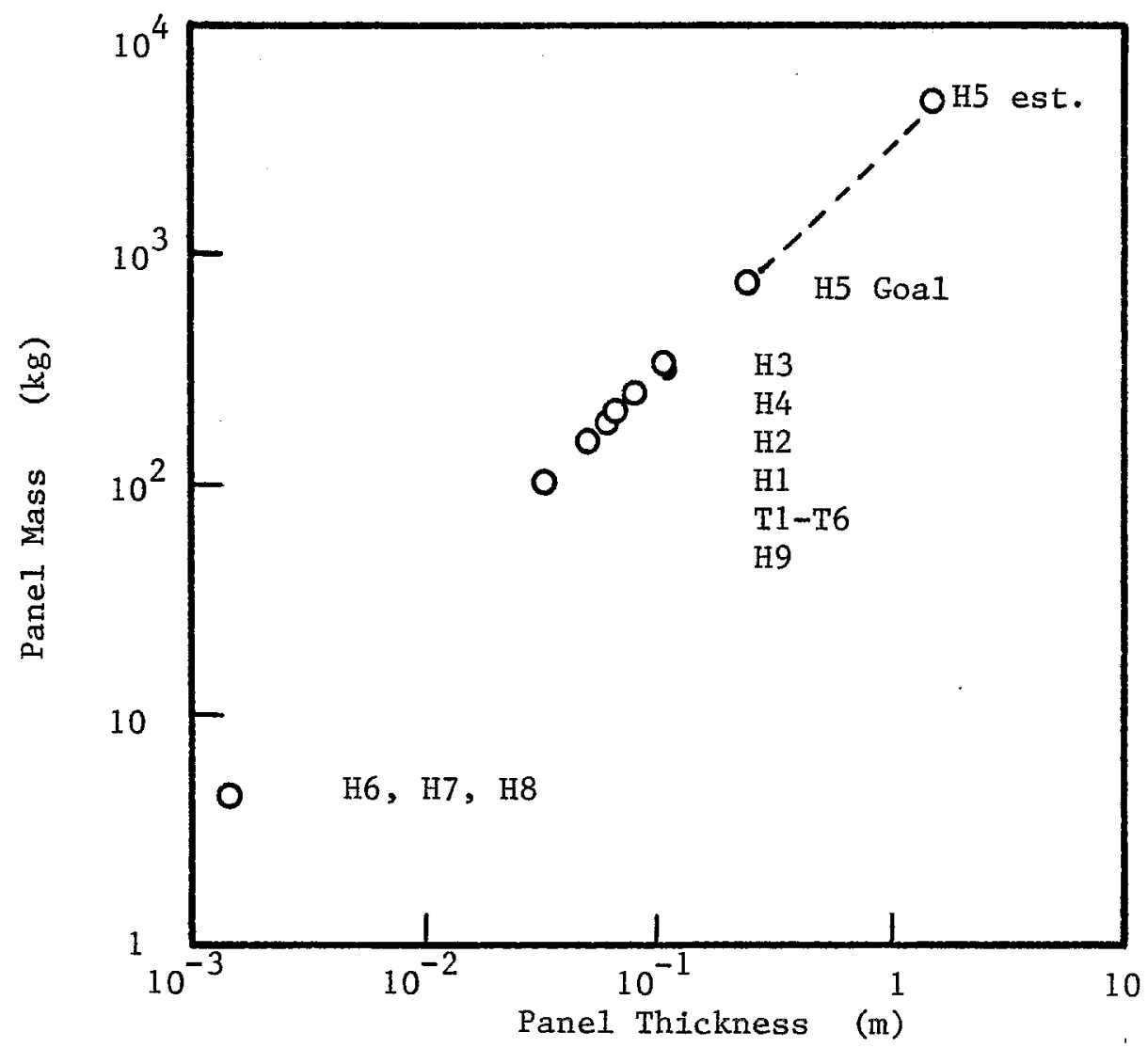

Figure 36. Structural Panel Mass

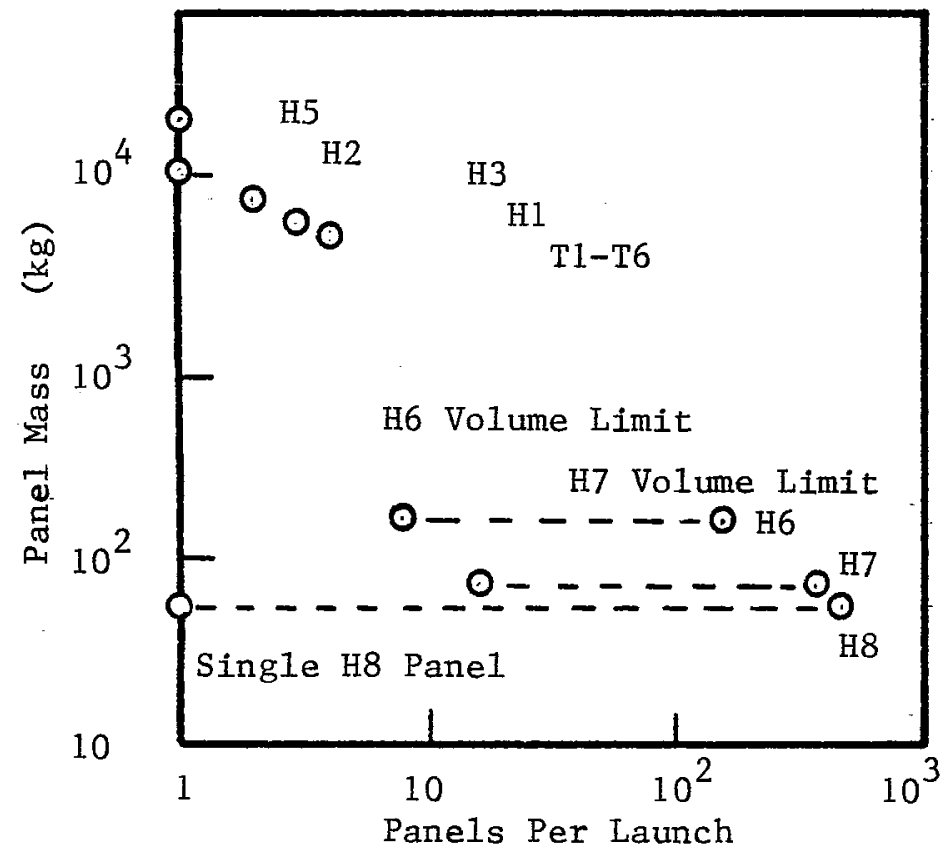

Figure 37. LEOBC Panels Per STS Lanuch 
TABLE 9. REVISED LEOBC STRUCTURAL AND FLOOR PANEL LAUNCH DATA SUMMARY

\begin{tabular}{|c|c|c|c|c|c|c|c|}
\hline \multirow{2}{*}{$\begin{array}{l}\mid \text { COMPO- } \\
\mid \text { NENT }\end{array}$} & \multicolumn{4}{|c|}{ DIMENSIONS（m) } & \multirow{2}{*}{$\begin{array}{c}\text { QTY/ } \\
\text { LAUNCH }\end{array}$} & \multirow{2}{*}{$\begin{array}{l}\text { NO. OF } \\
\text { ILAUNCHES }\end{array}$} & \multirow{2}{*}{$\begin{array}{l}\text { REMAINING } \\
\text { PIECES }\end{array}$} \\
\hline & a & $\mathrm{b}$ & 1 & QTY & & & \\
\hline $\mathrm{T} 1$ & 3.5 & 2.695 & 12.498 & 52 & 3 & 17 & 1 \\
\hline $\mathrm{T} 2$ & 3.5 & 2.695 & 12.449 & 52 & 3 & 17 & 1 \\
\hline T3 & 3.5 & 2.695 & 12.083 & 52 & 3 & 17 & 1 \\
\hline T4 & 3.5 & 2.695 & 11.717 & 52 & 3 & 17 & 1 \\
\hline T5 & 3.5 & 2.695 & 12.083 & 52 & 3 & 17 & 1 \\
\hline T6 & 3.5 & 2.695 & 12.449 & 52 & 3 & 17 & 1 \\
\hline $\mathrm{H} 1$ & 3.364 & 2.864 & 10.00 & 60 & 4 & 15 & 0 \\
\hline $\mathrm{H} 2$ & 3.210 & 3.028 & 12.475 & 30 & 1 & 30 & 0 \\
\hline $\mathrm{H} 3$ & 3.210 & 3.038 & 12.059 & 30 & 2 & 15 & 0 \\
\hline $\mathrm{H} 4$ & 3.212 & 3.036 & 11.123 & 30 & 4 & 7 & 2 \\
\hline H5 & 3.348 & 2.855 & 5.297 & 90 & 1 & 90 & 0 \\
\hline H6 & 3.742 & 1.339 & 10.000 & 15 & 8 & 1 & 7 \\
\hline $\mathrm{H} 7$ & 3.742 & 1.339 & 7.000 & 15 & 16 & 1 & 0 \\
\hline H8 & 4.000 & 4.000 & 0.150 & 1 & - & - & - \\
\hline H9 & 3.742 & 1.339 & 15.000 & 30 & 4 & 7 & 2 \\
\hline Fla & 2.450 & 3.679 & 12.078 & 52 & 24 & 2 & 4 \\
\hline F1b & 2.450 & 3.679 & 12.078 & 52 & 24 & 2 & 4 \\
\hline$F 2 a$ & 3.464 & 2.745 & 11.715 & 51 & 18 & 2 & 15 \\
\hline $\mathrm{F} 2 \mathrm{~b}$ & 3.464 & 2.745 & 11.715 & 51 & 18 & 2 & 15 \\
\hline F3 & 3.088 & 3.135 & 14.338 & 60 & 20 & 3 & 0 \\
\hline F4 & 3.328 & 2.878 & 10.527 & 100 & 19 & 5 & 5 \\
\hline F5 & 3.279 & 2.934 & 12.234 & 90 & 19 & 4 & 14 \\
\hline F6 & 3.217 & 3.002 & 13.356 & 80 & 20 & 4 & 0 \\
\hline F7 & 3.050 & 3.171 & 14.144 & 72 & 21 & 3 & 9 \\
\hline Spokes & 4.25 & 4.25 & 18.00 & 4 & 1 & 4 & 0 \\
\hline \multicolumn{5}{|c|}{ Number of Fu11, } & \multicolumn{3}{|c|}{254} \\
\hline Nu & $\mathrm{P}$ & 01 & & & & 8 & \\
\hline
\end{tabular}

TABLE 10 SUBSYSTEM OPTIONS

\begin{tabular}{|l|l|l|}
\hline LIFE SUPPORT & POWER GENERATION & THERMAL CONTROL \\
\hline CLOSED SYSTEM & SOIAR CELLS & PASS IVE \\
PARTIALLY REGENERATIVE & FUEL CELIS & ACTIVE \\
OPEN SYSTEM & NUCLEAR & \\
CENTRALIZED & RANKING CYCLE & \\
LOCALIZED & GRAYTON CYCLE & \\
\hline
\end{tabular}




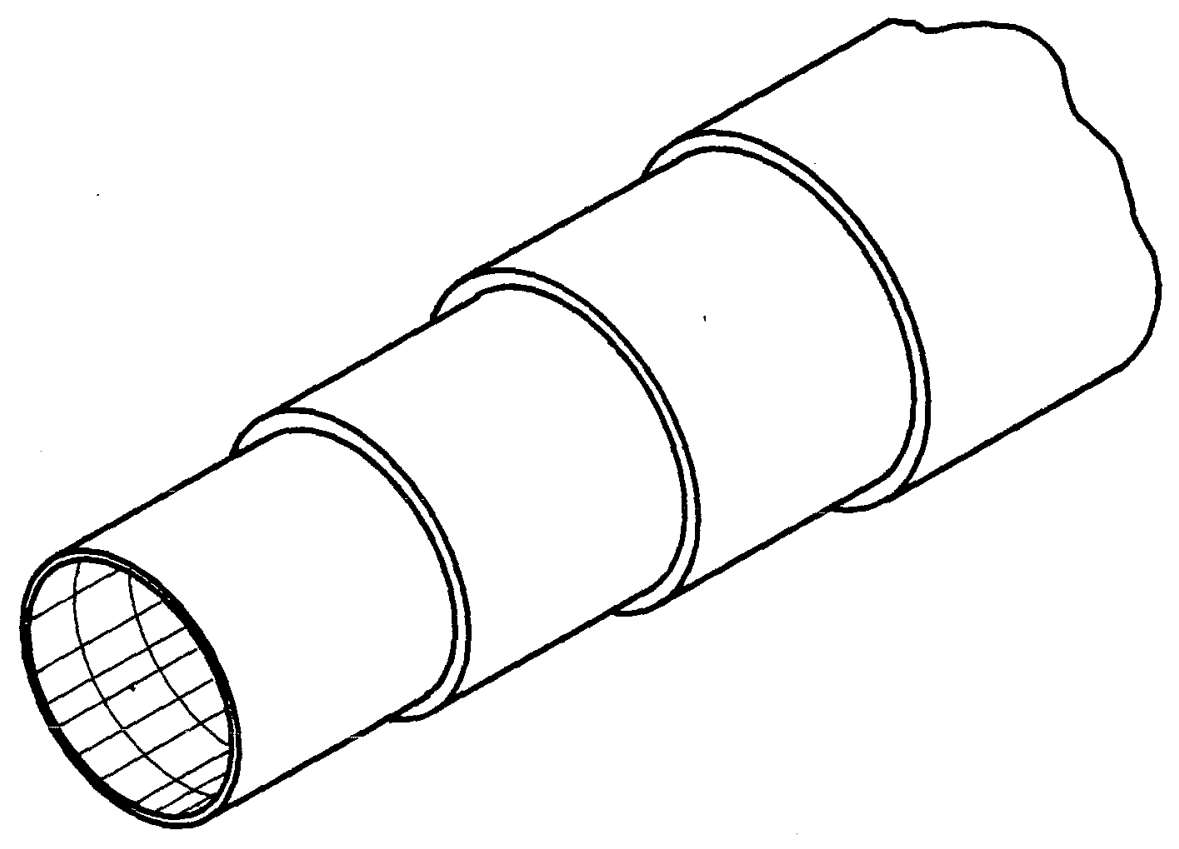

Figure 38. LEOBC Telescopic Spoke 
Interior furnishings, water and atmosphere necessary to bring LEOBC into full operational capability will require even more launches. Since these items have a density greater than the average density for a mass-limited launch, the number of launches required will be estimated assuming that $90 \%$ of the STS payload will be usable payload. Interior furnishings mass is estimated by using the established floor design load of $300 \mathrm{~kg} / \mathrm{m}^{2}$ and a $25 \% 1$ oad factor. The resulting $75 \mathrm{~kg} / \mathrm{m}^{2}$ value is then multiplied by the total floor area inside $L E O B C$, giving an internal furnishing mass of 1,691,200 $\mathrm{kg}$. A minimum of sixty-four STS launches will be required to bring this material to LEOBC. The calculations for estimating internal mass are found in Appendix E.

For comparison, the NASA Ames Research Center sponsored study in 1977 used a value of 43,000 kg per person for internal mass approximations. 153 Using this for LEOBC would result in an internal mass of $8,600,000 \mathrm{~kg}$, which is five times greater than proposed. The use of the lower value for $\angle E O B C$ is justified by observing that in most office areas less than half the floor space is occupied by furniture and that approximately half of the area in LEOBC's torus is left unfurnished. Also the basis for the $43,000 \mathrm{~kg}$ factor was the 1975 NASA Ames Study where interior furnishings were manufactured from residual material from processed lunar ore. This material is much denser than wood, plastic and corrugated panels which will comprise most of LEOBC's furnishings.

Specific subsystems, such as life support, power, and thermal control, are contributory variables to any space station design as it relates to total mass and final configuration (see Table 10). 
However, the trade studies and final selection for each subsystem are beyond the scope of this project. Therefore, a generic approach was taken in establishing internal mass by assuming that all materials and subsystems to be brought on board $\angle E O B C$ are included in the nominal floor loading parameter of $75 \mathrm{~kg} / \mathrm{m}^{2}$.

Potable water, which will be stored in the torus as shown in Appendix E, adds an additional $584,100 \mathrm{~kg}$ to the mass which must be transported to LEOBC. Due to excess lift capability when launching panels T1-T6, $\mathrm{H} 2$ and $\mathrm{H} 9,3770 \mathrm{~kg}$ of water will be carried aloft in a spherical tank with a 1.0 meter radius filled to $90 \%$ capacity. One tank per flight can be carried with panels T1-T6 and H9 while two tanks can be carried on each $\mathrm{H} 2$ flight. Thus, water will be carried on all 104 launches necessary to put panels Tl-T6 on orbit and 26 of the 30 required to put $\mathrm{H} 2$ panels on orbit.

The amount of oxygen and nitrogen necessary to pressurize ILEBC to 1.0 atm totals $88,146 \mathrm{~kg}$. By dedicating full-lift capability to atmospheric cryogens, $21,240 \mathrm{~kg}$ of nitrogen and $5310 \mathrm{~kg}$ of oxygen can be taken to LEOBC on each launch. Four launches will then be necessary to pressurize LEOBC with the excess from the fourth launch providing a $20.5 \%$ reserve of oxygen and nitrogen on board.

In total, the number of launches necessary to bring LEOBC to full operational capability (FOC) is 334 . An estimated waterfall timeline showing activities to FOC is shown in Figure 39 along with major milestones. Assumptions used for this estimate include:

- a two year design phase for the floor panels,

- a five year design phase for the structural she11,

o a new production line opening every six months, 


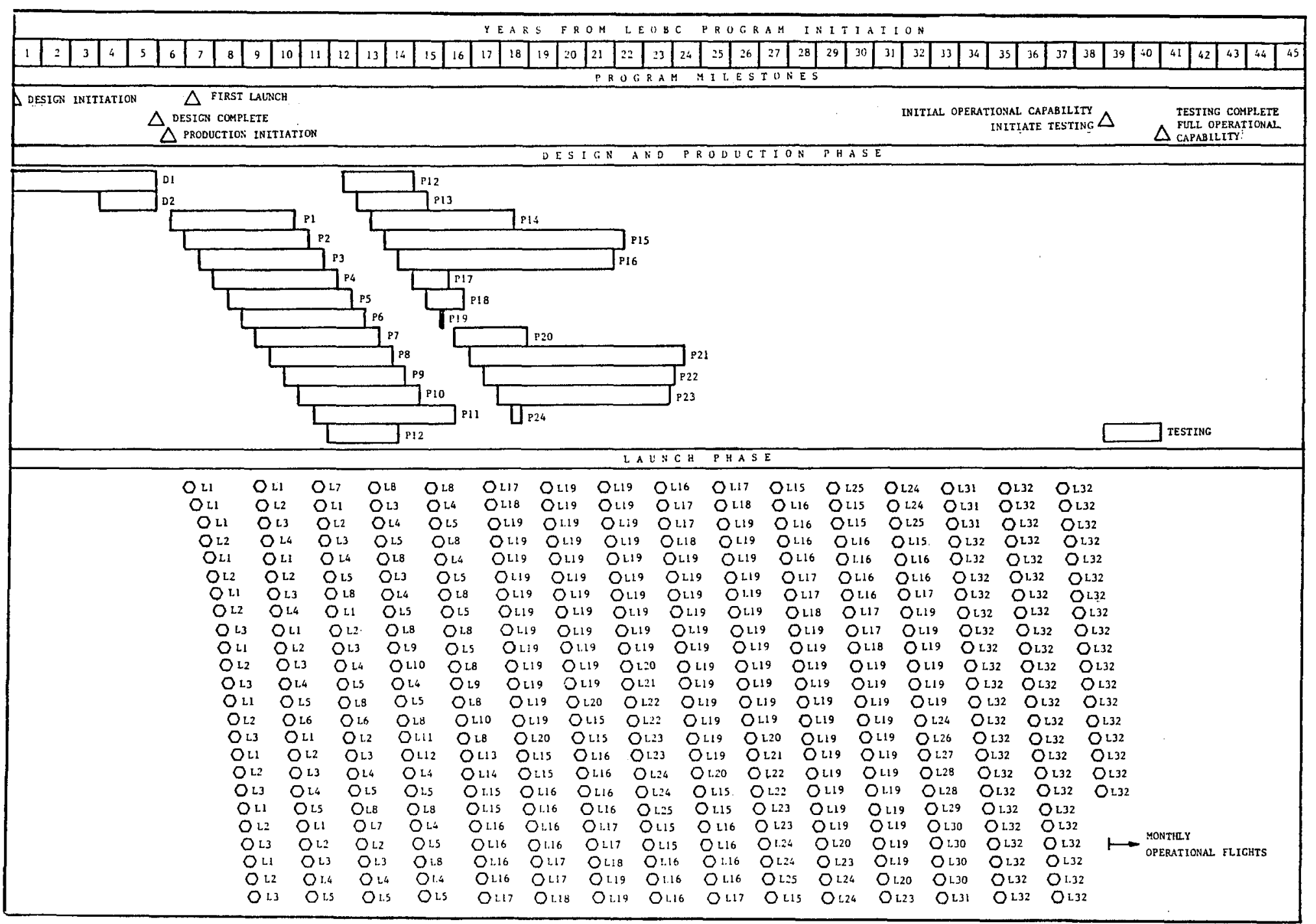

Figure 39. LEOBC Design, Fabrication And Construction Schedule 
- a fabrication rate of one panel per month,

- and a six month processing period from manufacture of the last panel per payload and the subsequent STS launch.

Material launches are set at one month centers with crew and supplies sent aloft on parallel flights. Initial operational capability (IOC)

can be established when LEOBC is pressurized and life support, guidance, navigation and control subsystems have been placed on board. 


\section{CHAPTER 7}

CLOSING REMARKS

Since this effort was initiated, three key developments have occurred which bring LEOBC closer to reality: 1) the Space Transportation System has achieved operational status, 2) the President of the United States has approved a Space Station program for NASA and 3) Commercialization of Space has begun to emerge and is seen as a major economic industry by 2000 .

NASA's Space Transportation System's first launch was on Apri1 12, 1981, and has been followed by twelve missions. During these missions, Space Shuttle crew members have deployed satellites, retrieved free-flying pallets and errant satellites, repaired spacecraft, redeployed spacecraft, proven the advantages to material processing and manufacturing in zero-g environments and flown a spacelab mission. These missions and activities have proven the viability and versatility of the launch vehicle baselined to carry LEOBC components into orbit. At the same time, key areas of the STS program are being transferred from NASA's control to private corporations. This currently includes ground processing at Kennedy Space Center and, in the future, orbital operations located at Johnson Space Center. Additionally, according to J. M. Beggs, the Shuttle fleet could be owned by a private corporation by 1988 or $1989 .^{160}$ This could begin much earlier if current negotiations between Astrotech and NASA are successful. ${ }^{161}$ These negotiations are aimed at the purchase of an existing orbiter and funding production of a fifth vehicle by Astrotech. Long range goals for Astrotech call for possible ownership of the entire STS fleet. 
The authorization for Space Station development by President Reagan during his 1984 State of the Union address also points to a greater level of activity in space. The establishment of Space Station as a goal says we are committed to space development and will always have a place to work in space. This is a key element to any large scale construction program in orbit such as LEOBC. Space stations are necessary for crew quarters, logistics center, preliminary zero-g experimentation, product development and production. However, as has happened with every launch vehicle and is foreseeable with the STS Orbiter, requirements always grow to meet and finally exceed current capabilities. This will most likely happen with Space Station as well.

Evidence for this possibility is presented in the 25 June 1984, Aviation Week \& Space Technology issue, dedicated to Commercialization of Space. McDonnell Douglas and Johnson \& Johnson are eyeing the Space Station as the location for their orbital processing and manufacturing. ${ }^{134} 3 \mathrm{M}$ would like to use the shuttle and Space Station as a research center. ${ }^{162}$ John Deere \& Co. is moving its zero-g experiments from parabolic flights to a Shuttle flight program. ${ }^{163}$ In addition, various other companies are reviewing Joint Endeavor Agreements with NASA and other avenues to produce space-manufactured products. In a11, 14 companies that are pursuing space product research and development are included in a cross-section of companies compiled by the Center for Space Policy at Cambridge, Massachussetts. 164 
If only half of these desire to operate in Space Station, with one specialist per company on-board, the initial capacity limit of space Station (6-10) will be reached. Thus, if the expansion into space is only partially realized, additional space stations will be needed, possibly leading to the need for an industrial park such as LEOBC with co-orbiting facilities for those processes which require minimal disturbing forces. Evaluation and testing of products could then be carried out at LEOBC in earth-typical labs.

What are the prospects for space commercialization? The Center for Space Policy projects gross annual revenues in excess of $\$ 65$ billion from specific space commercialization endeavors with $\$ 41.6$ billion coming from space processed materials. ${ }^{165}$ Rockwell International projects revenues from these same areas at $\$ 30$ billion per year. Taxes, according to Center for Space Policy, would be approximately $20 \%$ of this income, or $\$ 8.3$ billion. These revenues could be used to offset additional NASA budget expenditures necessary to implement programs such as those espoused by Waltz in 1981.125 This course was recently echoed by NASA's task force on free enterprise in Space when it said that, "The government should invest in high-leverage technologies and space facilities that encourage private investment. "166 In addition, White House and NASA policy statements in preparation may propose seed funding for commercial space ventures, market support for space-produced products, access to national space facilities and reduced shuttle launch fees to increase the rate of space commercialization. 165 
These developments bring LEOBC closer to reality than it was when this project was initiated four years ago. Time and economics, as well as market requirements, will ultimately define LEOBC's location and design. The approach proposed here is but one that is compatible with currently existing hardware. 
1. Hale, E. E. "The Brick Moon." The Brick Moon and Other Stories. Freeport, N.Y. Books for Libraries Press. (1899, Reprint 1970)

2. Blangonravor, A. A., ed. Collected Works of K. E. Tsiolkovskiy, Vol. II - Reactive Machines. NASA TI F-237. Moscow. USSR Academy of Sciences Publishing House, 1954.

3. Hutton, R. The Cosmic Chase. The New American Library. New York, (1981): pp. 15-16.

4. "Proceedings of the Manned Space Stations Symposium". International Astronatical Society, 1960, pp. 19-23.

5. Heppenheimer, T. A. Colonies in Space. Harrisburg, PA 17105. Stackpole Books, 1977, pp 94-95.

6. Von Braun, W. "Crossing the Last Frontier", Colliers, 22 March 1952, pp. 29, 72, 74 .

7. Johnson, R. D. \& Holbrow, C., ed. Space Settlements - A Design Study. NASA SP-413. Scientific \& Technical Information Office, 1977.

8. Billingham, J. \& Gilbreath, W. ed. Space Resources and Space Settlements. NASA SP-428. STIB. 1979.

9. Johnson, R. D., \& Holbrow, C., ed. Space Settlements - A Design Study. NASA SP-413. Scientific \& Technical Information Office. 1977. p. 9.

10. Ehricke, Dr. K. A., "A Long Range Perspective and Some Fundamental Aspects of Interstellar Evolution." Journal of the British Interplanetary Society. Vol 28. April 1975: 713-734.

11. Koelle, H.H., Engler, F.E., and Massey, J.W. "Design Criteria and Their Application to Economical Manned Satellites." Proceedings of The Manned Space Station Symposium. New York, Institute of the Aeronautical Sciences. 1960 pp. 24-35. 
12. Bernal, J. D. The World, the Flesh and the Devil.

Bloomington, Indiana Universities Press, pp. 11-28.

13. Shepherd, L. R. "Interstellar Flight". Journa1 of British Interplanetary Society. Vol II, No. 4 (July 1952).

14. Johnson, R. D., \& Holbrow, C., ed. Space Settlements - A Design Study. NASA SP-143. Scientific \& Technical Information Office. 1977. p. 5.

15. Kramer, S.B. and Byers, R.A. "A Modular Concept for a Multi-Manned Space Station." Proceedings of the Manned Space Station Symposium, New York. Institute of the Aeronautica1 Sciences, 1960. pp. 36-72.

16. Cole, D. M. Islands in Space, the Challenge of the Planetoids. Philadelphia, PA. Chilton Books, 1964.

17. O'Neill, G.K. "The Colonization of Space." Physics Today. (Sept. 1974) pp. 32-40.

18. 0'Neil1, G. The High Frontier. New York. William Morrow and Co., 1977

19. Space Shuttle System Summary. SSv80-1. Rockwe11 International, May 1980.

20. Life In Space. Alexandria, VA. Time-Life Books, 1983.

21. Fink, D. E. "Unique Skylab Rescue Mounted." Aviation Week \& Space Technology, (21 May 1973): 12-14.

22. "On-Time Launch of Skylab Crew Spurred by Early Fuel Loading." Aviation Week \& Space Technology, (4 June 1973): 23.

23. Covau1t, C. "Smoothness Masks New Skylab Launch." Aviation Week \& Space Technology, (6 Aug. 1973): 19-20.

24. Bulban, E. J. "Skylab Crew Motivation Stil1 High at End." Aviation Week \& Space Technology, (8 Oct. 1973): 16-17. 
25. "Skylab Crew Encounters Few Problems." Aviation Week \& Space Technology, (26 Nov. 1973): 24-26.

26. Bulban, E.J. "Skylab Called Basis for Future Missions." Aviation Week \& Space Technology, (18 Feb 1974): 18-19.

27. Covalt, C. "Skylab Tumbling Timing Linked to Control." Aviation Week \& Space Technology, (16 July 1979): 22-23.

28. "Soviets Launch New Salyat; 15th Spacecraft Since Aug 27." Aviation Week \& Space Technology, (3 Oct. 1977): 27.

29. "Failure to Achieve Rendezvous Curtails Soviet Soyuz Flight." Aviation Week \& Space Technology, (17 Oct. 1977), 25.

30. Covault, C. "Extra Docking Port Saves Salyut 6." Aviation Week \& Space Technology, (19 Dec. 1977): 11-12.

31. Covault, C. "Soviet Manned Flight Resupplies Salyut." Aviation Week \& Space Technology, (16 Jan. 1978): 20-21.

32. "Supply, Vehicle Dynamics Receive Focus on Salyut." Aviation Week \& Space Technology, (23 Jan. 1978): 19.

33. "Soyuz Tanker." Aviation Week \& Space Technology, (30 Jan. 1978): 33.

34. "Progress 1 Departs From Salyut 6." Aviation Week \& Space Technology, (13 Feb. 1978): 22.

35. Covault, C. "Soviets Bulld Reusable Shuttle." Aviation Week \& Space Technology, (20 March 1978): 15.

36. "Salyut 6 Reoccupied by Soviets." Aviation Week \& Space Technology, (26 June 1978): 21.

37. "Salyut 6 Again Manned by Four." Aviation Week \& Space Technology, (3 July 1978): 25. 
38. "Soyuz 30 Crew Returns to Earth." Aviation Week \& Space Technology, (10 July 1978): 17.

39. "Second Progress Mission Flown to Salyut 6 Station." Aviation Week \& Space Technology, (17 July 1978): 19.

40. "Soviets Take Manned Space Time Lead." Aviation Week \& Space Technology, (7 Aug. 1978): 21.

41. "New Progress Docks With Salyut 6." Aviation Week \& Space Technology, (14 Aug. 1978): 21.

42. "Spacecraft Switch at Salyut 6 Indicates Record Flight Attempt." Aviation Week \& Space Technology, (4 Sept. 1978): 27.

43. "Salyut 6 Crew Switches Soyuz to Allow New Progress Visit." Aviation Week \& Space Technology, (18 Sept. 1978): 26.

44. Covault, C. "Soviets Plan Larger Space Assemblies." Aviation Week \& Space Technology, (9 Oct. 1978): 55.

45. "Progress Used to Maneuver Salyut." Aviation Week \& Space Technology, (30 0ct. 1978): 19.

46. "Cosmonauts Land After 140-Day Flight." Aviation Week \& Space Technology, (6 Nov. 1978): 21.

47. "Soviets to Check Salyut 6." Aviation Week \& Space Technology, (5 March 1979): 23.

48. "Cosmonauts Use Tanker Supply In Refurbishing Salyut Vehicle." Aviation Week \& Space Technology, (19 March 1979): 33.

49. "Soviets Reveal Orbital Lab Space Plans." Aviation Week \& Space Technology, (9 April 1979): 21.

50. "Propulsion Problem Stops Rendezvous, Soyuz Lands." Aviation Week \& Space Technology, (16 April 1979): 20. 
51. Covault, C. "Progress Docking Extends Intensive Salyut Activities." Aviation Week \& Space Technology, (9 July 1979): 20 .

52. Covault, C. "Radio Telescope Erected on Salyut 6." Aviation Week \& Space Technology, (13 Aug. 1979): 54-55.

53. "Soviet Doctors Credit Excercise for Cosmonaut's Good Health." Aviation Week \& Space Technology, (27 Aug. 1979): 21-22.

54. Soviets Launch Unmanned Soyuz." Aviation Week \& Space Technology, (21 Dec. 1979): 16.

55. "New Digest." Aviation Week \& Space Technology, (31 March 1980): 28 .

56. "New Manned Visit to Salyut 6 Expected." Aviation Week \& Space Technology, (7 April 1980): 21.

57. "Soyuz 35 Launched." Aviation Week \& Space Technology, (14 Apri1 1980): 20.

58. "Soviets Launch Surveillance Spacecraft." Aviation Week $\&$ Space Technology, (5 May 1980): 25.

59. "Cosmonauts Complete Salyut 6 Refueling." Aviation Week \& Space Technology, (19 May 1980): 22 .

60. "New Digest." Aviation Week \& Space Technology, (26 May 1980): 25 .

61. "Soviet Actions Suggest Long Soyuz 35 Mission." Aviation Week \& Space Technology, (2 June 1980): 16.

62. "Soviets F1y First Manned Soyuz T." Aviation Week \& Space Technology, (9 June 1980): 22-23.

63. Covault, C. "Soviets Developing 12-Man Space Station." Aviation Week \& Space Technology, (16 June 1980): 26-29. 
64. "Vietnamese Cosomonaut Flies on Soyuz." Aviation Week \& Space Technology, (28 July 1980): 17-18.

65. "New Soyuz Extends Salyut Time Limit." Aviation Week \& Space Technology, (4 Aug. 1980): 23.

66. "Soyuz 38 Return to Earth Planned." Aviation Week \& Space Technology, (29 Sept. 1980): 24.

67. "New Progress Docks With Salyut." Aviation Week \& Space Technology, (6 Oct. 1980): 19.

68. "Popov, Ryumen Readapt Well After Completion of Salyut Flight." Aviation Week \& Space Technology, (20 Oct. 1980): 26-27.

69. "Russians Launch Three Cosmonauts to Man Salyut 6." Aviation Week \& Space Technology, (8 Dec. 1980) 23.

70. "Crew of Soyuz Repairs Salyut." Aviation Week \& Space Technology, (15 Dec. 1980): 22-23.

71. "Soviets Launch Second Satellite Intercept in Nine Months." Aviation Week \& Space Technology, (9 Feb. 1981): 28-29.

72. "Soviets Test Another Ki11 Satellite." Aviation Week \& Space Technology, (23 March 1981): 22-23.

73. "Soviets Launch New Crew to Orbiting Space Station." Aviation Week \& Space Technology, (30 March 1981): 24.

74. "Soyuz 39 Crew Completes Flight to Salyut 6." Aviation Week \& Space Technology, (6 April 1981): 22 .

75. "Soyuz Cosmonauts Dock with Salyut 6." Aviation Week \& Space Technology, (25 May 1981): 23.

76. "Soyuz T Cosmonauts Return to Earth." Aviation Week \& Space Technology, (1 June 1981): 20 . 
77. "Soviets Press Research In Manned Space F1ight." Aviation Week \& Space Technology, (15 June 1981): 56.

78. "Soviets Destroy Salyut 6 Station." Aviation Week \& Space Technology, (2 Aug. 1982): 19.

79. "Salyut 7 Launched." Aviation Week \& Space Technology, (26 Apri1 1982): 19.

80. "Soviets Launch Crew to Salyut 7." Aviation Week \& Space Technology, (17 May 1982): 28.

81. "Progress Tanker Resupplies Salyut 7." Aviation Week \& Space Technology, (17 May 1982): 28.

82. "Soviets Orbit Shuttle Vehicle." Aviation Week \& Space Technology, (14 June 1982): 18-19.

83. Lenorovitz, J. M., "Soviet/French Crew Launched in Soyuz." Aviation Week \& Space Technology, (28 June 1982): 24-25

84. "Progress Unloading Completed." Aviation Week \& Space Technology, (26 July 1982): 27 .

85. "Soviets Launch Woman." Aviation Week \& Space Technology, (23 Aug. 1982): 21.

86. "Crew of Soyuz T-7 Prepares Return to Earth From Salyut." Aviation Week \& Space Technology, (30 Aug. 1982): 14-15.

87. "New Digest." Aviation Week \& Space Technology, (6 Sept. 1982): 53 .

88. "New Digest." Aviation Week \& Space Technology, (27 Sept. 1982): 24 .

89. "Soviets Orbit Three Satellies to Start Navstar-Like Project." Aviation Week \& Space Technology, (18 Oct. 1982): 15. 
90. "Soviets Launch Program 16 Supply Craft." Aerospace Daily, Vo1. 118, No. 2. 2 Nov. 1982, p. 11.

91. Covault, C. "Cosmonauts Land at Night in Storm." Aviation Week \& Space Technology, (20 Dec. 1982): 22-23.

92. "Soviets Launch Module to Enlarge Salyut 7." Aviation Week \& Space Technology, (7 March 1983): 19.

93. "Soyuz T-8 Rendezvous With Salyut Fails." Aviation Week \& Space Technology, (25 April 1983): 26.

94 "Soyuz Failure Iaid to Error in Rendezvous." Aviation Week \& Space Technology, (2 May 1983): 21.

95. "New Crew Manning Soviet Salyut 7." Aviation Week \& Space Technology, (4 July 1983): 26.

96. "Soviets Identify Cosmos as Space Station's Tug." Aviation Week \& Space Technology, (11 July 1983): 16.

97. "New Digest." Aviation Week \& Space Technology, (22 Aug. 1983): 25 .

98. "Soviets Return Material From Salyut 7." Aviation Week \& Space Technology, (29 Aug. 1983): 22.

99. "Space Station Module Re-Enters Atmosphere." Aerospace Daily, Vol 123, No. 13. 20 Sept. 1983, p. 97.

100. "Soviet Cosmonauts Survive Launch Explosion." Aviation Week \& Space Technology, (3 Oct. 1983): 20.

101. "Progress Launched." Aviation Week \& Space Technology, (24 Oct. 1983): 25.

102. "Soviets Confident of Soyuz Reentry Viability." Aviation Week \& Space Technology, (21 Nov. 1983): 22 . 
103. "News Digest." Aviation Week \& Space Technology, (28 Nov. 1983): 31 .

104. "News Digest." Aviation Week \& Space Technology, (13 Feb. 1984): 27.

105. "News Digest." Aviation Week \& Space Technology, (27 Feb. 1984): 28 .

106. "Salyut 7 Cosmonauts continue Repair EVA's." Aviation Week \& Space Technology, (14 May 1984): 20.

107. "Joint Soviet/Indian Crew Docks with Salyut Station." Aviation Week \& Space Technology, (9 April 1984): 19.

108. "News Digest." Aviation Week \& Space Technology, (16 April 1984), 31 .

109. "News Digest." Aviation Week \& Space Technology, (23 April 1984): 30 .

110. "Soviets Launch Progress 21." Aerospace Daily, Vol 127, No. 6. 9 May 1984, p. 52.

111. "Progress 21 Docks with Salyut 7 Space Station Complex." Aerospace Daily, Vo1 127, No. 7, 11 May 1984, p. 68.

112 "Soviets Launch Progressd 22." Aerospace Daily, Vol 127, No. 21. 30 May 1984, p. 164.

113 "Soviet Seem Ready For Manned Space Mission." Aerospace Daily, Vo1 128, No. 11. 17 July 1984, p. 82.

114 "Soyuz T-12 Docks With Solyut." Aviation Week \& Space Technology, (23 July 1984): p. 23 .

115 "Three Cosmonauts Return From Salyut 7." Aerospace Daily, Vol 128, No. 14. 31 July 1984, p. 106.

116. "Space Operations News Update." The News From United Press International, (18 July 1984). 
117. "Soviets Resupply Salyut, Provide EVA Details." Aviation Week \& Space Technology, (20 August 1984): p. 25.

118. "Cosmonauts Land After 237-Day Flight." Aviation Week \& Space Technology, (8 October 1984): p. 17.

119. Covault, C. "Soviets Initiating Program On Modular Space Station." Aviation Week \& Space Technology, (20 July 1981): 22 .

120. Covau1t, C. "NASA Studies Manned Space Station." Aviation Week \& Space Technology, (4 Aug. 1980): 19-21.

121. Covington, C. \& Rowland, R. D. "Space Operations Center: Next Goal for Manned Space Flight?" Astronautics and Aeronautics, (September 1980): 30-37.

122. "Washington Roundup." Aviation Week \& Space Technology, (28 Nov. 1983): 17.

123. Covault, C. "President Orders Start On Space Station." Aviation Week \& Space Technology, (30 Jan. 1984): 16-19.

124. Randolph, A. "Sale of Galaxy Channels Stabilizes Fees." Aviation Week \& Space Technology, (25 July 1983): 56-57.

125. Waltz, D. "Is There Business In Space? Outlook for Commercial Space Materials Processing." AIAA 81-0891, May 1981.

126. "Joint-Venture Pact Leads to Space Processing." Aviation Week \& Space Technology, (31 May 1982): 56-57.

127. "Prototype Plan Follows Space Processing Test." Aviation Week \& Space Technology, (19 July 1982): 26-27.

128. "Third F1ight to Initiate Materials Processing." Aviation Week \& Space Technology, (1 March 1982): 59-59.

129. Covault, C. "Payload Tied to Commercial Drug Goal." Aviation Week \& Space Technology, (31 May 1982): 51-57. 
130. Kolcum, E. H. "Industry Awaits Reagan Policy on Space Launches." Aviation Week \& Space Technology, (16 May 1983): 46-47.

131. "Electrophoresis Device Performs Well in Space." Chemical \& Engineering News, (16 May 1983): 7.

132. "Joint Action Prevents Loss of Drug Project on Shuttle.", Aviation Week \& Space Technology, (10 Sept. 1984): 105

133. "Industry Observer." Aviation Week \& Space Technology, (28 Nov. 1983): 15.

134. "25 KW Power System Reference Concept (Preliminary)." PM-001, Program Development Preliminary Design Office. George C. Marshall Space Flight Center, (Sept. 1979).

135. Richman, R. W. "Electrophoresis in Space." McDonnell Douglas Corporation Briefing, (1982).

136. "Medicine Sales Forecast at \$1 Billion." Aviation Week \& Space Technology, (25 June 1984): 52-56.

137. Dixon, B. "Life." OMNI, (Oct. 1980): 28 .

138. Johnson, R. D., \& Holbrow, C., ed. Space Settlements - A Design Study. NASA SP-413. Scientific \& Technical Information Office. 1977, p. 21.

139. "Space Operations News Update", The News From United Press International, $7 \mathrm{July} 1983$

140. B1uth, B. J. "Human Systems Interfaces For Space Stations." NAG 2-255. AIAA/NASA Space Systems Technology Conference; Costa Mesa, CA. June 5-7, 1984.

141. Bluth, B. J. "The Psychology and Safety of Weightlessness." 15th Symposium on Space Rescue and Safety. IAA-82-252, International Astronautical Federation, 1982 
142. Green, J. A. Piland, W. M., \& Strong R. V. "Some Aspects of Locomotion and Cargo Handling in Simulated Artificial

Gravity." AIAA-71-886, 1971.

143. Stone, R. W., Jr. \& Piland, W. M., \& Strong, R. V. "Potential Problems Related to Artifical Gravity and Weightlessness." NASA TND-4980. (Jan. 1960).

144. Johnson, R. D. \& Holbrow, C., ed. Space Settlements - A Design Study. NASA SP-413. Scientific and Technical Information Office. 1977. p. 22.

145. Singer, F. S. ed. Manned Laboratories in Space. New York: Springe-Verlag New York. pp. 16-18

146. Kramer, S.B. and Byers, R.A. "A Modular Concept for a Multi-Manned Space Station." Proceedings of The Manned Space Stations Symposium. Institute of the Aeronautical Sciences. New York, 1960. pp. 47-49.

147. "Space Shuttle Space Suit/Life Support System", United Technologies Hamilton Standard News Release. Windsor Locks CT. Contact: Mark Sullivan: (203) 623-1621 ext. 2268. March 1984 .

148. Ede1, P. 0., "Predicting The Possibility of Decompression Sickness or the Bends In Manned orbital F1ight." Contract T-726818, T74000. NASA. 10 May 1968.

149. Roth, E. M. "Medical Considerations in the Selection of Space Cabin Atmospheres." Atmosphere in Space Cabin and Closed Environments. Kammermeyer, K. ed. New York: Appleton-Century-Crofts, 1966. pp. 13-31.

150. Johnson, R. D. \& Holbrow, C. ed. Space Settlements - A Design Study. NASA SP-413. Scientific and Technical Information Office. 1977. pp. 12-13, 15-16.

151. 0'Neil1, G. K. The High Frontier. New York: Lillian Morrow Cad, 1977. pp. 108-133 
152. Roth, E. M. Space Cabin Atmosphere Part IV, Engineering Tradeoffs of One-Versus Two-Gas System, A Literature Review. Scientific \& Technical Information Office, 1967. pp. 20-25.

153. Kramer, S.B.. and Byers, R.A. "A Modular Concept for a Multi-Manned Space Station." Proceedings of the Manned Space Stations Symposium, Institute of the Aeronautical Sciences, New York. 1960. p. 42 .

154. Johnson, R. D. \& Holbrow, C., (ed). Space Settlements - A Design Study. NASA SP-413. Scientific and Technical Information office. 1977, pp. 39-49

155. O'Neill, G. K. "Maximum-Strength Minimum-Mass Structures." In "Space-Based Manufacturing from Non-Terrestrial Materials." Progress in Astronautics and Aeronautics. Vo1. 57. AIAA. New York, 1977. pp. 161-171.

156., Bluth, B. J. "The Benefits and Dilemmas of an International Space Station." Acta Astronautica, Vol II, No. 2 pp. 149-153, 1984 .

157. Johnson, R. D., \& Holbrow, C., ed. Space Settlements - A Design Study NASA SP-143, Scientific and Technical Information Office. 1977. p. 111.

158. Roark, R. J. and Young, W. C. Formulas for Stress and Strain: Fifth Edition. New York Mc Graw-Hill Book Company, 1975. pp. 448-453

159. Hoffner, J. W. Radiation and Shielding in Space. Academic Press, New York, 1967: p. 303-309.

160. Mann, P. "Beggs Forsees Shuttle in Private Hands." Aviation Week \& Space Technology, (June 25, 1984): 20-21.

161. "Two Firms Ready to Buy, Produce Shuttle Orbiters." Aviation Week \& Space Technology, (25 June 1984): 116-119.

162. "3M Seeks New Materials, Processes." Aviation Week \& Space Technology, (25 June 1984): 65-73. 
163. "John Deer Plans Space Iron Research." Aviation Week \& Space Technology, (25 June 1984): 74-77.

164. "Broad Spectrum of Business Involved in Space Commercialization." Aviation Week \& Space Technology, (25 June 1984): 63-64.

165. Covault, C. "unique Products, Technology Spawn Space Business." Aviation Week \& Space Technology, (25 June 1984): 40-51

166. "Space Commerce Barriers To Be Eased." Aviation Week \& Space Technology, (25 June 1984): 18-19.

167. Protter, M. H., \& Movrey, Jr., C. B., Calculus with Analytic Geometry. Addison Wesley Publishing Company, 1970.

168. Roark, R. J., \& Young, W. C. Formulas for Stress and Strain. 5th Edition. New York. McGraw-Hill. 1975. p. 453.

169. Smith, S. E., Slakover, M., and Justic, H. K. Calculus. London. John Wiley \& Sons, 1938. 
APPENDIX A

SPACE STATION/HABITAT CONCEPTS

TABLE 11 HISTORICAL LISTING OF MANNED SATELLITE DESIGNS

1923 Herman Oberth - Conceptual description only, no drawings. First serious proposal. Suggested means of supplying artificial gravity and building in orbit.

1928 Baron Guido Von Pirquet - Conceptual design only. First concept embodying system of mutually beneficial satellites.

1928 Hermann Nordung - First design set on paper. Heavy rotating satellite with solar powered generatores. Observatory positioned away from main structure.

1929 Hermann Oberth - "Spaceport" and "Fixed-Orbit Station". Designs illustrated extreme differences between structures designed for orbit and those designed for earth.

1929 Hermann Oberth - "Asteroid-Mounted Space Telescope". Suggested use of asteroid as a basic satellite structure. Orbit change produced by reaction electrodes.

1948 Ross \& Smith - Twenty-four man satelite for observation, communication and research. Rotating station provided artificial gravity while movable arm permitted entrance and exit.

1951 Wherner von Braun - "Space Wheel". Concept originated in connection with "Mars Project", Originally 20-segment wheel, later changed to circular shaped rim. Largest and widest known.

1951 H. H. Koelle - This design was portion of paper taking into consideration the tie-in with orbital carrier vehicle with the objective of mininum cost. Essentially ring-shaped with spherical and cylindrical segments.

1953 K. W. Gatland - General presentation on fabrication.

1954 Krafft Ehricke - "Four Man Orbital Station". Concept included design of "Astrotug" for assembling station segments.

1959 Boeing Aircraft Company - Research station utilizing upper stage components and housing 12 men. 


\section{TABLE 11 (CONTINUED)}

1959 Krafft Ehricke - "Outposts". Conceptual presentation of satellites based on Atlas-type launch vehicle with growth potential to large stations.

1959 Koelle, H. H., Engler, F. E. and Massey, J. W. "Design Criteria and Their Application to Economical Manned Stations". 
TABLE 12 ADDITIONAL MANNED SATELLITE DESIGNS

1895 Konstantin Tsiolkovsky - Space station concept in science fiction story. Given from a technical viewpoint.

1903 Konstantin Tsiolkovsky - Included rotation for artificial gravity, the use of solar energy and a greenhouse for a closed economy into 1895 design.

1929 J. D. Bernal - Described cosmic ark for interstellar travel. Capable of supporting 10,000 people. Built from astroidal material.

1952 L. R. Shepherd - "Noah's Ark". Vehicle for interstellar travel. Oblate spheroid with artificial gravity.

1960 Freeman Dyson - Proposed habitats in heliocentric orbits which would form complete sphere about sun. This "Dyson Sphere" would use sun's energy so completely only infrared energy would escape.

1960 Kramers, S. B. and Byers, R. A. - A modular space station and support system concept presented to the IAS Manned Space Station Symposium in 1960. The station consisted of cylinder and spheres and was rotated to provide $1 \mathrm{~g}$ at the living area radius.

1963 Dandridge Cole - Proposed hollowing out asteroids for use as observation posts and farming.

1974 Gerard O'Neil1 - "Island I". A stubby cylinder 1500 feet in diameter, patterned after "Bernal Sphere".

"Island III" - A four mile diameter by twenty mile long space city.

19751975 NASA/Ames Study Group - "Stanford Torus". Torus with approximately four mile circumference and a 400 foot minor radius. Sized for $1 \mathrm{~g}$ at one $\mathrm{rpm}$, capable of supporting 10,000 people.

1975 Krafft Ehricke - "Astropolis" and "Androce11". Large, self-contained, rotating complexes housing many inhabitants. Capable of travelling throughout and beyond solar system and duplicating other world environments in special modules.

1977 NASA/Ames Study Group - "Crystal Palace". 


\section{APPENDIX B \\ SPACE STATION MISSIONS}

TABLE 13 SKYLAB MISSIONS

DATE LAUNCHED

DATE RETURNED

1. 14 May 1977

12 July 1979

2. 25 May 1973

22 June 1973

3. 28 July 1973

25 Sept. 1973

4. 16 Nov. 1973

$8 \mathrm{Feb} .1974$
VEHICLE

TYPE \& NUMBER

Skylab

Skylab I

(Apo11o)

Skylab II

(Apollo)

Skylab III

(Apo11o)
CREW

Pete Conrad Joseph Kerwin Paul Weitz

Alan Bean Jack Lousman Owne Barriott

Gerald Carr Edward Gibson William Pogue 


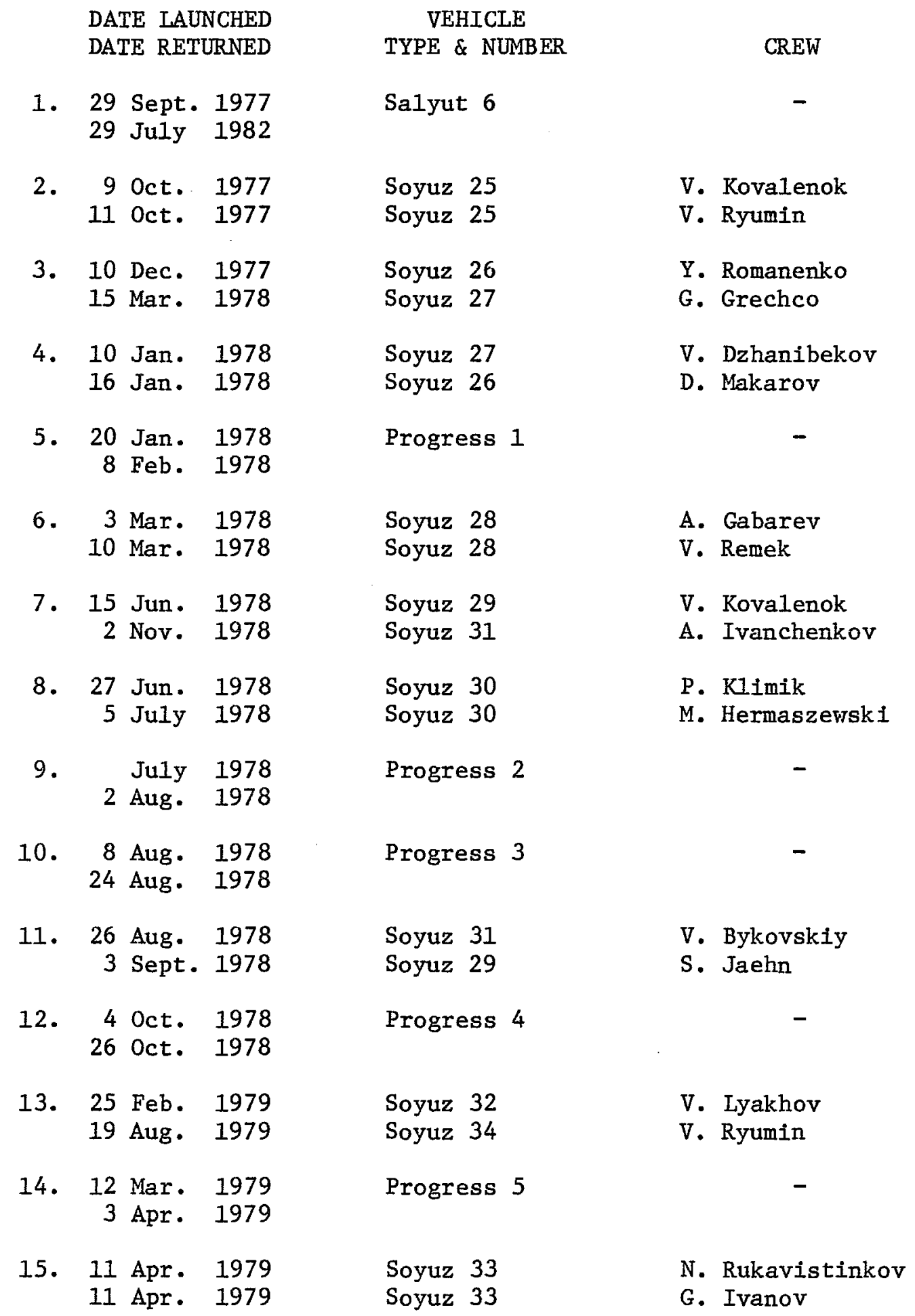


TABLE 14 (CONTINUED)

DATE LAUNCHED

DATE RETURNED

16. 13 May 1979

8 June 1979

17. 6 June 1979

13 June 1979

18. 28 June 1979

$20 \mathrm{July} 1979$

19. 16 Dec. 1979

26 March 1980

20. 27 Mar. 1980

26 Apr. 1980

21. 9 Apr. 1980

11 Oct. 1980

22. 27 Apr. 1980

22 May 1980

23. 26 May 1980

3 June 1980

24. 5 June 1980

9 June 1980

25. 23 July 1980

30 July 1980

25. 29 June 1980

19 July 1980

26. 18 Sept. 1980

26 Sept. 1980

27. 28 Sept. 1980

9 Dec. 1980

28. 27 Nov. 1980

$10 \mathrm{Dec} .1980$

29. 24 Jan. 1981

21 March 1981
VEHICLE

TYPE \& NUMBER

CREW

Progress 6

Soyuz 34

Soyuz 32

Progress 7

Soyuz $\mathrm{T}-1$

Progress 8

Soyuz 35

Soyuz 37

L. Popov

V. Ryumin

Progress 9

Soyuz 36

Soyuz 35

Soyuz $\mathrm{T}-2$

Soyuz T-2

Soyuz 37

Soyuz 36

Progress 10

Soyuz 38

Soyuz 38

Y. Romanenko

A. T. Mendez

Progress 11

Soyuz $\mathrm{T}-3$

Soyuz T-3

L. Kizim

G. Strekalov
B. Farkas

Y. Ma1yshen

V. Aksenov

V. Gorbatko

P. Tuan
V. Kubasov

Progress 12 
TABLE 14 (CONTINUED)

DATE LAUNCHED

DATE RETURNED

30. 12 Mar. 1981 30 May 1981

31. 22 March 1981 30 March 1981

32. 14 May 1981

22 May 1981

33. 19 April 1982

34. 13 May 1982

10 Dec. 1982

35. 24 June 1982

2 July 1982

36. 19 Aug. 1982

21 Aug. 1982

37. 23 May 1982

6 June 1982

38. 10 JuIy 1982

14 Aug. 1982

39. 19 Sept. 1982

11 Oct. 1982

40. 31 Oct. 1982

13 Dec. 1982

41. 21 Apri1 1983

22 April 1983

42. 27 June 1983

23 Nov. 1983

43. 2 March 1983

23 Aug. 1983

19 Sept. 1983
VEHICLE

TYPE \& NUMBER

CREW

Soyuz $\mathrm{T}-4$

Soyuz T-4

Soyuz 39

Soyuz 39

Soyuz 40

Soyuz 40

Salyut 7

Soyuz T-5

Soyuz T-7

Soyuz T-6

Soyuz T-6

Soyuz T-7

Soyuz $T=5$

Progress 13

Progress 14

Progress 15

Progress 16

Soyuz T-8

V. Titov

A. Serebrov

G. Strekalov

Soyuz T-9

Soyuz T-9

V. Lyakhov

A. Aleksandrov
A. Berezovoy

V. Dzanibekov

A. Ivantichekov

J. Chretien

L. Popov

A. Serebrov

S. Sovitskaya

Cosmos 1443

Cosmos 1443 Reentry Vehicle

Cosmos 1443 Station tug 
TABLE 14 (CONTINUED)

DATE IAUNCHED

DATE RETURNED

44. 17 Aug. 1983

18 Sept. 1983

45. 20 Oct. 1983

16 Nov. 1983

46. 8 Feb. 1984

2 Oct. 1984

47. 21 Feb. 1984 March 1984

48. 2 April 1984

11 April 1984

49. 15 April 1984

7 May 1984

50. 9 May 1984

26 May 1984

51. 28 May 1984

15 July 1984

52. 17 July 1984

29 July 1984

53. 14 Aug. 1984
VEHICLE

TYPE \& NUMBER

Progress 17

Progress 18

Soyuz $T-10$

L. Kizim

V. Solover

0 . Atkov

Progress 19

Soyuz T-11

Soyuz $T-10$

Y. Malyshev

G. Stickalov

R. Sharma
Progress 20

Progress 21

Progress 22

Soyuz T-12

Soyuz T-12

Progress 23
V. Dzanibe1ces

I. Volk

S. Savitskaya 


\section{APPENDIX $C$}

SHAPE EQUATIONS DEVELOPMENT

In developing the basic shape equations, various methods were used. Where the equation is obvious, or common knowledge, no explanation or derivation is presented. However, when a specific approach is used, it will be identified and, in the first use, explained.

Equations are developed for each of the following parameters:

Volume
$\begin{aligned} & \text { - Total enclosed volume } \\ & \text { Habitable Volume - That volume which lies within the region } \\ & \text { bounded by the ratio } \Delta \mathrm{g} / \mathrm{g}\end{aligned}$
$\begin{array}{ll}\text { Surface Area } & \text { - Area of shell } \\ \text { Projected Area } & \text { - Area defined by maximum habitable volume } \\ \text { width times its circumference }\end{array}$
$\begin{array}{ll}\text { Floor Area } & \text { That floor space which has a minimum } \\ & \text { ceiling height of two meters. }\end{array}$


I. Sphere

A. Volume

$$
V_{s}=\frac{4}{3} \pi R^{3}
$$

eq 9

B. Habitable Volume

From the Theorem of Pappus, the volume of revolution is defined by equation 10 or 11 .

$$
V_{s}=2 \pi \int_{F} \int_{y} d A
$$

$$
V_{S}=2 \pi \iint x d A
$$

If that volume is revolved about the $\mathrm{x}$ or $\mathrm{y}$ axis, respectively.

Using equation 10 and adding the limits of integration yields. 


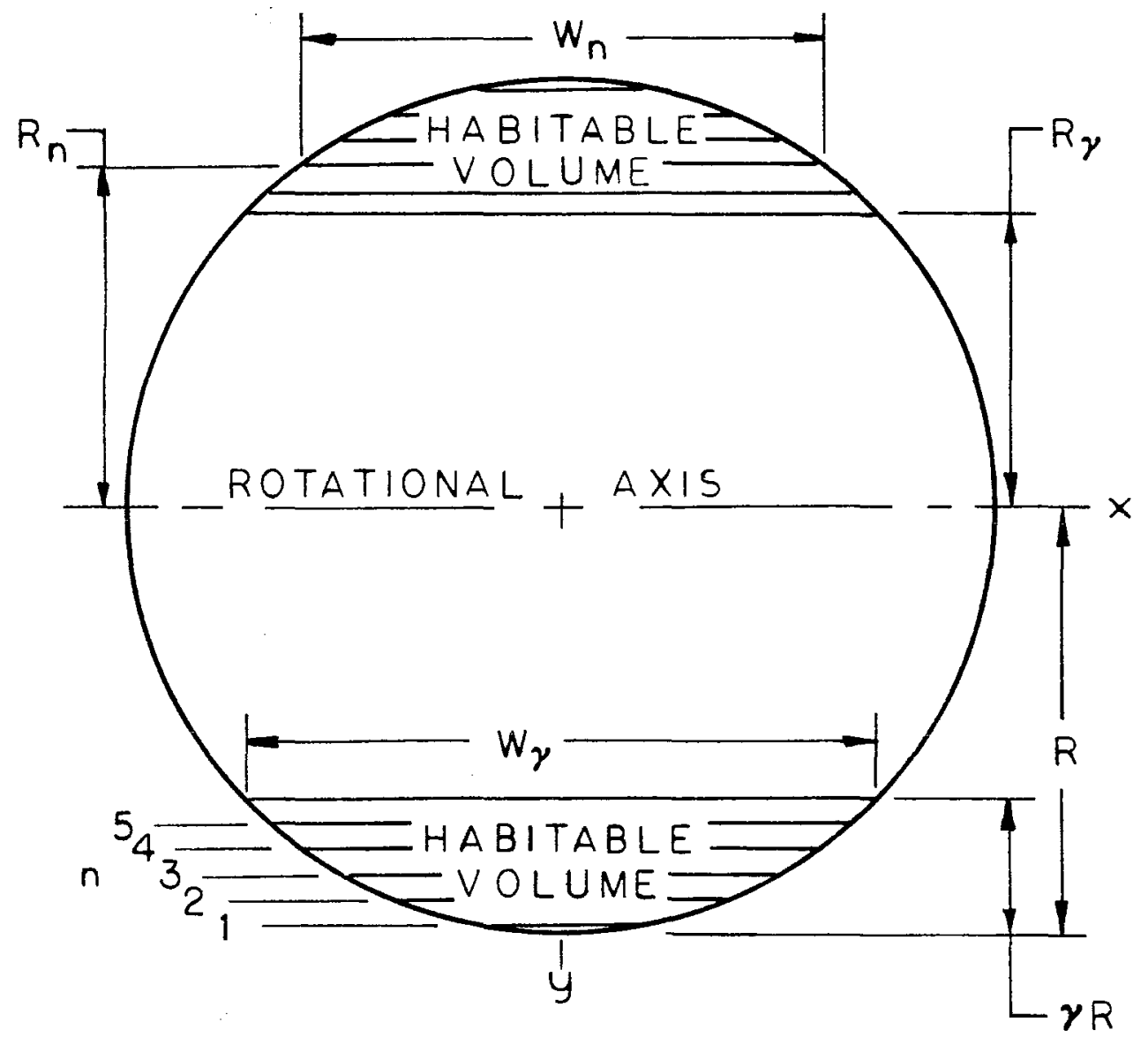

Figure 40. Spherical Habitat Characteristics 
110

$$
H V_{S}=4 \pi \int_{0}^{R\left(2 \gamma-\gamma^{2}\right)^{1 / 2}} \int_{R(1-\gamma}^{\sqrt{R^{2}-\gamma^{2}}} y d y d x \quad \text { eq } 12
$$

Integration by $\mathrm{y}$ and evaluating at $y_{1}$ and $y_{2}$ results in

$$
H V_{S}=2 \pi \int_{0}^{R\left(2 \gamma-\gamma^{2}\right)^{/ 2}} \cdot\left[R^{2}\left(2 \gamma-\gamma^{2}\right)-x^{2}\right] d x \text { eq } 13
$$

The final result is found by integrating by $x$ and evaluating at $x_{1}$ and $x_{2}$. This is shown in equation 14 .

$$
H V_{s}=\frac{4 \pi R^{3}}{3}\left(2 \gamma-\gamma^{2}\right)^{3 / 2} \quad \text { eq } 14
$$

C. Surface Area

$$
S A_{S}=4 \pi R^{2}
$$

$$
\text { eq } 15
$$

D. Projected Area

$$
P A_{s}=2 \pi R_{\gamma} W_{\gamma}
$$

eq 16 
Where

$$
R_{r}=R(1-r)
$$

eq 17

and

$$
W_{Y}=2 R\left(2 r-r^{2}\right)^{1 / 2}
$$

eq 18

therefore

$$
P A_{S}=4 \pi R^{2}(1-\gamma)\left(2 \gamma-\gamma^{2}\right)^{1 / 2}
$$

The maximum projected area for a sphere is produced when $\gamma$ is equal to 0.2929.

F. Floor Area

The total number of floors available in a particular sphere is determined by dividing the habitable volume height, namely $\gamma R$, by the value set for floor spacing. For the 
purpose of this study, this value has been set equal to three meters. Therefore, the radius, as a function of the number of floors in any spherical structure is given by equation 20 .

$$
R=\frac{3 N+1}{r}
$$

Total floor area is now determined by the summation of individual floor widths times the circumference over the total number of floors, as shown in equation 21.

$$
F A_{S}=2 \pi \sum_{n=1}^{N} R_{n} W_{n}
$$

Where

$$
R_{n}=R-3 n+2
$$

and

$$
W_{n}=2[R(6 n-4)-(3 n-2)]
$$


Following substitution of eq 22 and el 23 into eq 21 , the
floor area, as a function of spherical radius and floor
number, is given by eq 24 .
$F A_{S}=4 \pi \sum_{n=1}^{N}[R-3 n+2]\left[R(6 n-4)-(3 n-2)^{2}\right]^{1 / 2}$ eq 24

II. Dumbbel1, Multiple Dumbbell and Beaded Torus

Equations for the multiple dumbell and beaded torus are identical

to those of the dumbbell except they contain an added multiplier,

$M$, for the number of dumbbell pairs. For the multiple dumbbel1, M may assume any real integer. However, for the beaded torus, is a discontinuous torus formed by individual spheres. In this instance, $M$ is defined by

$$
M=I_{n}+\left[\frac{\pi}{2 \sin ^{-1} \eta}\right]+1
$$

and the radius necessary to accommodate $M$ dumbbell pairs in a beaded torus is

$$
R=\frac{\eta R}{\sin \frac{\pi}{2 M}}
$$

Due to those simililarities, only the dumbbell equations will be explained.

A. Volume

$$
V_{d}=\frac{8}{3} \pi \eta^{3} R^{3}
$$




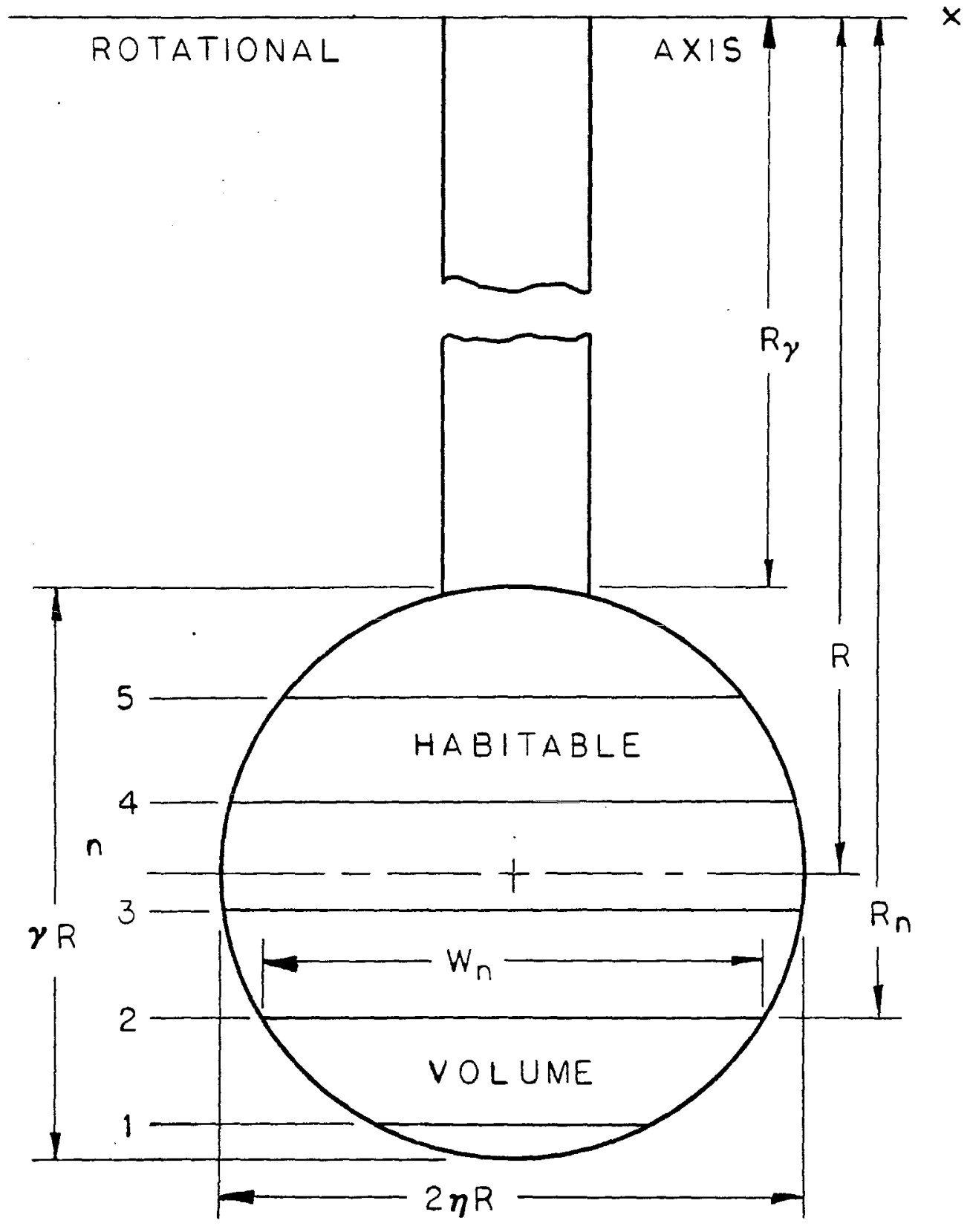

Figure 41. Dumbbe11, Beaded Torus Habitat Characteristics 
115

B. Habitable Volume

By using the disk method of integration, habitable volume is defined by

$$
H V_{d}=\pi \int_{a}^{b}[f(x)]^{2} d x \quad \text { eq } 28
$$

where

$$
f(x)=\left[\eta^{2} R^{2}-(x-R(1-\eta))^{2}\right]^{1 / 2} \quad \text { eq } 29
$$

giving

$$
[f(x)]^{2}=2 x R(1-\eta)-R^{2}(1-2 \eta)-x^{2} \quad \text { eq } 30
$$

By substituting equation 30 into equation 28 , adding the limits of integration and remembering there are two volumes for each dumbbell, habitable volume is given by the integral

$$
H V_{d}=2 \pi \int_{R(1-y)}^{R}\left[2 \times R(1-\eta)-R^{2}(1-2 \eta)-x^{2}\right] d x \quad \text { eq } 31
$$

Following integration and evaluation at the upper and lower limits, habitable volume, as a function of rotational radius, aspect ratio and gravity gradient, is

$$
\begin{aligned}
H V_{d}= & \frac{2 \pi R^{3}}{3}\left\{3(1-\eta)\left(2 r-\gamma^{2}\right)-3(1-2 \eta)\right. \\
& \left.-Y\left[3(1-\gamma)+\gamma^{2}\right]\right\}
\end{aligned}
$$


116

Recalling that for the dumbbell, $\gamma$ and $R$ are chosen such that $\gamma \geq 2 \eta$, the habitable volume becomes

$$
H V_{d}=\frac{8}{3} \pi \eta^{3} R^{3}
$$

eq 33

C. Surface Area

$$
S A_{d}=8 \pi \eta^{2} R^{2}
$$

eq 34

D. Projected Area

$$
P A_{d}=2 \pi W_{\gamma}^{2}
$$

eq 35

where

$$
W_{\gamma}=\left[\eta^{2} R^{2}-(\eta R-\gamma R)^{2}\right]^{\frac{1}{2}}
$$

eq 36

therefore

$$
P A_{d}=2 \pi R^{2}\left(2 \eta \gamma-\gamma^{2}\right)
$$

eq 37

again, since $\gamma=2 \eta$, the maximum value of $W_{\gamma}$ is $R \eta_{3}$ giving the maximum projected area of

$$
P A_{d}=2 \pi \eta^{2} R^{2}
$$

eq 38 


\section{E. Floor Area}

For the dumbbell, and every other two-radii shape, the minor radius is given as

$$
r=\frac{3 N+1}{2}=\eta R
$$

and the floor area is

$$
F A_{d}=2 \pi \sum_{n=1}^{N} \frac{W_{n}^{2}}{4}
$$

where

$$
W_{n}=2[\eta R(6 n-4)-(3 n-2)]^{\frac{1}{2}}
$$

for $\mathrm{R} \eta \geq \mathrm{R}-1$, and

$$
W_{n}=2\left[6 \eta n R-9 n^{2}\right]^{1 / 2}
$$

when $\mathrm{R} \eta \leq \mathrm{R}-1$. This change occurs because the upper floors' widths are determined by their 2-meter clearance rather than their actual width. To accommodate this change in $W_{n}$, a new term, $N 1$ is defined,

$$
N I=\operatorname{Int}\left[\frac{\eta R-2}{3}+1\right]
$$

and the summation is carried out in two steps, as illustrated on the following page. 
118

$$
\begin{aligned}
F A_{d}=2 \pi & \left\{\sum_{n=1}^{N 1}\left[\eta R(6 n-4)-(3 n-2)^{2}\right]\right. \\
& \left.+\sum_{n=N 1+1}^{N}\left[6 \eta n R-9 n^{2}\right]\right\}
\end{aligned}
$$$$
\text { eq } 44
$$

III. Cylinder

A. Volume

$$
V_{c}=\frac{4 \pi R^{3}}{3}\left(1+\frac{3}{4} \alpha\right) \quad \text { eq } 45
$$

B. Habitable Volume

Using the Theorem of Pappus, habitable volume for a cylinder with spherical end caps is found by using 46 .

$$
\begin{aligned}
H V_{C} & =4 \pi \int_{0}^{\frac{R \alpha}{2}} \int_{R(1-x)}^{R} y d y d x \\
& +4 \pi \int_{\frac{R \alpha}{2}}^{R\left[\alpha+\left(2 x-x^{2}\right)^{\frac{T}{2}}\right]} \int_{R(1-v)}^{\left[R^{2}-\left(x-\frac{R \alpha}{2}\right)^{2}\right]^{\frac{1}{2}}} y d y d x \text { eq } 46
\end{aligned}
$$

Integrating by $\mathrm{y}$ and evaluating at $\mathrm{R}_{1}=0$ and $\mathrm{R}_{2}=\mathrm{R} \alpha / 2$ yields

$$
\begin{aligned}
& H V_{c}=2 \pi \int_{0}^{\frac{R \alpha}{2}} R^{2}\left(2 \gamma-\gamma^{2}\right) d x \\
& +i \pi \int_{\frac{R \alpha}{2}}^{R\left[\frac{\alpha}{2}+\left(2 r-y^{2}\right)^{1 / 2}\right.}\left\{R^{2}\left[\left(2 \gamma-\gamma^{2}\right)-\frac{\alpha^{2}}{4}\right]-R \alpha x-x^{2}\right\} d x \text { eq } 47
\end{aligned}
$$

This result is now integrated by $x$ to obtain the habitable volume as a function of radius, gravity gradient and aspect ratio, as shown in equation 48 . 


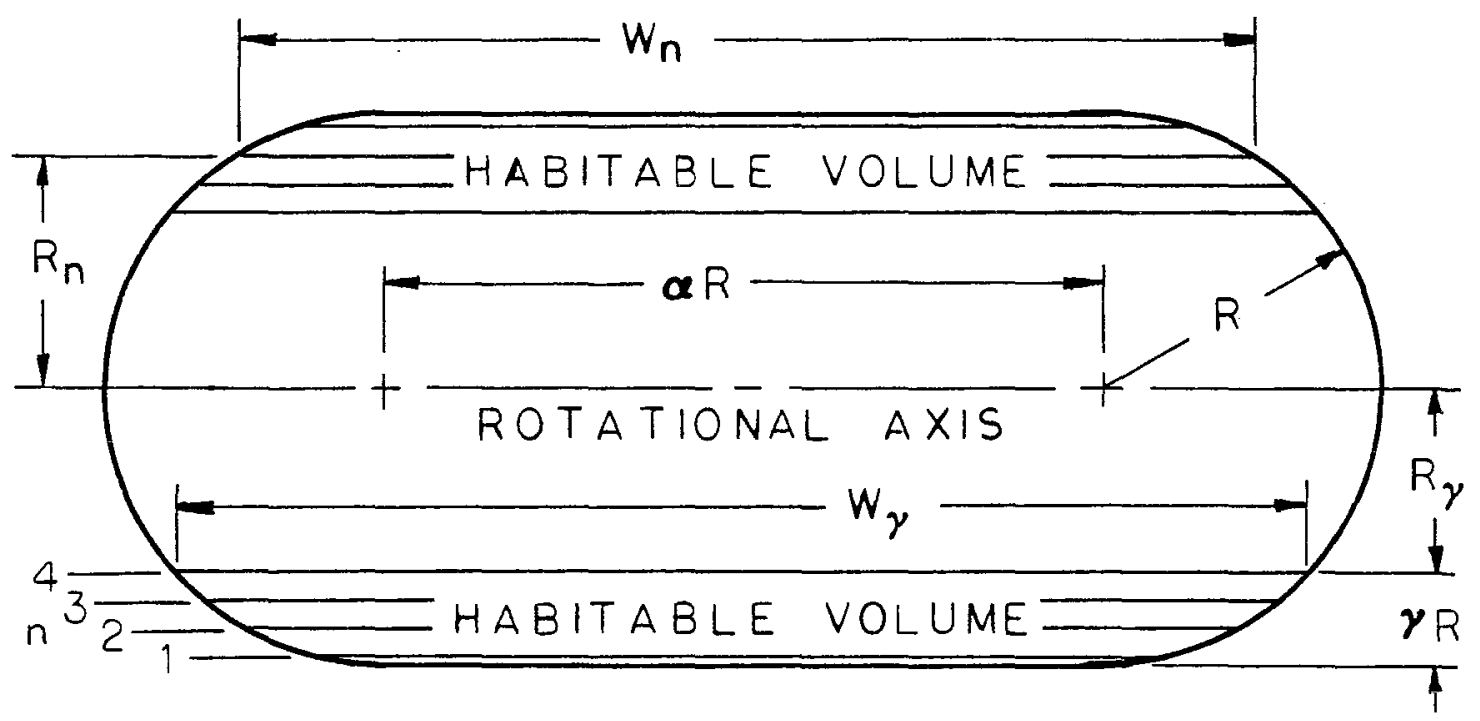

Figure 42. Cylindrical Habitat Characteristics 
120

$$
H V_{C}=\frac{4}{3} \pi R^{3}\left[\left(2 \gamma-\gamma^{2}\right)^{3 / 2}+\frac{3 \alpha}{4}\left(2 \gamma-\gamma^{2}\right) \quad \text { eq } 48\right.
$$

C. Surface Area

$$
S A_{C}=4 \pi R^{2}\left(1+\frac{\alpha}{2}\right)
$$

eq 49

D. Projected Area

$$
P A_{C}=2 \pi R_{\gamma} W_{\gamma} \quad \text { eq } 50
$$

Recall that $\mathrm{R}_{\gamma}=\mathrm{R}(1-\gamma)$ and $\mathrm{W}=\mathrm{R}\left(2 \boldsymbol{\gamma}-\boldsymbol{\gamma}^{2}\right)^{\frac{1}{2}}$ from equations 17 and 18. Therefore, $R_{\gamma}$ for the cylinder is the same as for the sphere and $\mathrm{w}_{\gamma}$ is increased by the cylinder barrel length, $\alpha$. With these substitutions into equation 50 , the projected area becomes

$$
P A_{C}=4 \pi R^{2}(1-\gamma)\left[\left(2 \gamma-\gamma^{2}\right)^{1 / 2}+\frac{\alpha}{2}\right] \quad \text { eq } 51
$$

For a cylinder with spherical end caps, the maximum projected area depends on the value of $\gamma$. To be consistent with the sphere, a value of 0.2929 shall be used.

E. Floor Area

$$
F A_{c}=4 \pi \sum_{n=1}^{N} R_{n} W_{n} \quad \text { eq } 52
$$


Where $R_{n}$ and $W_{n}$ are obtained from equations 22 and 23 .

Therefore, equation 52 can be written as

$$
\begin{aligned}
F A_{c}=4 \pi \sum_{n=1}^{N} & (R-3 n+2)\{C R(6 n-4)-(3 n-2)]^{1 / 2} \\
& \left.+\frac{R \alpha}{2}\right\}
\end{aligned}
$$

IV. Torus and Cylindrical Torus

A. Volume

1. Circular Cross-Section Torus

$$
V_{t}=2 \pi^{2} \eta^{2} R^{3}
$$

eq 54

2. Cylindrical Cross-Section Torus

$$
V_{c t}=2 \pi^{2} \eta^{2} R^{3}\left(1+\frac{2 \alpha}{\pi \eta}\right)
$$

B. Habitable Volume

The habitable volume of a torus can be found using the shell method of integration for a volume of revolution. This is expressed as

$$
V_{t}=2 \pi \int_{a}^{b} x[f(x)] d x
$$

where $f(x)$ for the circular torus is

$$
f(x)=\left[\eta^{2} R^{2}-(x-R)^{2}\right]^{1 / 2}
$$




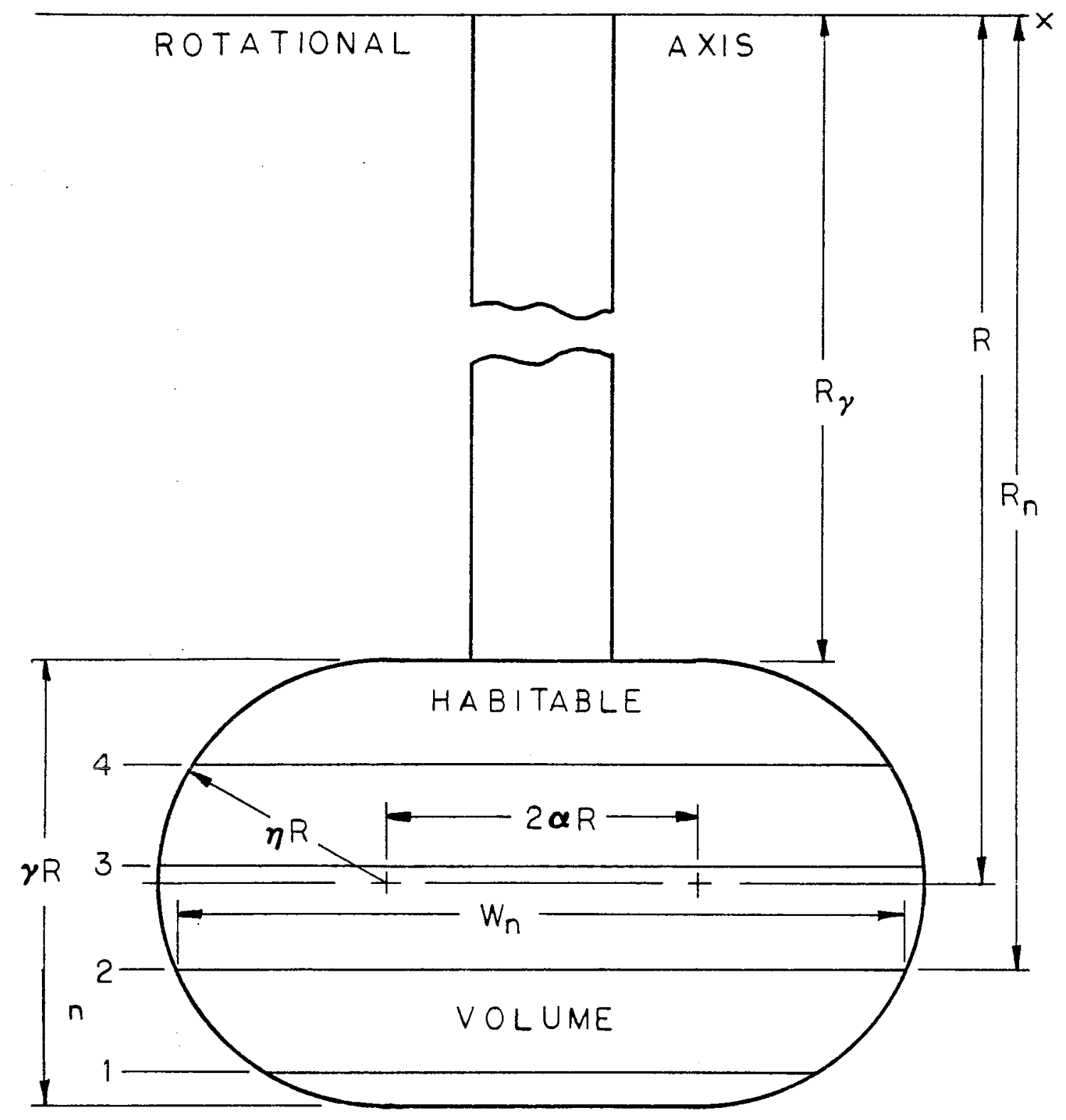

Figure 43. Toroidal Habitat Characteristics 
123

Using the substitutions $u=x-r$ and $d u=d x$, equation 56 becomes

$$
V_{t}=4 \pi \int_{u_{1}=R[\eta(1-r)-r]}^{u_{2}=R \eta}(u+R)\left[\eta^{2} R^{2}-u^{2}\right] d u \quad \text { eq } 58
$$

Expanding this, the integral becomes

$$
\begin{aligned}
V_{t}=4 \pi & {\left[\int_{R[\eta(1-\gamma)-r]}^{R} u\left[\eta^{2} R^{2}-u^{2}\right]^{1 / 2} d u\right.} \\
& +\int_{R[\eta(1-r)-r)}^{\eta R} R\left[\eta^{2} R^{2}-u^{2}\right]^{1 / 2} d u
\end{aligned}
$$

eq 59

Integrating by $\mathrm{u}$ and evaluating yields

$$
\begin{aligned}
& V_{t}=\frac{2 \pi R^{3}}{3}\left\{2\left[2 \eta\left(\gamma-\gamma^{2}\right)+\eta^{2}\left(2 \gamma-\gamma^{2}\right)-v^{2}\right]^{3 / 2}\right. \\
& +3 \eta^{2} \pi-3\left[2 \eta\left(\gamma-\gamma^{2}\right)+\eta^{2}\left(2 \gamma-\gamma^{2}\right)-\gamma^{2}\right]^{1 / 2} \quad \text { eq } 60 \\
& \left.-3 \eta^{2} \sin ^{-1} \frac{(\eta(1-v)-v)}{\eta}\right\}
\end{aligned}
$$

For the cylindrical torus, $f(x)$ is given by

$$
f(x)=\frac{R_{\alpha}}{2 \eta}+\left[\eta_{2} R^{2}-(x-R)^{2}\right]^{1 / 2} \quad \text { eq } 61
$$

and, since the volume of a cylindrical shell of height $\alpha R /(2-\eta)$ is

$$
V=\frac{\pi \alpha \Omega^{3}}{2 \eta}\left(1+\eta^{2}\right)\left(2 \gamma-\gamma^{2}\right)
$$

eq 62 
124

The volume of the cylindrical torus can be found by adding

this term to equation 61 , yielding

$$
\begin{aligned}
V_{C t}= & \frac{2 \pi R^{3}\left\{2 \eta\left(r-r^{2}\right)+\eta^{2}\left(2 r-r^{2}\right)-r^{2}\right]^{3 / 2}}{3}\left\{\frac{3}{2}\left[2 \eta\left(r-r^{2}\right)+\eta^{2}\left(2 r-r^{2}\right)-r^{2}\right]^{1 / 2}\right. \\
& \left.-\frac{3}{2} \eta \sin ^{-1} \frac{\eta(1-r)-r}{\eta}+\frac{3 \eta^{2} \pi}{4}+\frac{3 \alpha}{2 \eta}(1+\eta)^{2}\left(2 r-r^{2}\right)\right\}^{\text {eq }} 63
\end{aligned}
$$

Again, as was stated for the dumbbell, the design of this

type of structure is such that the entire cross-section falls

within the bounds of . Therefore, by substituting

$2 \eta /(1+\eta)$ for in both equations 60 and 63 , they reduce to equations 54 and 55 respectively.

C. Surface Area

1. Circular Torus

$$
S A_{t}=4 \pi^{2} \eta R^{2}
$$

eq 64

2. Cylindrical Torus

$$
S A_{C t}=4 \pi^{2} \eta R^{2}\left(1+\frac{\alpha}{\eta}\right)
$$

eq 65

D. Projected Area

!. Circular Torus

$$
P A_{t}=4 \pi \eta R^{2}
$$

eq 66 
2. Cylindrical Torus

$$
R_{c t}=4 \pi \eta R^{2}\left(1+\frac{\alpha}{2 \eta}\right)
$$

eq 67

E. Floor Area

1. Circular Torus

The floor area for a circular torus is given by equation 68

$$
F A_{t}=2 \pi \sum_{n=1}^{N} R_{n} W_{n}
$$

where

$$
R_{n}=R(1+n)-3 n+2
$$

eq 69

and, as was true for the dumbbell, $\mathrm{W}_{\mathrm{n}}$ has two values

$$
W_{n}=2\left[R(6 n-4)-(3 n-2)^{2}\right]^{1 / 2}
$$

for floors beyond the radius $\mathrm{R}=\mathrm{I}, \cdots \mathrm{and}=\cdots$

$$
W_{n}=2\left[6 \eta n R-9 n^{2}\right]^{1 / 2}
$$

for floors of radius less than $R+1$. Combining equations 68-71, and recalling that $W_{N} 1$ applies for all $\mathrm{n}<N 1$, where $\mathrm{N} 1=\operatorname{Int}\left(\frac{\eta \mathrm{R}-2}{3}+1\right)$, the floor area can be found by evaluating equation 68 . 
126

$$
\begin{aligned}
F A_{t}= & 4 \pi\left\{\sum_{n=1}^{N 1}[R(1+\eta)-3 n+2]\left[R(6 n-4)-(3 n-2)^{2}\right]^{\frac{1}{2}}\right. \\
& \left.+\sum_{n=N 1+1}^{N}[R(1+\eta)-3 n+2]\left[6 \eta n R-9 n^{2}\right]^{1 / 2}\right\}
\end{aligned}
$$

2. Cylindrical Torus

The floor area for the cylindrical torus is similar to that of the circular torus, except for the added term $R / 2$ in the expression for $W_{n}$. This gives

$$
\begin{aligned}
F A_{C t} & =4 \pi\left\{\sum_{n=1}^{N 1}[R(1+\eta)-3 n+2]\left[R(6 n-4)-(3 n-2)^{2}+\alpha R\right]\right. \\
+ & \left.\sum_{n=N 1+1}^{N}[R(1+\eta)-3 n+2]\left\{\left(6 \eta n R-9 n^{2}\right)^{\frac{1}{2}}+\alpha R\right]\right\}
\end{aligned}
$$

V. Crystal Palace

A. Volume

The volume of the "Crystal Palace" is determined by using the theorem of Pappus, as cited before.

$$
V_{c \rho}=2 \pi \bar{R} A
$$

eq 74

where $A$ is the cross-sectional area, given by

$$
A=\operatorname{L\eta }^{2} R^{2}\left[\pi\left(N+\frac{1}{4}\right)+2 N\right] \quad \text { eq } 75
$$

with the mean radius, $\bar{R}$ defined as

$$
\bar{R}=R\left(1+\frac{3}{2} L \eta\right)
$$

eq 76 


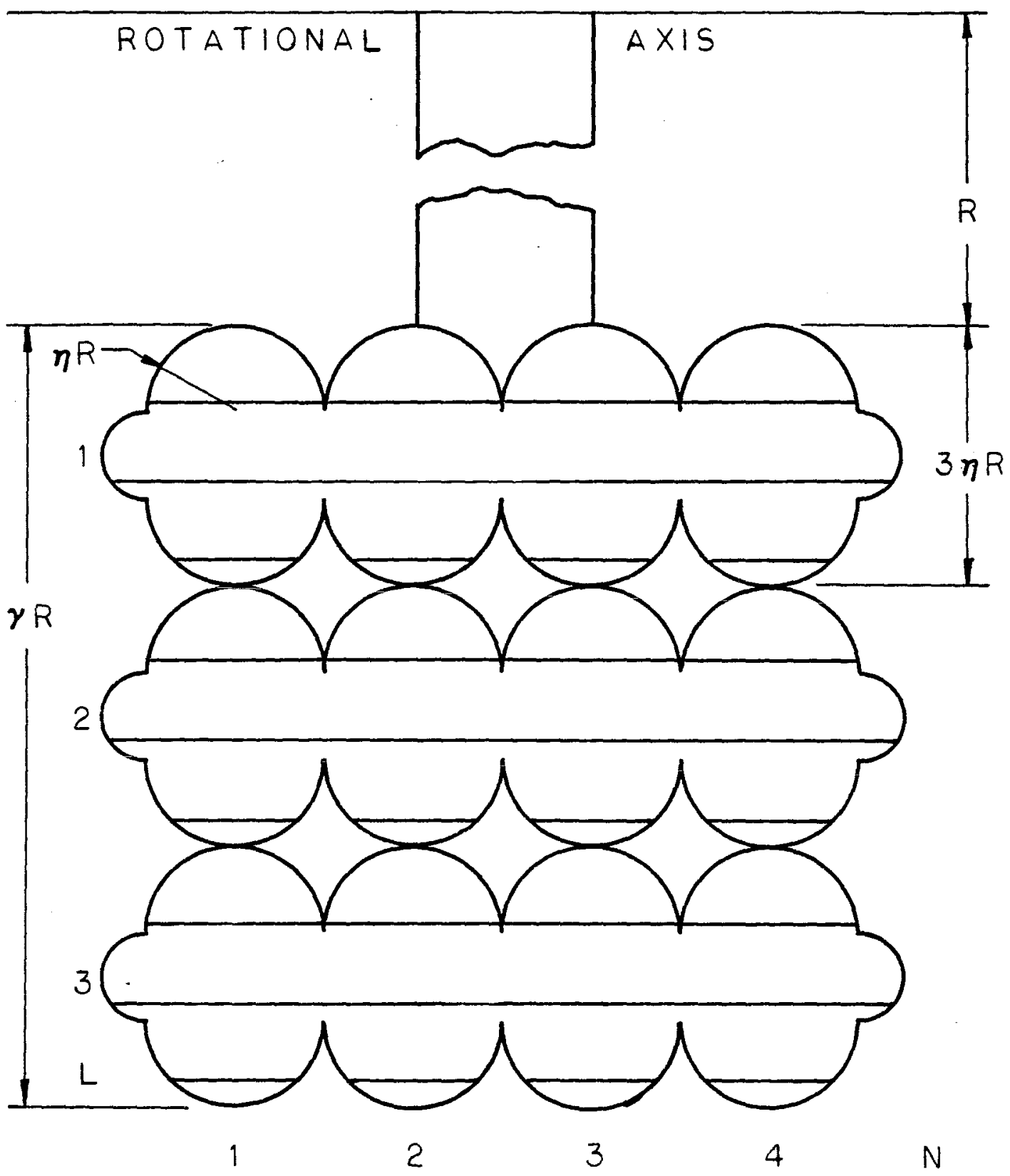

Figure 44. Crystal Palace Habitat Characteristics 
Substituting equations 75 and 76 into equation 74 gives

$$
V_{C \rho}=\pi^{2} \eta^{2} R^{3} N(2+3 \eta L)\left(1+\frac{2}{\pi}+\frac{1}{N}\right)
$$

B. Habitable Volume

By definition, the habitable volume for the "Crystal Palace" is equal to the actual volume.

c. Surface Area

The surface area of a solid of revolution can be defined as the product of its perimeter and the path described by its centroid. Therefore,

$$
S A_{C P}=2 \pi P \bar{R}
$$

where

$$
P=\pi \eta L R(2 N+1)
$$

Multiplying equation 79 by the circumference described by the area centroid yields

$$
S A_{C P}=4 \pi^{2} \eta N R^{2}\left(1+\frac{1}{2 N}\right)
$$

D. Projected Area

The projected area, as defined in Reference 8 is

$$
P A_{C p}=\pi \eta N R^{2}\left(2+\frac{1}{N}\right) \sum_{l=1}^{L}(2+\eta(1+2 l)
$$


E. Floor Area

Due to the design of the "Crystal Palace", floor area is calculated for a single minor radius $(r=4)$. With this

limitation, floor area is

$$
\begin{aligned}
F A_{C P} & =2 \pi N \sum_{l=1}^{L}\left[2(R+2 \eta l R-2)(\eta R-1)^{1 / 2}\right. \\
& +\left(R+3 \eta l R-\frac{3}{2} \eta R\right)\left(1+\frac{1}{2 N}\right) \eta R \\
& \left.+2(R+3 \eta l R-\eta)(6 \eta R-9)^{1 / 2}\right]
\end{aligned}
$$

V. Two-Axis-Stretched Ellipse of Revolution

A. Volume

Using the shell method of integration, the volume is defined by using equation 54 , where

$$
f(x)=R \alpha+\frac{E}{\delta} \sqrt{S^{2} R^{2}-(x-\beta R)^{2}} \quad \text { eq } 83
$$

for $\beta \mathrm{R}<\mathrm{x}:<\mathrm{R}$, and

$$
f(x)=R(\alpha+\epsilon)
$$

for $0<x<\beta R$. Substituting equations 83 and 84 into equation 56 and adding limits of integration yields

$$
\begin{aligned}
V_{e}=4 \pi \int_{0}^{\beta R} x R(\alpha+t) d x \\
+4 \pi \int_{\beta R}^{R} x\left[\alpha R+\frac{\epsilon}{\delta}\left[\delta^{2} R^{2}-(x-\beta R)^{2}\right]_{d x}^{\frac{1}{2}} \text { eq } 85\right.
\end{aligned}
$$




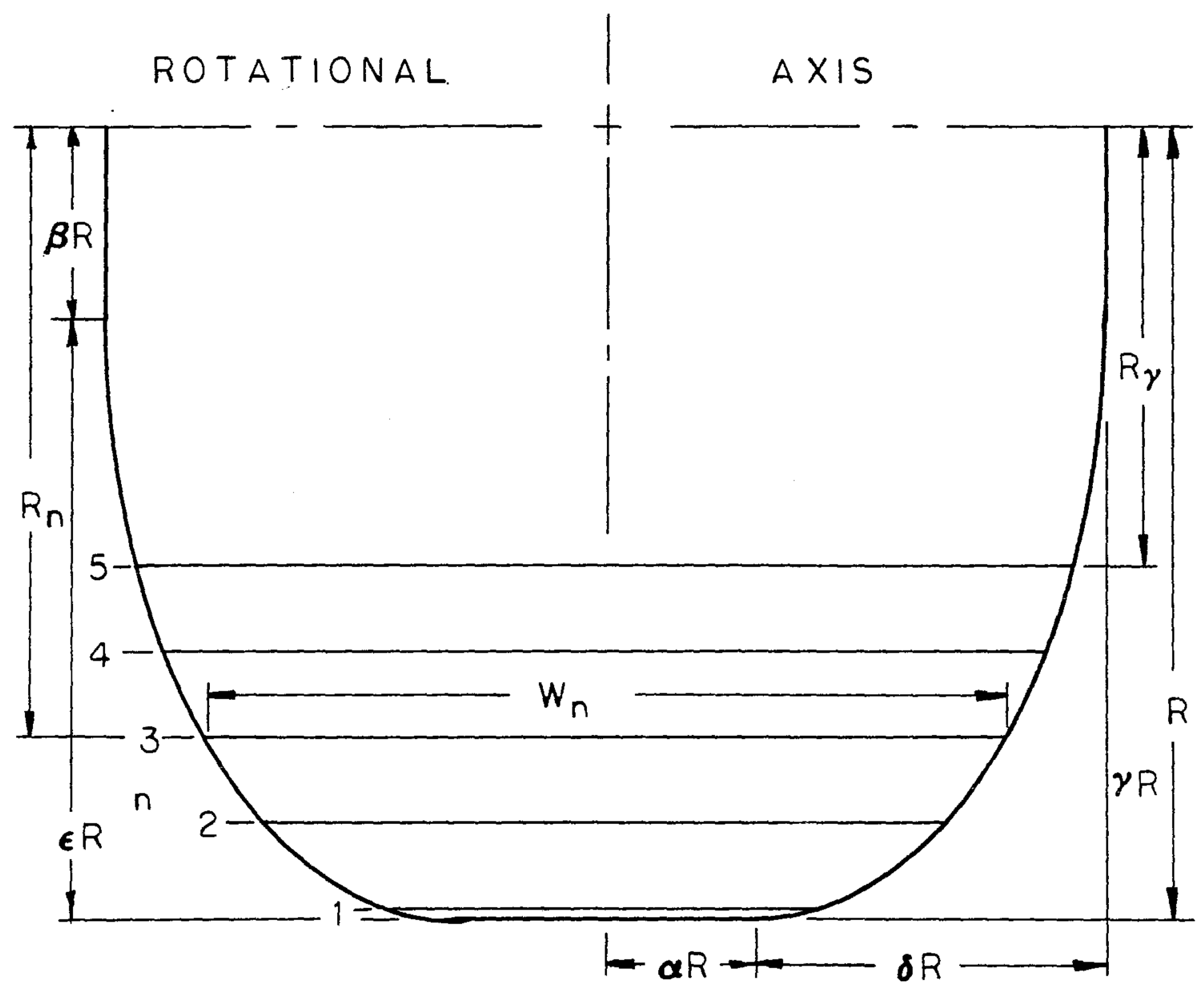

Figure 45. Two-Axis-Stretched Ellipse Characteristics: 
131

Integrating by $x$ and evaluating gives

$$
\begin{aligned}
& V_{e}=\frac{2 \pi R^{3}}{3}\left\{3 \beta^{3}(\alpha+\epsilon)+3 \beta(1-\beta)\left[\delta^{2}-(1-\beta)^{2}\right]^{1 / 2}\right. \\
& \left.+2\left[\delta^{2}-(1-\beta)^{2}\right]^{3 / 2}+3 \delta^{2} \beta \sin ^{-1} \frac{(1-\beta)}{\delta}-\delta^{3}\right\} \\
& \text { eq } 86
\end{aligned}
$$

B. Habitable Volume

The habitable volume of the expanded ellipse of revolution

can take on any of three configurations: 1) $\boldsymbol{\gamma}>1-\beta$,

2) $\gamma<1-\beta$, and 3) $\boldsymbol{\gamma}=1-\beta$. Each of these are developed below.

$$
\begin{aligned}
& \text { Case 1. } \gamma>1-\beta \\
& H V_{e}=4 \pi \int_{R(1-\gamma)}^{\beta R} x R(\alpha+\epsilon) d x \\
& +4 \pi \int_{A R}^{R} x\left\{R \alpha+\frac{\epsilon}{S}\left[S^{2} R^{2}-(x-\beta R)^{2}\right]^{\frac{1}{2}}\right\} d x \quad \text { eq } 87
\end{aligned}
$$

Integration and evaluation of this case yields

$$
\begin{aligned}
H V_{e} & =\frac{2 \pi R^{3}}{3}\left\{3 \beta^{2}(\alpha+\epsilon)-3(1-\gamma)^{2}(\alpha+\epsilon)\right. \\
& +3 \beta(1-\beta)\left[\delta^{2}-(1-\beta)^{2}\right]^{1 / 2} \\
& \left.+2\left[\delta^{2}-(1-\beta)^{2}\right]^{3 / 2}+3 \delta^{2} \beta \sin ^{-1} \frac{(1-\beta)}{S}-\delta^{3}\right\} \text { eq } 88
\end{aligned}
$$

Case 2. $\boldsymbol{\gamma}<1-\beta$

$$
H V_{e}=4 \pi \int_{R(1-\gamma)}^{R}\left\{\alpha R+\frac{\epsilon}{\delta}\left[\delta^{2} R^{2}-(x-\beta R)^{2}\right]^{1 / 2}\right\} d x \quad \text { eq } 89
$$


132

Integration and evaluation of Case 2 yields

$$
\begin{aligned}
H V e & =\frac{2 \pi R^{3}}{3}\left\{2\left[S^{2}-(1-\beta)^{2}\right]^{3 / 2}-2\left[S^{2}-(1-\gamma-\beta)^{2}\right]^{3 / 2}\right. \\
& +3 \beta\left\{(1-\beta)\left[S^{2}-(1-\beta)^{2}\right]^{1 / 2}-(\gamma-\beta)\left[S^{2}-(1-\gamma-\beta)^{2}\right]^{1 / 2}\right. \\
& +3 S^{2} \beta\left[\sin ^{-1} \frac{(1-\beta)}{J}-\sin ^{-1} \frac{(1-\gamma-\beta)}{S}\right]
\end{aligned}
$$

Case 3. $\boldsymbol{\gamma}=1-\beta$

$$
H Y_{e}=4 \pi \int_{\beta R}^{R} x\left\{\alpha R+\frac{6}{\delta}\left[S^{2} R^{2}-(x-\beta R)^{2}\right]^{1 / 2}\right\} d x \text { eq } 91
$$

Integrating and evaluating equation 91 gives

$$
\begin{aligned}
H V_{e}= & \frac{2 \pi R^{3}}{3}\left\{2\left[\delta^{2}-(1-\beta)^{2}\right]^{3 / 2}-2 \delta^{3}\right. \\
& +3 \beta\left[(1-\beta)\left(\delta^{2}-(1-\beta)^{2}\right)\right]^{1 / 2} \\
& \left.+3 \delta^{2} \beta \sin ^{-1} \frac{(1-\beta)}{S}\right\}
\end{aligned}
$$

C. Surface Area

The surface area of the two-axis-stretched ellipse of revolotion is given by

$$
S A_{e}=4 \pi \alpha R^{2}+\pi \beta^{2} R^{2}+\sum_{K=1}^{K} 2 \pi \bar{R}_{k} d s_{k} \quad \text { eq } 93
$$

where

$$
d s=\left[\left(y_{2}-y_{1}\right)^{2}+\left(x_{2}-x_{1}\right)^{2}\right]^{1 / 2}
$$

eq 94

and

$$
\bar{R}=\frac{x_{1}+x_{2}}{2}
$$

eq 95 


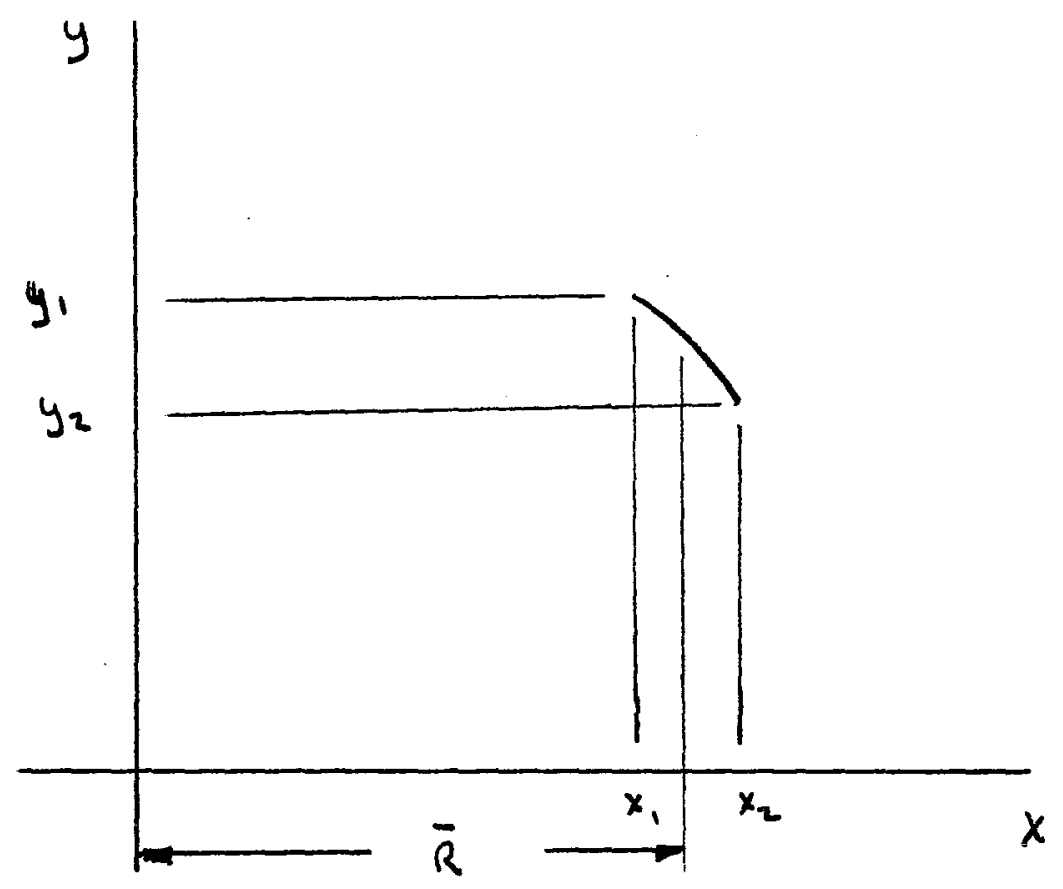

Figure 46. Differential Element ds in $x-y$ Plane 
134

The relationship between $x_{1}, x_{2}, y_{1}, y_{2}, \bar{R}$, and $d s$ is shown in Figure 46. From this figure and the equation for an ellipse, $y_{1}$ can be written as

$$
y_{1}=\alpha R+\frac{6}{J}\left[\delta^{2} R^{2}-\left(x_{1}-\beta R\right)^{2}\right]^{\frac{1}{2}} \quad \text { eq } 96
$$

and $y_{2}$ can be written as

$$
y_{2}=\alpha R+\frac{\epsilon}{J}\left[S^{2} R^{2}-\left(x_{2}-\beta R\right)^{2}\right]^{1 / 2}
$$

eq 97

Substituting these values for $\mathrm{y}_{1}$ and $\mathrm{y}_{2}$ into equation 93 and integrating by summation over the range of $R$, the surface area is found to be given by

$$
\begin{aligned}
& S A_{e}=4 \pi \alpha R^{2}+2 \pi \beta^{2} R^{2} \\
& +\frac{\pi \epsilon}{S} \sum_{i=1}^{I}\left(x_{i}+x_{i+1}\right)\left[\left(x_{L+1}^{2}-x_{i}^{2}\right)+2 \beta R\left(x_{L+1}-x_{i}\right)\right]_{\text {eq }}^{\frac{1}{2}}
\end{aligned}
$$

D. Projected Area

As before, the projected area for the two-axis-stretched ellipse of revolution is given by

$P A_{e}=2 \pi R_{\gamma} W_{\gamma}$

eq 99

where

$$
R_{\gamma}=R(1-\gamma)
$$

eq 100 
135

and

$$
W_{\gamma}=2 R\left\{\alpha+\frac{\epsilon}{S}\left[\delta^{2}-(1-\gamma-\beta)^{2}\right]^{1 / 2}\right\} \quad \text { eq } 101
$$

leaving, upon substitution into equation 99 ,

$$
P A_{e}=4 \pi R^{2}(1-\gamma)\left\{\alpha+\frac{\epsilon}{\delta}\left[\delta^{2}-(1-\alpha-\beta)^{2}\right]^{\frac{1}{2}}\right\} \quad \text { eq } 102
$$

E. Floor Area

Floor area for the two-axis-stretched ellipse of revolution

is defined as

$$
F A_{e}=2 \pi \sum_{n=1}^{N} R_{n} W_{n}
$$

eq 103

where

$$
R_{n}=R-3 n+2.5
$$

eq 104

and

$$
W_{n}=2\left\{R \alpha+\frac{\epsilon}{\delta}\left[\delta^{2} R^{2}-\left(R-3 n+2.5 \beta R^{2}\right]\right\} \text { eq } 105\right.
$$

By summing over the entire number of floors in the structure, equation 105 becomes

$$
\begin{aligned}
F A_{e}= & 4 \pi \sum_{n=1}^{N}(R-3 n+2.5) * \\
& \left\{R \alpha+\frac{\epsilon}{\delta}\left[\delta^{2} R^{2}-(R-3 n+2.5-R \beta)^{2}\right]^{1 / 2} \text { eq } 106\right.
\end{aligned}
$$


APPENDIX D

SHELL THICKNESS ESTIMATES

Shell thickness estimates were made for LEOBC to corroborate the volume-limited payload estimates used to determine the required number of launches to construct LEOBC. This was accomplished by using the equation 1 isted below:

$$
\begin{aligned}
& t_{t}=\left[\frac{\rho_{0} \eta}{2}+\frac{\rho_{g}}{\pi}\right] \frac{R}{\sigma_{w}-\rho g_{c}} \\
& t_{h_{1}}=\frac{1}{\sigma_{w}}\left[P_{0}^{2} R^{2}+F^{2}\right]^{1 / 2} \\
& t_{h_{2}}=\frac{P_{0} R_{2}}{2 \sigma_{w}}\left[5-4 \frac{R_{2}}{R_{1}}+\left(\frac{R_{2}}{R_{1}}\right)^{2}\right]^{1 / 2} \\
& \text { for the torus, cylindrical and ellipsoidal sections of the hub, }
\end{aligned}
$$$$
\text { eq } 107
$$$$
\text { eq } 108
$$$$
\text { eq } 109
$$
respectively. The calculations follow.

\section{Torus Thickness}

For the torus, the following values hold:

$$
\begin{aligned}
& P_{0}=0.58 \text { atm } \\
& \mathrm{P}=300 \mathrm{~kg} / \mathrm{m}^{2} \quad \sigma_{\mathrm{W}}=8000 \mathrm{psi} \\
& \eta=0.035 \\
& \mathrm{~g}=0.5 \mathrm{~g}_{\mathrm{E}} \\
& \rho=2.976 \mathrm{~g} / \mathrm{cm}^{3} \\
& \mathrm{R}:=100 \mathrm{~m} \\
& g_{c}=1
\end{aligned}
$$


137

Substituting these values into equation 107 gives the following results:

$$
\begin{aligned}
& t_{t}=\left[\frac{0.58 \mathrm{~atm}(0.035)}{2}+\frac{300 \mathrm{~kg} / \mathrm{m}^{2}(0.5 \mathrm{gg})}{\pi}\right] \frac{100 \mathrm{~m}}{8000 \mathrm{ps1}-2.976 \mathrm{~g} / \mathrm{cm}^{3}(0.5 \mathrm{~g})(100 \mathrm{~m})}
\end{aligned}
$$

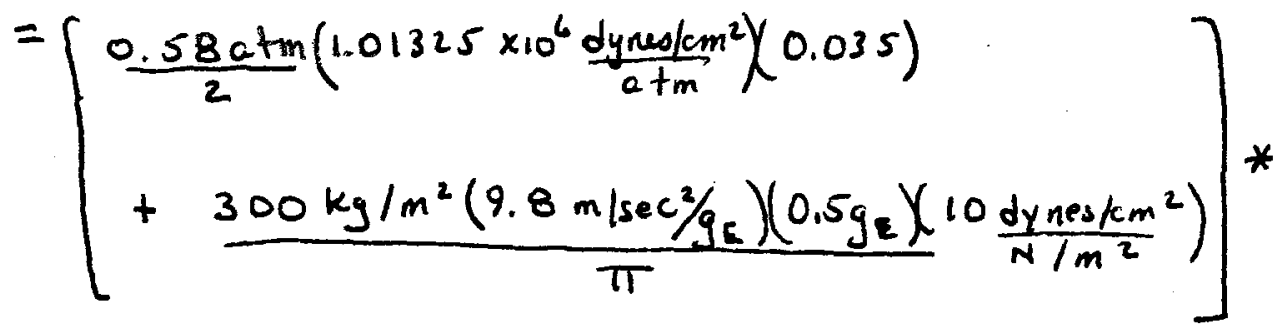

$$
\begin{aligned}
& {\left[\frac{100 \mathrm{~m}\left(100 \frac{\mathrm{cm}}{\mathrm{m}}\right)}{8000 \mathrm{psi}\left(68947.6 \frac{\mathrm{dynes}_{\mathrm{km}}}{\mathrm{p}_{\mathrm{st}}}\right)-2.976 \mathrm{gm} / \mathrm{cm}^{2}(0.5 \mathrm{gc})(980 \mathrm{em})(10000 \mathrm{~cm})}\right]} \\
& =0.27865 \mathrm{~cm}
\end{aligned}
$$




\section{Cylindrical Section Thickness}

Thickness of the cylindrical sections at radil of 30 and 9 meters is estimated by combining stresses for an internally or externally pressurized tube and for a tube thickness is first estimated for the pressure case.

Where

$$
\begin{aligned}
& \rho \quad=0.58 \mathrm{~atm}, \\
& \sigma_{\mathrm{W}} \quad=8000 \mathrm{psi} \\
& \text { and } \mathrm{R}=30 \mathrm{~m} \text { and } 9 \mathrm{~m}
\end{aligned}
$$

Therefore

$$
t_{30}=3.1373 \mathrm{~cm}
$$

And

$$
t_{9}=0.9592 \mathrm{~cm}
$$

The axial load on the inner and outer cylinders was found by replacing the axial pressure load by a resultant force at the centroid radius and solving for $F_{1}$, and $F_{2}$ (see Figure 465 ). $P, F_{1}$, and $\mathrm{F}_{2}$ have the dimensions atm-meter.

$$
\begin{aligned}
& F_{1}+F_{2}=R=\pi P_{0}\left(R_{0}^{2}-R_{i}^{2}\right) \\
& R_{0} F_{1}+R_{i} F_{2}-R \bar{R}=0 \\
& \bar{R}=\frac{\sum A_{r} R}{\sum A_{r}}
\end{aligned}
$$


d

Al 
140

Cylindrical Section Thickness

Thickness of the cylindrical sections at radii of 30 and 9 meters is estimated by combining stresses for an internally or externally pressurized tube with uniform axial load: The internal pressure and material working stress are the same as form the torus.

The axial load on the inner and outer cylinders was found by replacing the axial pressure load by a resultant force at the centroid radius and solving for $F 1$ and $F 2$ (see Figure 47 ). The dimensions of F1 and F2 are atmometers.

$$
\begin{array}{ll}
F_{1}=R\left(\frac{\bar{R}-R_{i}}{R_{0}-R_{i}}\right) & \text { eq } 110 \\
F_{2}=R\left(1-\frac{\bar{R}-R_{i}}{R_{0}-R_{i}}\right) & \text { eq } 111
\end{array}
$$

The thickness is then found by substituting the expression for the resultant pressure load, $\mathrm{R}$ (equation 112 ), into equation 110 and 111 , and dividing by the working stress. The expressions for thickness due to: the axial load are given by equation 113 and 114 .

$$
\begin{array}{ll}
R=\frac{P_{0} \pi\left(R_{0}^{2}-R_{i}^{2}\right)}{2 \pi \bar{R}} & \text { eq } 112 \\
t_{i}=\frac{P_{0}}{\bar{R} \sigma_{\omega}}\left(R_{0}+R_{i}\right)\left(R_{0}-\bar{R}\right) & \text { eq } 113 \\
t_{0}=\frac{P_{0}}{\bar{R} \sigma_{w}}\left(R_{0}+R_{i}\right)\left(\bar{R}-R_{i}\right) & \text { eq } 114
\end{array}
$$


These expressions are then combined with the expressions for thick $\rightarrow$ ness due to the hoop stress by taking the square root of the sum of the squares of the ehicknesses (equation 115).

$$
t=\sqrt{t_{h}^{2}+t_{c}^{2}}
$$

The final expressions for the cylindrical section thicknesses are given by equations 116 and 117 .

$$
\begin{aligned}
& t_{i}=\frac{P_{0}}{\sigma_{w}}\left[\frac{\left(R_{0}+R_{i}\right)^{2}\left(R_{0}-\bar{R}\right)^{2}}{\bar{R}^{2}}+R_{i}^{2}\right]^{1 / 2} \quad \text { eq } 116 \\
& t_{0}=\frac{P_{0}}{\sigma_{w}}\left[\frac{\left(R_{0}+R_{i}\right)^{2}\left(R_{i}-\bar{R}\right)^{2}}{\bar{R}^{2}}+R_{0}^{2}\right]^{\frac{1}{2}} \text { eq } 117
\end{aligned}
$$

$\therefore$ These equations give an estimated thickness of $1.29 \mathrm{~cm}$ and $4.03 \mathrm{~cm}$ for the inner and outer cylindrical walls, respectively. The resultant pressure load is applied at a radius of $21.949 \mathrm{~m}$.

\section{E11iptical Dome Thickness}

Thickness for the ellipse of revolution surface is estimated using the equation for any smmoth figure of revolution as given in Reference 169. The problem with this equation is that it breaks down as $R_{2}$ approaches infinity and it assumes tangential support only. Since the surface in question has axial support at the inner radius where $R_{2}$ also approaches infinity, a weighted average for each section is used in determining mass estimates: (equation 118)

$$
t_{\text {weighted average }}=\frac{\sum A t}{\sum A} \quad \text { eq } 118
$$


where $R_{1}$ is the radius of curvature of the meridian and $R_{2}$ is the distance measured along the normal to the shell to the axis of revolution. The radius of curvature, from refernce 169 is

$$
R_{1}=\frac{\left[1+(d y / d x)^{2}\right]^{3 / 2}}{d^{2} y / d^{2} x^{2}}
$$

wher $\mathrm{y}$ is the function shown in equation 120 .

$$
y=\frac{b}{a}\left[a^{2}-(x-h)^{2}\right]^{\frac{1}{2}}+k
$$

The first and second derivatives, with respect to $x$ are

$$
\begin{aligned}
& \frac{d y}{d x}=-\frac{b}{a}(x-h)\left[a^{2}-(x-h)^{2}\right]^{-4 / 2} \text { eq } 121 \\
& \frac{d^{2} y}{d x^{2}}=-\frac{b}{a}\left\{(x-h)^{2}\left[a^{2}-(x-h)^{2}\right]^{-3 / 2}+\left[a^{2}-(x-h)^{2}\right]^{-1 / 2} 122\right.
\end{aligned}
$$

Therefore,

$$
R_{1}=\frac{1+\frac{\frac{b^{2}}{a^{2}}(x-h)^{3 / 2}}{a^{2}-(x-h)^{2}}}{-b / a\left\{(x-h)^{2}\left[a^{2}-(x-h)^{2}\right]^{-3 / 2}+\left[a^{2}-(x-h)^{2}\right]^{-/ / 2}\right\}}
$$

The distance between the surface of revolution and the axis, along a normal to the surface, $R_{2}$ is found by solving for the slope of the normal at $x$, finding the intercept of the axis of revolution and solving for the distance.

The slope of the normal is given by the negative inverse of the curve, or 
143

$$
\begin{array}{ll}
m_{M}=-\frac{1}{m_{C}} & \text { eq } 124 \\
m_{N}=-\frac{1}{d y} \mid d x & \text { eq } 125
\end{array}
$$

From the equation of a line, equation :126, the intercept with the axis of revolution is given as

$$
\begin{array}{ll}
y=m x+b & \text { eq } 126 \\
b=y-m x & \text { eq } 127
\end{array}
$$

The distance between the surface and the axis of revolution is

$$
d=\left[\left(x_{1}-x_{2}\right)^{2}+\left(y_{2}-y_{1}\right)^{2}\right]^{1 / 2} \quad \text { eq } 128
$$

where $x_{1}$ is the $x$-coordinate of the point of interest on the curve, $x_{2}$ is $0, y_{1}$ is the $y$-coordinate of the point of interest on the curve and $y_{2}$ is the $y$-intercept at the axis of revolution. Therefore,

$$
R_{2}=\left\{x_{1}^{2}+\left[y_{1}-\left(y_{1}-m x\right)\right]^{2}\right\}^{1 / 2} \quad \text { eq } 129
$$

Simplifying, this becomes

$$
R_{2}=\times\left[1+m^{2}\right]^{1 / 2}
$$

eq 130 
Substituting the inverse of the expression for the sope of the curve from equation 121 into equation $130, R_{2}$ becomes

$$
R_{1}=x\left[1+\frac{a^{2}}{b^{2}}\left(\frac{a^{2}-(x-h)^{2}}{(x-h)^{2}}\right)\right]^{1 / 2}
$$

Now that $R_{1}$ and $R_{2}$ are defined, thickness can be estimated as a function of hub radius. Combining $t_{1}$ and $t_{2}$ into an equivalent thickness as before, solving for $t$ and replacing eq by ${ }_{w}$ yields

$$
t=\frac{P_{0} R_{2}}{2 \sigma_{W}}\left[5-\frac{4 R_{2}}{R_{1}}+\left(\frac{R_{2}}{R_{1}}\right)^{2}\right]^{1 / 2} \quad \text { eq } 132
$$

Since this gives a varying thickness as a function of radius, a weighted average thickness if: found using equation 133

$$
t_{w A}=\frac{\sum_{i=1}^{n} \frac{P_{0} R_{2}}{2 \sigma_{w}}\left[s-\frac{4 R_{2}}{R_{1}}+\left(\frac{R_{2}}{R_{1}}\right)^{2}\right]^{1 / 2} * 2 \pi \bar{R}_{i} d s^{2}}{\sum_{L=1}^{n} 2 \pi \bar{R}_{i} d s^{2}} 133
$$

where $R_{i}$ and $d s$ are as defined by equation 94 and 95 of Appendix $C$. 
APPENDIX E

LEOBC INTERNAL MASS CALCULATIONS

\section{Interna1 Furnishings}

Internal furnishings mass is found by assuming a loading factor of $25 \%$ on the floor load design value of $300 \mathrm{~kg} / \mathrm{m}^{2}$. Total floor area for LEOBC is given in Table TBD as $22,549 \mathrm{~m}^{2}$. Therefore

$$
\begin{aligned}
M_{I f} & =0.25 * 300 \frac{\mathrm{kg}}{\mathrm{m}^{2}} * 22549 \mathrm{~m}^{2} \quad \text { eq } 134 \\
& =1,691,125 \mathrm{~kg}
\end{aligned}
$$

Atmospheric Mass

Atmospheric mass is determined using ideal gas relationships, this Is appropriate due to the low pressures and temperatures involved.

$$
n=\frac{P_{0} V}{R T}
$$

Where $n$ is the number of moles, $R$ is the univeral gas constant, the internal pressure and $V$ is the total volume. For IEOBC, the following values are applicable:

$$
\begin{gathered}
P_{0}=0.58 \mathrm{~atm} \quad R=0.082057 \frac{\mathrm{latm}}{0 \mathrm{Kgmole}} \\
V=73837 \mathrm{~m}^{2} \quad T=21^{\circ} \mathrm{C} \\
m=28.8 \mathrm{~g} / \mathrm{gmole}
\end{gathered}
$$

Therefore, the number of moles required is

$$
n=1,775,166,4 \text { gmoles }
$$


The mass is found by multiplying the number of moles by the gram formula mass of LEOBC's atmosphere. Since the composition is $20 \%$ oxygen and $80 \%$ nitrogen, this is

$$
\begin{aligned}
m & =0.8(28)+0.2(32) \\
& =28.8 \mathrm{~g} / \mathrm{gmole}
\end{aligned}
$$

The total atmospheric mass is now found to be

\section{Water Mass}

$$
m=\frac{28.8 * 1.775,166.4}{1000}=51,124.8 \mathrm{~kg}
$$

The maximum water mass on board LEOBC is Iimited by the holding tank in the torus. As discussed in the text, this tank is beneath the first floor and is 2 meters wide. Its height is 1 imited to 1 meter with a nominal fill depth of 0.5 meters. (Figure 48 ) Volume is found by using disk method of summation such that

$$
V=\sum_{n=1}^{N} \pi\left(\bar{R}_{r}^{2}-\bar{R}_{2}^{2}\right) \Delta x
$$

Where $\overline{\mathrm{R}}_{2}=103 \mathrm{~m}, \Delta \mathrm{x}=0.01$ and

$$
\bar{R}_{1}=\frac{200+\left[\left(3.5-x_{1}\right)^{2}+\left(3.5-x_{2}\right)^{2}\right]^{1 / 2}}{2}
$$




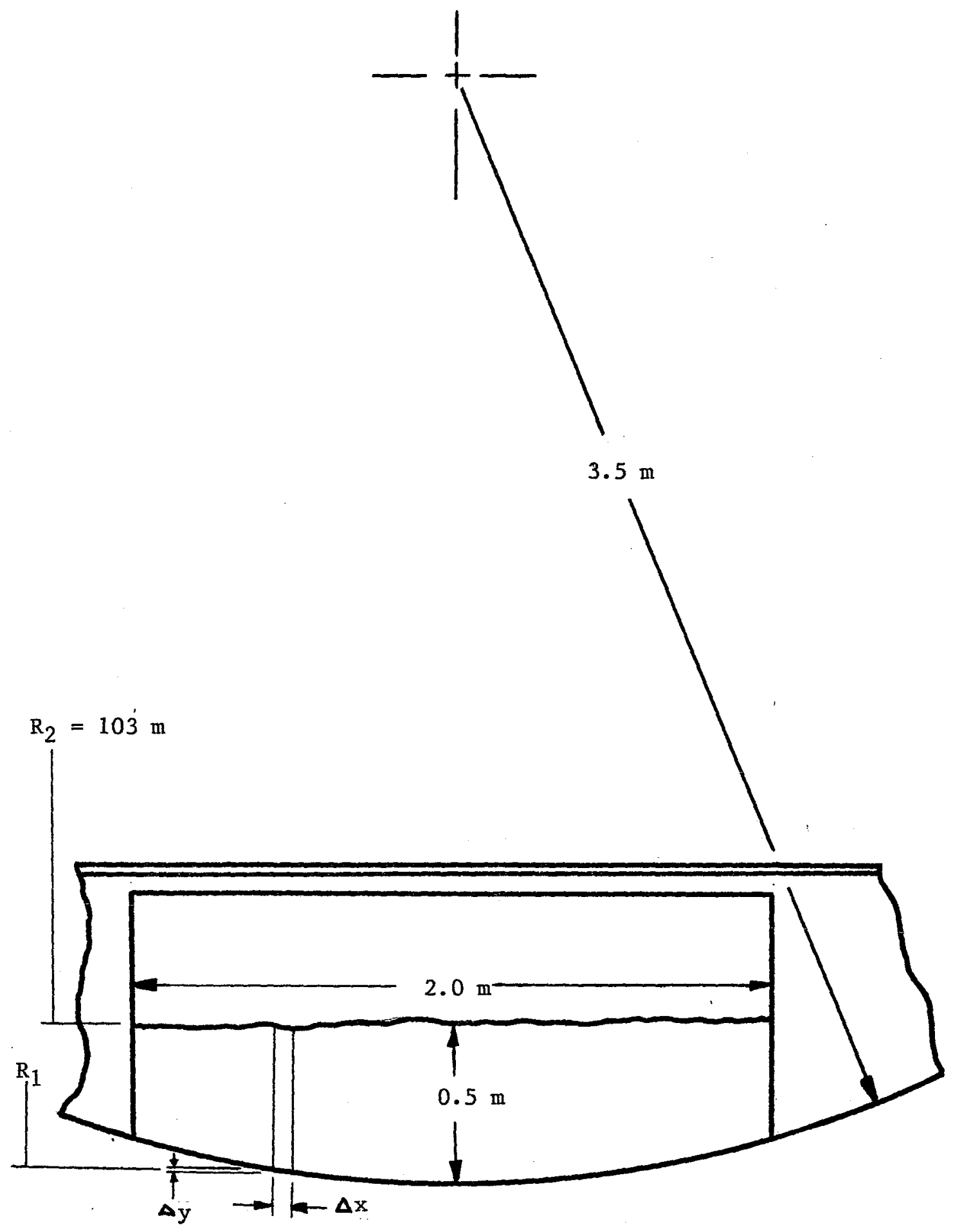

Figure 48. LEOBC Potable Water Tank 
From this we find a water tank volume of

$$
V=587.343 \mathrm{~m}^{3}
$$

Since water has a density of $1000 \mathrm{~kg} / \mathrm{m}^{3}$, a total of $587,343 \mathrm{~kg}$ can be stored on LEOBC. LEOBC will be considered operational when half of this water is onboard. 